Linköping Studies in Science and Technology, Dissertation No. 2049
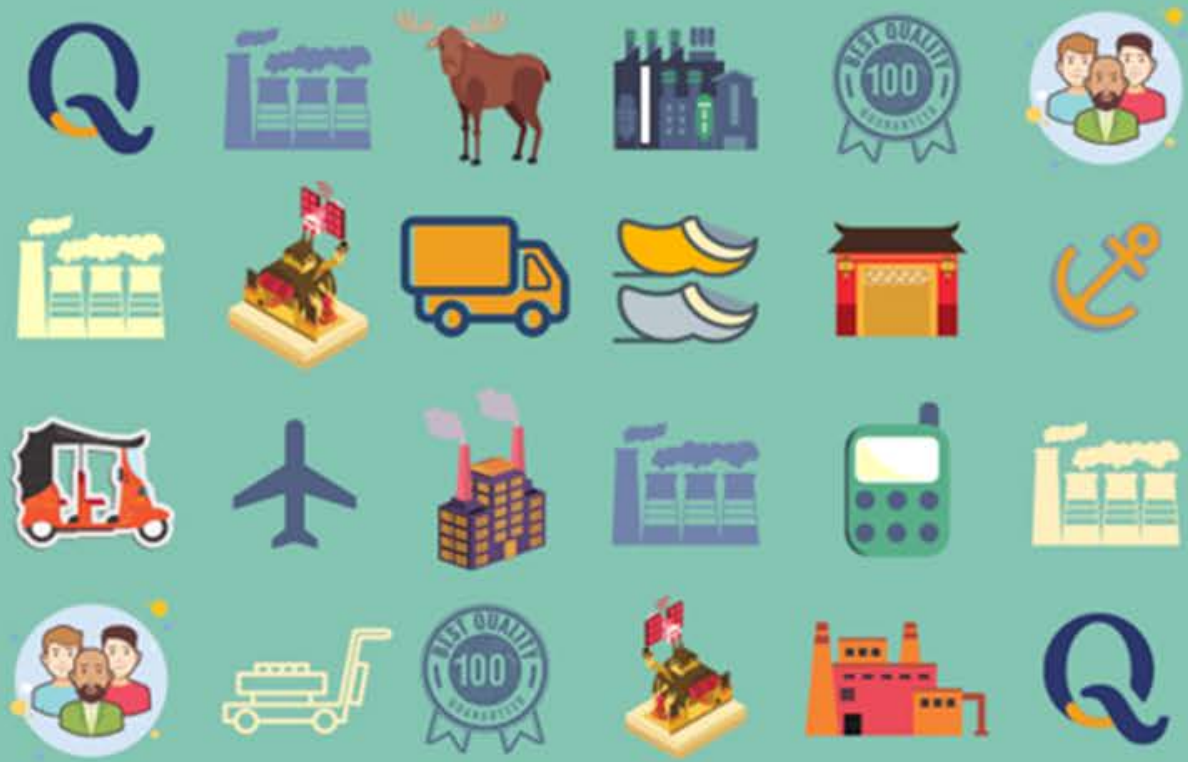

\title{
Managing Quality in \\ Cross-cultural Settings
}

Promporn Wangwacharakul 
Linköping Studies in Science and Technology

Dissertation No. 2049

\title{
Managing Quality in Cross-cultural Settings
}

\author{
Promporn Wangwacharakul
}

I.0U UNNGDNG

Logistics and Quality Management

Department of Management and Engineering

Linköping University, SE-581 83 Linköping, Sweden

Linköping 2020 
Cover art by Yuttapoom Puttisong and Promporn Wangwacharakul

(c) Promporn Wangwacharakul, 2020 unless otherwise noted

Published articles have been reprinted with the permission of the copyright holder.

ISSN 0345-7524

ISBN 978-91-7929-896-8

Printed in Sweden by Printed by LiU-Tryck, Linköping 2020

Distributed by:

Linköping University

Department of Management and Engineering

SE-58183 Linköping, Sweden

Tel: +4613281000 


\section{Abstract}

As companies become multinational with subsidiaries in different countries and global customers, they face challenges in managing quality related to cultural diversity. During the past decades, cross-cultural quality management research has emerged, aiming to understand the link between culture and quality management, and to provide support for quality management in different cultural contexts. This research field becomes increasingly important considering global industries of today. Nevertheless, the first standpoint in identifying challenges in cross-cultural quality management in multinational companies remains to be an open question. This also leads to the need for developing an instrument to understand cultural diversity in quality management, from both an internal perspective related to employees and an external perspective related to customers.

This thesis aims to provide an insight into managing quality in cross-cultural settings, focusing on both multinational companies and companies having global customers. Three studies have been conducted combining qualitative and quantitative research methods. First, case studies were employed to explore the research field and identify challenges in managing quality related to national cultural diversity in multinational companies. The second study developed an instrument based on anchoring vignettes survey to understand cultural diversity in quality management and applied it in two settings. The third study combined an interview-based study with a case study using mixed methods to further investigate and consolidate the results gained from the first two studies, leading to the suggestion of possible strategies to manage quality in multinational companies.

The thesis findings identify three challenges in managing quality in multinational companies: 1) to translate and implement quality management approaches; 2) to motivate and engage employees in quality work; and 3) to establish shared perceptions of quality management values among employees. Further, an instrument based on anchoring vignettes is suggested to study quality management performance across subsidiaries and to measure customer satisfaction across borders. This instrument contributes to better understanding of cultural diversity and improves the comparability of survey results in quality management measurements. Regarding possible strategies, global integration is needed when a quality culture is weak. In the long-term, companies should promote technical aspects of quality management to form a 'backbone' of the quality management system and to set a basis for shared perceptions of quality management values and goals. Consequently, a strong quality culture can be established and companies can benefit from local adaptation of practices. 



\section{Sammanfattning}

När företag blir alltmer multinationella, med dotterbolag i olika länder och globala kunder, så möter de utmaningar i att bedriva kvalitetsutveckling som berör kulturell mångfald. Under de senaste decennierna har forskning på kvalitetsutveckling i mångkulturella sammanhang växt fram. Denna forskning syftar till att förstå sambandet mellan kultur och kvalitetsutveckling samt att stödja kvalitetsutveckling i olika kulturella kontexter. Detta forskningsfält ökar i betydelse i takt med den ökande globaliseringen. Trots det kvarstår behovet av att identifiera utmaningarna med kvalitetsutveckling i mångkulturella sammanhang. Detta leder även till behovet att utveckla ett instrument för att förstå kulturell mångfald i kvalitetsutveckling, både utifrån ett internt perspektiv, relaterat till de medarbetarna, men också utifrån ett externt perspektiv, relaterat till kunder.

Denna avhandling syftar till att ge insikter i hur kvalitetsutveckling bedrivs i mångkulturella sammanhang och fokuserar på både multinationella företag samt företag som har globala kunder. Tre studier har genomförts vilka har kombinerat både kvalitativa och kvantitativa metoder. I den första studien genomfördes en fallstudie för att utforska forskningsfältet och identifiera utmaningar i hur multinationella företag arbetar med kvalitetsutveckling relaterat till kulturell mångfald. I den andra studien utvecklades ett instrument baserat på en enkät som utifrån så kallade förankringsvinjetter sökte öka förståelsen för kulturell mångfald i kvalitetsutveckling. Detta instrument tillämpades sedan i två olika kontexter. I den tredje studien kombinerades en intervjubaserad studie med en fallstudie, där flera olika metoder användes, för att ytterligare undersöka och befästa resultaten från de två första studierna samt ge förslag på olika strategier för att bedriva kvalitetsutveckling i multinationella företag.

Avhandlingen identifierar tre huvudsakliga utmaningar i kvalitetsutveckling för multinationella företag: 1) att översätta och implementera ansatser för kvalitetsutveckling; 2) att motivera och involvera medarbetare i kvalitetsarbete; samt 3) att etablera gemensamma värderingar inom kvalitetsutveckling bland medarbetare. Vidare så föreslås ett instrument baserat på förankringsvinjetter för att kunna studera resultatet av kvalitetsutveckling mellan dotterbolag samt mäta kundtillfredsställelse över landsgränser. Detta instrument bidrar till att bättre förstå kulturell mångfald och ökar möjligheten att jämföra resultat från enkätundersökningar när effekterna av kvalitetsutveckling skall mätas. När det gäller möjliga strategier pekar resultaten på att det behövs global integrering när kvalitetskulturen är svag. På längre sikt bör företag främja de tekniska aspekterna av kvalitetsutveckling för att skapa en grund för kvalitetsledningssystem och en förståelse för gemensamma värderingar och mål. Därmed kan en stark kvalitetskultur etableras och företag kan gynnas genom lokala anpassningar av hur kvalitetsarbetet styrs i praktiken. 



\section{Acknowledgement}

A fortune teller once told me that I would get a PhD. I was not convinced at all then. Moreover, after I finished writing and presenting my Master thesis, I promised myself not to pursue any more academic challenges in my life. Well, here I am! I cannot achieve this without supports from many people to whom I would like to express my gratitude.

First, I want to thank Bonnie Poksinska, my main supervisor for the great opportunity you gave me since the day we met. You have been guiding and supporting me in every possible way during these years. Thank you for advices and comments, and for not losing hope on me!

I also would like to thank my secondary supervisor, Martina Berglund. I have learned a lot from you while we are working together. Being careless as I am, you teach me to pay more attention to detail especially in writing.

Thank you to Mattias Elg for comments on the previous version of this thesis as well as a fruitful discussion during the pre-final seminar.

As for my two co-authors, Ulrika Harlin and Per Gullander from Sweria IFV, thank you for the opportunity to work with you in the project as well as your great support for the papers. Also, thanks to Silvia Márquez Medina for helps in developing and testing the customer satisfaction questionnaire.

My work in this thesis would have been harder, if it is not for Peter Wiqvist (and Malin who held a disputation party where I met Peter). Thanks for the help in searching opportunities for gathering data in your company. It is a big contribution to my work and makes it more complete.

I would like to thank all of my colleagues from the division of Logistics and Quality Management for the good working environment and atmosphere as well as fun social activities. Especially both active members and alumni of the LQ PhD-gang, thanks for inspiration, laugh and joy we have together. Special thanks to Magdalena for feedbacks on parts of my thesis draft, and Jason for help with 'sammanfattning' and for answering my random questions.

Thank you to all my dear friends for making this academic journey very joyful. Thanks, Ksenia for happy lunch, fika, all the laugh we shared and weekends with kids. Again, you are the very important person that make my PhD journey happens! Thank you, Ingrid for friendship, life tips, and especially for saving my life with the French questionnaire. It is not good you are not around (Linköping) anymore and I miss you a lot. Jelena and Priscilla, it is nice to hang out with you girls and know that I am not the only one lost in this foreign academic world with motherhood.

As a Thai person far away from home, I have many Thai friends here who always support me and cheer me up. There are so many of you that I cannot name you all, but you know who you are and I am very grateful for your support. 
With all the best to my family in Thailand, thank you Mommy for all your love and care. Thanks, my little brother Nu, who is a great support. Daddy, you have always been a role model for me and thanks for a constant push toward a PhD.

This last gratitude would be for my husband and kids. Thank you so much, Yuttapoom, for always be here for me with encouragement, love and support in both academic and personal life. Thanks, my dear Lumine and Luxx, for making my life full of happiness though it becomes a little more complicated!

Promporn Wangwacharakul,

Linköping, February 2020

PS. Oh! Thank you 'Mia the Cat' for sweet and relax moments during all these years! 


\section{List of Appended Papers}

\section{Paper I}

Wangwacharakul, P., Berglund, M., Harlin, U. and Gullander, P. (2014), "Cultural aspects when implementing lean production and lean product development - experiences from a Swedish perspective", Quality Innovation Prosperity, Vol. 18, No. 1, pp. 125-140.

A previous version of this paper was presented and published in the proceedings of the $16^{\text {th }}$ International Conference of Quality and Service Sciences (QMOD-ICQSS), Portoroz, Slovenia, 2013.

\section{Paper II}

Wangwacharakul, P., Berglund, M. and Harlin, U. (2020), "Quality management to facilitate new product introduction across borders", International Journal of Productivity and Quality Management. (in press)

A previous version of this paper was presented and published in the proceedings of the $17^{\text {th }}$ International Conference of Quality and Service Sciences (QMOD-ICQSS), Prague, Czech Republic, 2014.

\section{Paper III}

Wangwacharakul, P. and Poksinska, B.B. (2017), "Using anchoring vignettes to study quality management across cultures", International Journal of Quality and Service Sciences, Vol. 9, No. 3/4, pp. 302-316.

A previous version of this paper was presented and published in the proceedings of the $19^{\text {th }}$ International Conference of Quality and Service Sciences (QMOD-ICQSS), Rome, Italy, 2016.

\section{PaperIV}

Wangwacharakul, P., Medina, S.M. and Poksinska, B.B. (2019), "Cross-cultural comparability of customer satisfaction measurement - The case of mobile phone service providers" (accepted to International Journal of Quality and Service Sciences)

A previous version of this paper was presented and published in the proceedings of the $21^{\text {th }}$ International Conference of Quality and Service Sciences (QMOD-ICQSS), Cardiff, Wales, UK, 2018.

\section{Paper $V$}

Wangwacharakul, P. (2019), "Quality management in cross-cultural settings: challenges and possible strategies for quality managers"

A previous version of this paper was presented and published in the proceedings of the $26^{\text {th }}$ EurOMA Conference, Helsinki, Finland, 2019. 
The conference paper has been improved according to reviewer's comments and is intended for journal submission.

\section{Paper VI}

Wangwacharakul, P. and Poksinska, B.B. (2020), "Common yet diverse - A case study of managing quality in a multinational company"

Working paper 


\title{
Contributions of Authors
}

\author{
Paper I-Wangwacharakul, P., Berglund, M., Harlin, U. and Gullander, P.
}

Berglund initiated the paper. As the first author, I took main responsibility for the section dealing with lean product development, including the theoretical framework, data collection and analysis. Berglund and I planned and led the writing process. Harlin and Gullander were responsible for the section dealing with lean production. All authors contributed to writing and improving the paper.

Paper II - Wangwacharakul, P., Berglund, M. and Harlin, U.

I initiated the paper, based on an idea from existing data that Berglund and Harlin had gathered in another research project. Berglund and I carried out follow-up interviews to gather more data, and wrote the first draft of the paper. I led the writing process and took main responsibility for writing the theoretical framework, analysis, and a part of the methodology and data collection. All authors contributed to improving the paper.

Paper III - Wangwacharakul, P. and Poksinska, B.B.

Poksinska initiated the paper. I took the lead in designing the questionnaire, collecting the data and writing the paper. Poksinska gave comments to the questionnaire and helped to improve it. I wrote the first draft of the paper, which was then improved together with Poksinska.

Paper IV - Wangwacharakul, P., Medina, S.M. and Poksinska, B.B.

Poksinska initiated the paper. I conducted the pre-study. Medina designed, translated (from English to Swedish and Spanish) and tested the questionnaire as a part of her Master's thesis, of which Poksinska and I were supervisors. Poksinska and I subsequently improved the questionnaire. Then, I translated it from English to Thai, while Poksinska did from English to Polish. As the first author, I took the lead in the data collection and the writing process. Poksinska and I jointly analyzed the data and improved the paper, to which Medina gave comments.

Paper V-Wangwacharakul, $P$.

As single author, I planned, designed and wrote all parts. I also gathered and analyzed the data. However, Poksinska helped to frame the theoretical conceptual model and commented on the draft manuscript.

Paper VI - Wangwacharakul, P. and Poksinska, B.B.

I initiated, planned, collected the data, analyzed them, and led the writing process. Poksinska took part in improving the questionnaire and the draft manuscript. 



\section{Table of Contents}

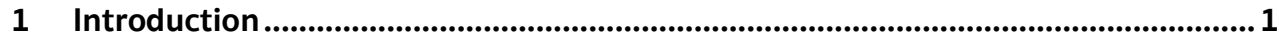

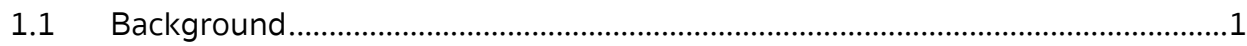

1.1.1 Quality Management in Multinational Companies............................................2

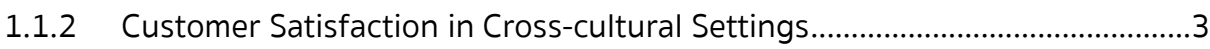

1.1.3 Organizational Settings in Multinational Companies ..........................................4

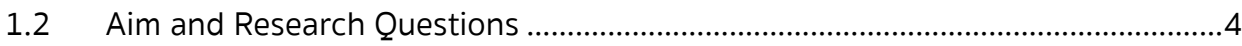

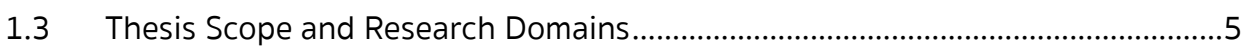

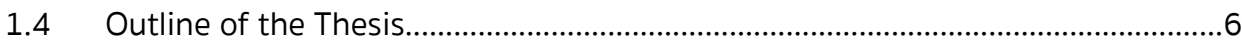

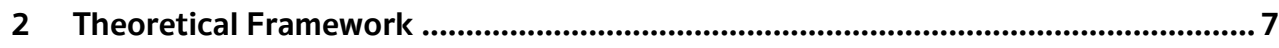

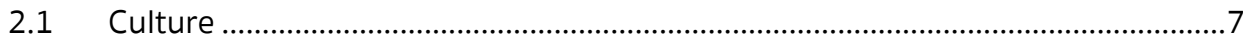

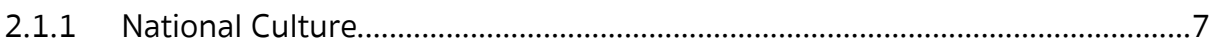

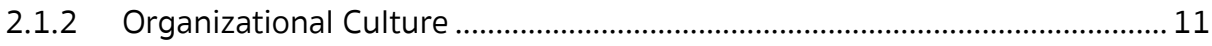

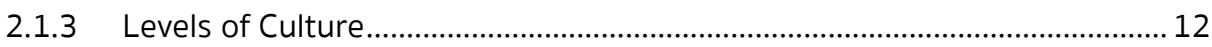

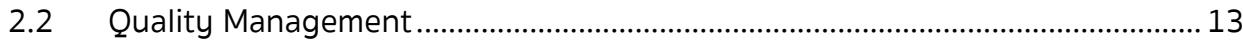

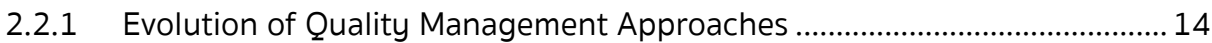

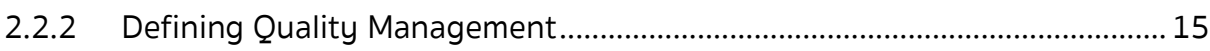

2.2.3 Quality Management in Cross-cultural Settings .............................................. 21

2.2.4 Quality Management Measurements in Cross-cultural Settings ................... 24

2.3 Multinational Companies from an Organizational Perspective ......................... 25

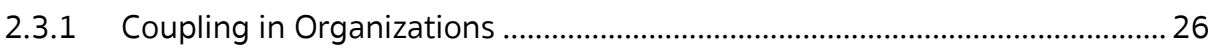

2.3.2 Boundary Spanning in Multinational Companies ......................................... 28

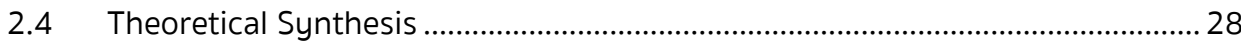

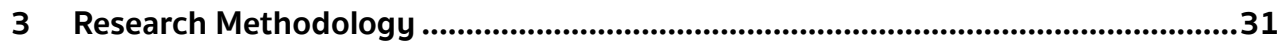

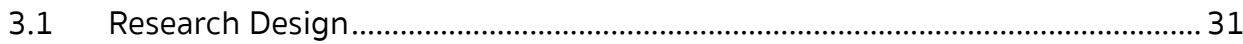

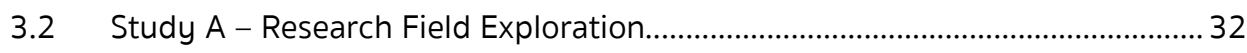

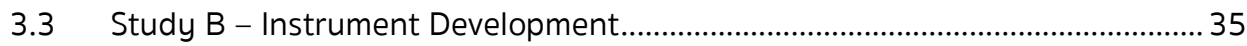

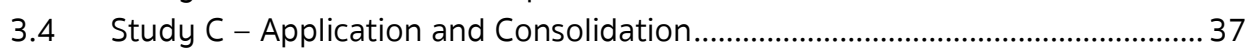

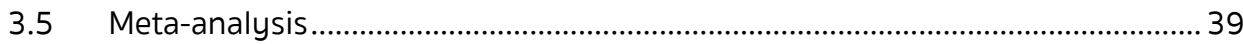

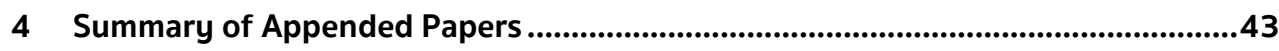

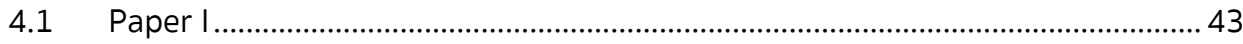

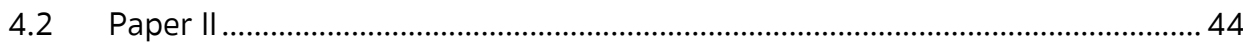

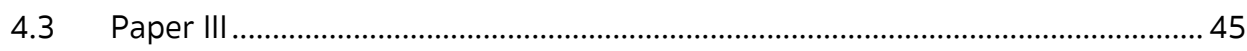

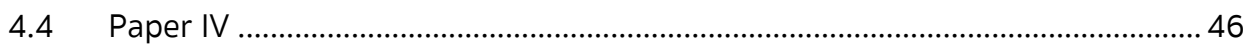

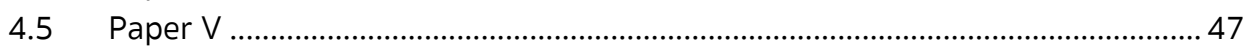

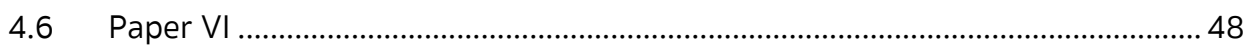

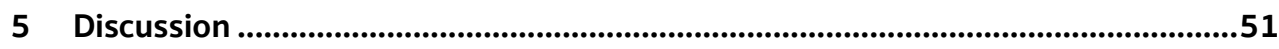

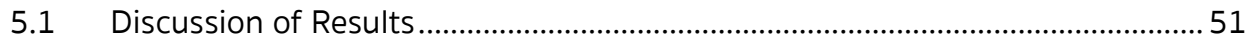

5.1.1 Challenges in Managing Quality Related to National Cultural Diversity in

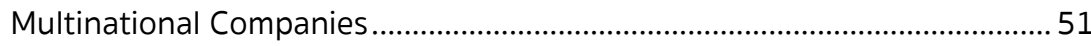

5.1.2 Understanding Cultural Diversity in Quality Management .............................54

5.1.3 Strategies to Manage Quality in Multinational Companies ............................56 


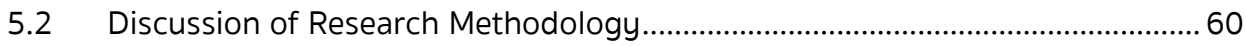

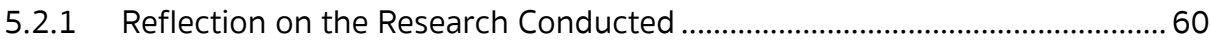

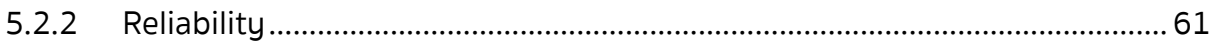

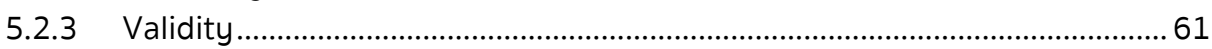

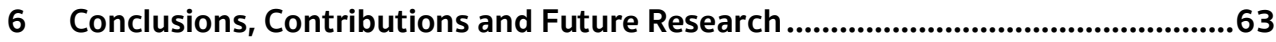

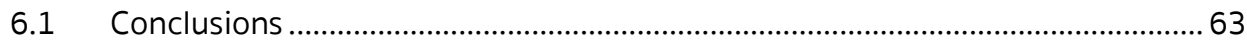

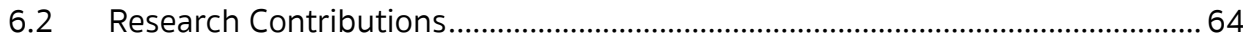

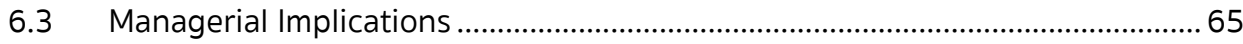

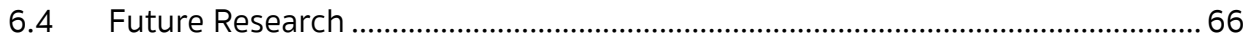

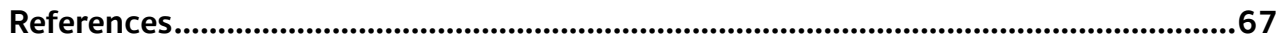




\section{Figures and Tables}

\section{List of Figures}

Figure 1: Thesis scope in relation to research domains and the research questions........6

Figure 2: Levels of culture related to national and organizational culture (adapted from

Schein, 2010)

Figure 3: Relationships between the conceptual and operational levels of quality management ........................................................................................................... 16

Figure 4: Matrix combining the I-R framework and the tight-loose coupling dimension (Spender and Grevesen, 1999) ............................................................................ 27

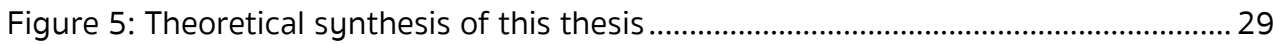

Figure 6: Connection between national, organizational culture and QM (adapted from Schein's model)

\section{List of Tables}

Table 1: Comparison of national culture dimensions based on Hofstede et al. (2010), Trompenaars and Hampden-Turner (2012) and Chhokar et al. (2013) ................8

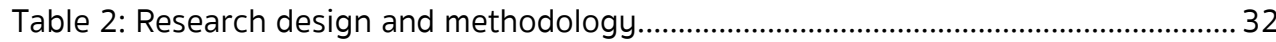

Table 3: Overview of data collection and analysis method in study A ..............................33

Table 4: Data collection and analysis methods in Sub-study C-2 ................................... 39

Table 5: Studies, research methods, and aims of the appended papers .......................... 40

Table 6: Appended papers, contributions and research questions addressed.................52 



\section{Introduction}

This chapter presents the topic and context of the thesis, and consists of four sections. First, the background is discussed in relation to quality management, culture and multinational companies. Then, the aim and research questions are specified. The third section describes the scope of the thesis and its domains of research. The fourth section presents an outline of the thesis.

Imagine a company that has its headquarters in Sweden and subsidiaries in Italy, Japan, China, Thailand, and Brazil, with customers all over the world. Production is high in all subsidiaries, and several deliveries are made to customers every day. Operators in one subsidiary discover a quality problem in a product that they consider to be minor. They allow the defect to pass, without paying much attention to it. When the same situation happens in another subsidiary, the production line is stopped to find the causes of the defect and to fix the issue at its root. The product development department has recently worked on a new product and launched it on different markets. The product sells well and is a success in Europe, but is a failure in the US.

Companies nowadays operate beyond national borders. The example above offers a glimpse into possible challenges in managing quality that arise when different attitudes toward quality are held by employees in different subsidiaries. Geographical distance and time differences no longer cause difficulties or barriers in collaboration, thanks to modern technology that enhances communication (Tsui et al., 2007). However, the company described above still faces several challenges, and many of them are associated with cultural diversity. Since national culture affects how people think, feel and act (Hofstede et al., 2010), people from different cultural backgrounds tend to have different expectations and understandings, and behave in different ways in similar circumstances (Swidler, 1986; Brislin, 2000). As this company is operating in many countries with local employees from different cultural backgrounds, the national cultural diversity of employees leads to challenges in managing quality. Similarly, customers from different countries have different needs and different perceptions of the same products or services. It is, thereby, challenging for companies to satisfy global customers. This thesis considers both employees and customers in multinational settings, and explores the cross-cultural challenges related to quality management.

\subsection{Background}

The management and improvement of quality are important parts of business strategy for companies to establish and sustain products or services of high quality, and thereby achieve high customer satisfaction (e.g. Anderson et al., 1994; Dean and Bowen, 1994; 
Flynn et al., 1995; Kaynak, 2003; Dale et al., 2007; Weckenmann et al., 2015). Quality management $(\mathrm{QM})$ has been defined as a philosophy or an approach to management consisting of a set of mutually reinforcing principles to accomplish the aim of the organization (Dean and Bowen, 1994; Deming, 1994). The principles of QM integrate social and technical aspects (Flynn et al., 1995; Ho et al., 2001; Sousa and Voss, 2002). The technical aspects aim to manage and improve the product and process quality, while the social aspects aim to create an environment that supports the effective use of the technical aspects (Flynn et al., 1995; Sousa and Voss, 2002). As a result, the technical aspects of $\mathrm{QM}$ comprise concrete techniques and tools such as product design techniques, process management tools, statistical process control, and information analysis tools. In contrast, the social aspects of $\mathrm{QM}$ comprise such values as management commitment, customer focus, and employee empowerment, and is related to the organizational work setting and the people who work with the technical aspects. In this thesis, an organizational work setting is considered to consist of formal arrangements such as goals, strategies, organizational structure, and reward systems, and social factors such as culture, leadership style, and interactions between people (Porras and Robertson, 1992). In order to achieve better organizational performance and higher customer satisfaction, both social and technical aspects of QM need to be promoted and practiced within an organization (Powell, 1995; Samson and Terziovski, 1999; Kaynak, 2003; Nair, 2006).

QM requires that people adopt, maintain and practice its principles systematically, which has led several studies to suggest that the social aspects have a stronger connection to organizational performance than the technical one (Samson and Terziovski, 1999; Naor et al., 2008). For successful and sustainable quality management, people within the organization need to understand the principles of $Q M$, embrace its philosophy or values, and use QM techniques and tools to monitor, control and improve quality (Thiagarajan and Zairi, 1997). As previously indicated, national culture influences what people expect, and how they perceive and behave (e.g. Swidler, 1986; Brislin, 2000; Hofstede et al., 2010). Thus, companies with high cultural diversity - such as multinational companies (MNCs) - may face challenges in managing quality as a consequence of different understandings of $\mathrm{QM}$ principles, and these companies need strategies for quality management in their organizations.

$\mathrm{QM}$, culture and MNCs are three aspects that are important to understand quality management in cross-cultural settings. Therefore, QM in MNCs is presented in relation to national and organizational culture. Further, challenges related to customers in crosscultural settings are raised. Finally, to set the context of this thesis, organizational settings of MNCs are explained based on concepts that arise from organizational theory.

\subsubsection{Quality Management in Multinational Companies}

A multinational company (MNC) consists of a group of geographically dispersed organizations (Ghoshal and Bartlett, 1990). Given that, the cultural settings of MNCs are 
quite complex. This thesis considers two types of culture in MNCs - national and organizational culture. National culture refers to the cultures of the countries in which the headquarters and subsidiaries are situated. Organizational culture refers to the way in which attitudes, values and norms are embraced within a specific organization (Trompenaars and Hampden-Turner, 2012). Organizational culture is referred to as the shared culture of an MNC in this thesis.

The strategies, goals and organizational culture of MNCs are determined primarily by the headquarters (Ghoshal and Bartlett, 1990). However, at subsidiaries, the employees and their actions are embedded in the context of the local country, which might differ from that of the headquarters. Furthermore, the subsidiaries are also a part of their company networks, which makes them diverse from their locally embedded peers (Drogendijk et al., 2010; Schotter and Beamish, 2011). In other words, the local contexts are shaped by the national cultures of the subsidiaries, while the subsidiaries are influenced also by the organizational culture of the MNC. Adler and Gundersen (2007) suggest that the local national cultures have more impact on employees and organizational work settings at subsidiaries than the organizational culture of the MNC propagated down from the headquarters. Nevertheless, such varied cultural contexts may create diversity that arises between individuals or groups who do not share the same social norms (van Maanen and Laurent, 2016).

Previous research has shown that QM is related to national culture (Chevrier, 2009). There are distinct patterns in how certain quality practices are adopted in certain countries, and different aspects of national culture facilitate or inhibit the outcomes of QM implementation (Vecchi and Brennan, 2009; Vecchi and Brennan, 2011). In addition, many studies have indicated that organizations need to align their organizational culture with their QM values in order to succeed in managing quality (Dean and Bowen, 1994; Powell, 1995; Mak, 1999; Mohammad Mosadegh Rad, 2006; Barouch and Kleinhans, 2015). QM practices are influenced also by the cultural setting of an organization (Prajogo and Sohal, 2006; Baird et al., 2011; Gambi et al., 2015). As a result, employees at the headquarters and subsidiaries may have a different understanding and may practice $Q M$ differently. Previous research has established a connection between $Q M$ and national and organizational cultures, but further research is required in QM in MNCs. Therefore, this thesis aims to contribute with the knowledge in this aspect.

\subsubsection{Customer Satisfaction in Cross-cultural Settings}

Definitions of 'quality' have changed as the field of QM has evolved. One factor, however, has remained constant: quality is defined primarily by customers (e.g. Juran, 1988; Bergman and Klefsjö, 2010). To this end, customer satisfaction is an important measure of how a company's products or services perform in relation to customer requirements (Fornell, 1992; Hill et al., 2017). However, it is difficult to evaluate and compare customer satisfaction in cross-cultural settings, since the level of satisfaction with products and services, and how people express feedback, may be influenced by cultural factors. 
Previous studies have shown that customers evaluate the same kind of services differently in different countries (Winsted, 1997; Mattila, 1999), and that customer feedback and satisfaction differ between nations (Johnson et al., 2002; Voss et al., 2004). Johnson et al. (2002) compared national customer satisfaction ratings between three countries, and showed that ratings were lower in Sweden and Germany than in the USA. Previous research has suggested that national culture influences customer satisfaction ratings, but few studies have been carried out.

Further, customer satisfaction is commonly measured using a traditional questionnaire, and doubts have long been raised about the cross-cultural comparability of results obtained with such instruments. Several issues in cross-cultural surveys can arise from questionnaire design, translation, response scale, and level of analysis (Scheuch, 1993; Cavusgil and Das, 1997; Malhotra et al., 2005; van Herk et al., 2005). These issues make the comparisons of survey responses from respondents with different cultural backgrounds not valid, but the shortcomings are often ignored and the responses treated equally (Chevalier and Fielding, 2011). Therefore, the risk arises when using a traditional questionnaire to measure customer satisfaction in cross-cultural settings that the results are misinterpreted and lead to incorrect conclusions. Consequently, companies need a measurement instrument that enables customer satisfaction ratings to be compared, and this thesis addresses this issue.

\subsubsection{Organizational Settings in Multinational Companies}

MNCs are dispersed organizations that consist of several interdependent subsidiaries (Ghoshal and Bartlett, 1990). Due to intense global competition, subsidiaries need to have close communication linkages with each other and coordinated strategies, while ensuring that the organizational structure of an MNC is flexible enough to keep up with changes in the global market and to allow cross-unit learning (Ghoshal and Westney, 2016). Further, Westney (2016) suggested that subsidiaries need to adapt the company's organizational work setting to the local context, including the national culture.

Coupling is commonly used to describe the extent of interdependence between two entities on the loose-tight continuum (Weick, 1976). It has been used to study several phenomena in MNCs, such as organizational structure (e.g. Beekun and Glick, 2001; Pache and Santos, 2013), organizational culture (e.g. Lemon and Sahota, 2004; Kwantes and Glazer, 2017), and the performance of subsidiaries (e.g. Lin, 2014). This thesis uses the organizational concept of 'coupling' to understand, analyze and suggest strategies for managing quality in MNCs.

\subsection{Aim and Research Questions}

Previous research has established the relationship between $Q M$, national culture and organizational culture. However, there are still research gaps regarding the management 
of quality in cross-cultural settings. In the case of MNCs, there is a need to understand and cope with quality management challenges, which are related to employees and organizational work settings and associated with different national cultural backgrounds. Previous research has suggested that cross-cultural challenges are present in managing quality, but most of the studies have examined either the national or the organizational level. Thus, a need remains to further explore $\mathrm{QM}$ in which both national and organizational cultures are entangled, as is the case for MNCs. In addition, companies that have customers from different national cultural backgrounds face challenges to collect and analyze customer feedback, in particular to compare feedback from different customer groups. This makes it difficult to manage quality and satisfy customers.

Therefore, this thesis aims to provide insight into managing quality in cross-cultural settings, where MNCs and companies that have customers in different countries are studied. To fulfill this aim, the following research questions are formulated:

RQ1: What are the challenges in managing quality related to national cultural diversity in MNCs?

RQ2: How can cultural diversity in QM be studied:

a) from an internal perspective of the MNCs?

b) from an external perspective of the customers?

RQ3: What are possible strategies to manage quality in MNCs?

To answer RQ1, challenges in managing quality that arise from national cultural diversity in MNCs are examined. In connection to RQ2, an instrument to study QM in cross-cultural settings is developed and suggested from two perspectives. The first is an internal perspective of MNCs (RQ2a), which focuses on employees' perceptions of QM principles and QM performances at the headquarters and in the subsidiaries. The second (RQ2b) is an external perspective related to measuring customer satisfaction across borders. This instrument aims to improve understanding of cultural diversity in QM. Finally, the answer to $\mathrm{RQ3}$ provides possible strategies to handle the challenges discussed in RQ1, and support in managing quality in the cross-cultural settings of MNCs.

\subsection{Thesis Scope and Research Domains}

The scope of this thesis covers three management research fields: QM, culture and MNCs, which are combined in the research questions as shown in Figure 1. This thesis focuses on the intersection between $\mathrm{QM}$ and culture, which gives the research domain of crosscultural QM. In this domain, research usually focuses on quality management that occurs in different cultural backgrounds. The empirical materials in all six appended papers fall into this research domain, although they focus on different aspects of QM in crosscultural settings, such as, customers, QM principles, and QM practices. Another research domain studied in this thesis is QM in MNCs, which is a subset of cross-cultural QM as 
illustrated in Figure 1. RQ1 and RQ3 are both included in this domain, as they address managing quality in MNCs. RQ2 is positioned partially in the domain of QM in MNC (RQ2a) and partially in the general cross-cultural QM (RQ2b, which examines not only MNCs, but companies with customers in different national cultural backgrounds).

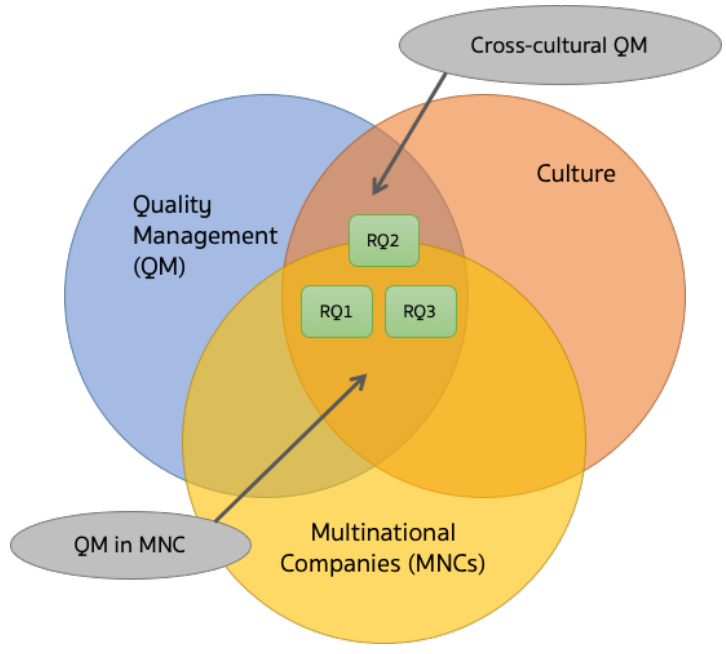

Figure 1: Thesis scope in relation to research domains and the research questions

\subsection{Outline of the Thesis}

This thesis consists of a compilation summary (Chapters 1 to 6 ) and six appended papers (Appendix). The compilation summary connects the papers and combines the knowledge developed in the papers to form a unified academic contribution. The thesis is organized as follows.

- Chapter 1: Introduction - Background, previous research in the related fields, aim, research questions, thesis scope and research domains

- Chapter 2: Theoretical framework - Conceptual framework regarding culture, QM, and MNCs from an organizational perspective

- Chapter 3: Methodology and research design - Descriptions of the overall research design, research methodologies including data collection and analysis of the three studies (Studies A, B and C)

- Chapter 4: Summary of appended papers - Findings and contributions of the six appended papers

- Chapter 5: Discussion - Results discussion based on the research questions and six appended papers, and methodology discussion as a reflection on the research conducted

- Chapter 6: Conclusions and future research - Conclusions, theoretical contributions, managerial implications and suggestions for future research 


\section{Theoretical Framework}

This chapter reviews relevant literature and theoretical perspectives related to the aim and research questions of this thesis. It contains four sections, three of which present the main theoretical concepts on which the thesis is based, while the fourth is a synthesis of these. The first section provides a theoretical background about culture, with a focus on national and organizational culture. The second section presents quality management and its components. The third section then discusses multinational companies from an organizational perspective. The fourth section provides a synthesis of the three main theoretical concepts previously presented in the chapter.

\subsection{Culture}

It is hard to formulate a universal definition of culture (Schein, 2010; Alvesson, 2012; Chhokar et al., 2013). According to Hofstede et al. (2010), culture is "the collective programming of the mind which distinguishes the member of one group or category of people from another". Schein (2010) defines culture as "a pattern of shared basic assumptions that was learned by a group as it solved its problems of external adaptation and internal integration, that has worked well enough to be considered valid and, therefore, to be taught to new members as the correct way to perceive, think and feel in relation to those problems". These two definitions show that the concept of culture focuses on the sharedness of internal intellect, i.e. on the programming of the mind, or the basic assumptions held by members of the group (Chhokar et al., 2013) that can be reflected externally in terms of symbols (Alvesson, 2012). In this thesis, culture is viewed as a system of common symbols and meanings based on shared values and assumptions (Alvesson, 2012). Symbols are visible objects or phenomena, such as a statement or an action, while meanings are the interpretation behind them (ibid). As a result, culture influences individual behavior and the interpretation of other people's behavior (Spencer-Oatey, 2004).

Culture is shaped in everyday life through the interactions of people, as they bring with them culture from past experiences. Such culture is regularly reinforced or has new elements added through new experiences or meetings with new people (Schein, 2010). However, it is strong and stable when it is group-based (ibid). Management research has studied various types of culture at different levels, for example, regional, national, organizational, functional, etc. This thesis focuses on two types of culture - national and organizational culture.

\subsubsection{National Culture}

Several models of national culture have been developed from empirical studies. The purpose of a national culture model is to show various dimensions that present 
phenomena in society that differ between different nations (Hofstede et al., 2010). The three most cited models in cross-cultural research are Hofstede et al. (2010), Trompenaars and Hampden-Turner (2012), and the GLOBE project model (Chhokar et al., 2013). The focus of the models and the dimensions used in them differ, while considerable similarities among them make it possible to group them as shown in Table 1 and discussed in the following section.

Table 1: Comparison of national culture dimensions based on Hofstede et al. (2010), Trompenaars and Hampden-Turner (2012) and Chhokar et al. (2013)

\begin{tabular}{|l|c|l|l|}
\hline National cultural dimensions & $\begin{array}{l}\text { Hofstede et al. } \\
\text { (2010) }\end{array}$ & $\begin{array}{l}\text { Trompenaars and } \\
\text { Hampden-Turner (2012) }\end{array}$ & $\begin{array}{l}\text { GLOBE (Chhokar et } \\
\text { al., 2013) }\end{array}$ \\
\hline Power distance & $\bullet$ & & $\bullet$ \\
\hline Individual vs. group identity & $\bullet$ & $\bullet$ & $\bullet$ \\
\hline Relations and motivation & $\bullet$ & $\bullet$ & $\bullet$ \\
\hline Uncertainty avoidance & $\bullet$ & $\bullet$ & \\
\hline Time orientation & $\bullet$ & $\bullet$ & \\
\hline Human affairs and emotions & $\bullet$ & $\bullet$ & \\
\hline Specific vs. diffuse & & $\bullet$ & \\
\hline Universalism vs. particularism & & $\bullet$ & \\
\hline
\end{tabular}

Power distance is the extent to which the members of the group expect and accept that power is distributed unequally, with greater power at higher levels (Hofstede et al., 2010; Chhokar et al., 2013). Individuals experience this first within families, then schools, and finally workplaces as they grow up.

Individual vs. group identity describes the degree to which people see themselves as functioning more as a community or as individuals (Hofstede et al., 2010; Trompenaars and Hampden-Turner, 2012). An individualist culture is one in which the ties between individuals are loose, and everyone is expected to look after themselves and their immediate family. A collectivist society, in contrast, is one in which people are viewed as members of a group and their individual preferences are subordinate to those of the group (Hofstede et al., 2010). Chhokar et al. (2013) divide this dimension into two components that show different perspectives. The first is in-group collectivism and refers to the way in which individuals express pride, loyalty and cohesiveness to the group to which they belong. The second is institutional collectivism and reflects the 
extent to which an institution (the nation in this case) encourages and rewards the collective distribution of resources and actions.

Relations and motivation includes dimensions that direct a personal way of working, including equality, respect, humanity, and results orientation. Hofstede et al. (2010) uses gender roles to designate the two ends of a spectrum as masculinity vs. femininity. The emotional gender roles are clear in a masculine society: men should be assertive, ambitious and tough, for example, while women should be tender and caring. In a masculine society, people prefer challenging work, opportunities for high earnings, and chances for job promotion. As a result, this dimension affects decision-making and the ways in which conflicts are handled, as well as how people are motivated in the workplace. GLOBE defined four other dimensions: assertiveness, gender egalitarianism, humane orientation, and performance orientation, and established conceptual connections to the masculinity and femininity levels defined by Hofstede (Chhokar et al., 2013). Trompenaars and Hampden-Turner (2012) expressed this dimension as achievement vs. ascription. An achievement society is one in which people are judged on their performance, while an ascription is one in which status is gained by birth, gender, age or social connections.

Uncertainty avoidance is the behavior used by people who feel threatened by ambiguous or unknown situations (Hofstede et al., 2010). According to Chhokar et al. (2013), people in society with high uncertainty avoidance strive to avoid ambiguous situations by relying on established social norms, rituals and practices to decrease the probability of unpredictable future events. Uncertainty avoidance is not to be confused with risk avoidance. A society in which uncertainty avoidance is high does not try to control risks, but looks for a proper structure in their institutions and relationships between people (Hofstede et al., 2010). Trompenaars and Hampden-Turner (2012) did not define an uncertainty avoidance dimension, but the dimension that measures attitude toward the environment reflects this to some extent. They analyze approaches to the environment, and distinguish between societies in which individuals try to take control and those in which the world is more powerful, and nature is seen as something to be feared (ibid). This dimension reflects to some extent how people in the society react to external forces beyond their control, and how they react to mistakes they make.

Time orientation describes how people consider long- or short-term perspective of life. Some societies do not value highly previous achievements, and consider it more important to plan for the future (Trompenaars and Hampden-Turner, 2012). This is captured by the GLOBE dimension of future orientation, in which people plan for and invest in the future (Chhokar et al., 2013). According to Hofstede et al. (2010), longterm orientation reflects a pragmatic future-oriented perspective, rather than a conventional historical short-term point of view.

Human affairs and emotions is related to how people should behave or express their feelings, and how they should spend their lives in a society (Hofstede et al., 2010; 
Trompenaars and Hampden-Turner, 2012). In some societies, business relationships are goal-oriented and instrumental, while in other societies human affairs and the display of emotions is considered appropriate (Trompenaars and Hampden-Turner, 2012). Hofstede et al. (2010) add a dimension of indulgence vs. restraint, citing one cultural dimension in the World Value Survey. Indulgence refers to a tendency to allow people to show emotion, enjoy life and have fun; while restraint comes from a conviction that such gratification must be regulated by strict social norms. This dimension reflects the opportunities individuals have to make choices, and promote their quality of life, wellbeing, and self-expression.

Specific Vs. diffuse describes the extent to which people should get involved in a business relationship (Trompenaars and Hampden-Turner, 2012). A diffuse relationship is required in some countries, it is necessary to get to know the persons involved, their history, and contexts, before business can proceed. The process must be allowed to take time. The dimension reflects how people should interact, and how they should do business in the society.

Universalism vs. particularism concerns the extent to which people stick to the rules (Trompenaars and Hampden-Turner, 2012). In a universalism society, people place a high value on laws and principles, and tend to follow the rules strictly. In contrast, in a particularism society, people may allow a specific situation or personal relationship to override general principles.

It is difficult to compare the cultural dimensions of the three models head-to-head. Some criteria reflected in one cultural dimension of the Hofstede model are reflected in many dimensions of the GLOBE and Trompenaars models. Moreover, the authors have examined each other's model, and in some case put forward criticism. For example, Hofstede (1996) re-analyzed Trompenaars' model and raised concerns about the content validity of the instrument. The creators of the the GLOBE model claim that their cultural dimensions are based on previous work in the cross-cultural field, including Hofstede's (Chhokar et al., 2013), but some conflicts can be seen. For example, GLOBE defines the power distance and uncertainty avoidance dimensions using the same terms, but the questions in the survey were so differently formulated that Hofstede et al. (2010) suspected that the concepts had been confused. Others have criticized Hofstede's work (McSweeney, 2002; Earley, 2006; Smith, 2006). For example, McSweeney (2002) claimed that the Chinese Value Survey on which Hofstede based the fifth dimension invalidates the dimension of uncertainty avoidance. This issue should have been resolved before accepting the validity of the survey, by adding the fifth dimension to the results. Other researchers have argued that Hofstede made too many assumptions in the study to allow such a grand-value assessment to be made (McSweeney, 2002; Earley, 2006). However, much research into cross-cultural quality management is based on these three national cultural models, despite the criticisms: Hofstede's model (e.g. Lagrosen, 2003; Flynn and Saladin, 2006; Zgodavova et al., 2017), Trompenaars and Hampden-Turner's model (e.g. 
Brady et al., 2001; Mathews et al., 2001), and GLOBE model (e.g. Vecchi and Brennan, 2011).

Nations should not be equated with societies (Hofstede et al., 2010). Societies are the pure form of social phenomena in which culture occurs, while nations can be seen as a formal attempt to group societies, and then apply other institutional factors, such as laws, to all the societies in the group (ibid). As a result, some nations consist of several societies. Switzerland, for example, is divided into several societies, based partly on the origin of the population and their mother tongue (German, French or Italian), but all societies are members of one nation and obey the same laws (Chevrier, 2009). This leads to another criticism of using national culture in research: it is too broad and neglects other factors that influence the culture of societies (McSweeney, 2002). National culture, however, is commonly used in research into cross-cultural management, as it defines recognized clusters with adequately developed research studies (Chevrier, 2009; Hofstede et al., 2010; Trompenaars and Hampden-Turner, 2012).

Based on previous research, this thesis assumes that national cultures differ, and examines how such differences affect quality management in cross-cultural settings. Cultural dimensions are only used at general level and the criticism of cultural models, although relevant, is not considered as a limitation to fulfill the aim of the thesis.

\subsubsection{Organizational Culture}

Organization by itself is a subjective construct, but the people involved in the organization are the ones who give meaning to the organization, based on their own cultural programming (Trompenaars and Hampden-Turner, 2012). Organizational culture is the cultural program that is created and maintained within an organization, and it can be strengthened by encouraging the same values and norms (Alvesson, 2012). Previous studies have suggested that a strong organizational culture enhances competitive advantage and performance (e.g. Peters and Waterman, 1982; Barney, 1986; Valmohammadi and Roshanzamir, 2015).

Organizational culture usually grows from three sources: 1) the beliefs, values and assumptions of the organization's founders; 2) the learning experiences of the group members; and 3) new beliefs, values and assumptions brought in by new group members and leaders (Schein, 2010). The culture is initially established mostly by the first source, since the founders have chosen the mission, context and employees, and established the basic values and norms within the organization (Schein, 2010). This first source of organizational culture loses its importance as the organization grows (Alvesson, 2012). As the organization evolves, new employees join the group and act as the third source. The second source of organizational culture becomes important if the group remains stable and learning experiences are shared among the employees (Schein, 2010). 


\subsubsection{Levels of Culture}

Culture can be analyzed at several levels, such as national, regional, ethnic, religious, gender-based, and organizational (Hofstede et al., 2010). The previous sections have discussed two levels of culture - national and organizational. In the case of MNCs, subsidiaries situated in different countries have employees rooted in different national cultures. National culture is usually gained early in life, since it is rooted in families, schools, etc., and becomes deeply imprinted onto people's minds (Hofstede et al., 2010; Trompenaars and Hampden-Turner, 2012). Organizational culture, in contrast, is gained when one joins an organization, later in life. Thus, national and organizational cultures are positioned at different cultural levels.

Although culture can be seen as the medium through which people experience and live their lives, cultural elements are embedded in visible material situations and the social structure of organizations (Alvesson, 2012). Schein (2010) identified three major levels of cultural analysis (Figure 2). Artifacts are superficial: they can be seen, heard and felt, and include such features as language, technology, myths and stories. Some artifacts lie at deeper cultural levels, such as the visible behavior of people. Although artifacts are visible and easy to observe, they are very difficult to interpret without understanding the other levels of culture. Espoused values are the shared beliefs that result from group learning. They are, for example, strategies, goals and philosophies that have been proved

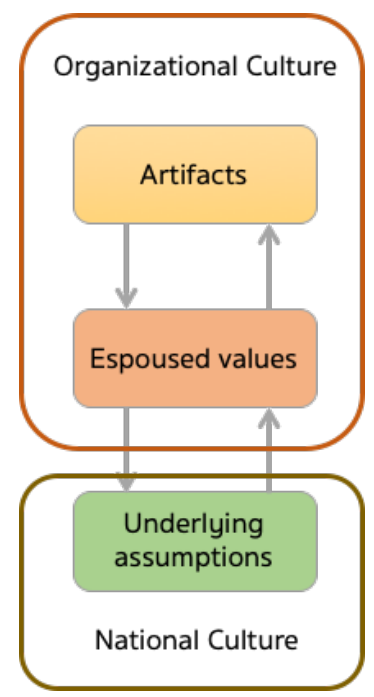

Figure 2: Levels of culture related to national and organizational culture (adapted from

Schein, 2010)

to be successful, and are accepted by the group members. Espoused values are at the conscious level of people's minds, and can be used to predict behavior at the artifacts level. Underlying assumptions lie at the deepest level: these are the beliefs and values 
that are essentially the same within a social unit. They are imprinted deep in people's minds and are non-negotiable within the group (Schein, 2010).

These three levels of culture are intertwined in two directions (Schein, 2010). The essence of a culture lies in the underlying assumptions that affect how people feel, act on, and perceive values and norms at the espoused level. The espoused values are subsequently reflected at the surface level in terms of artifacts. Conversely, artifacts can gradually affect the espoused values, which may eventually become transformed into the underlying assumptions. However, this transformation is difficult, highly anxietyprovoking for the group, and takes very long time (Schein, 2010).

Trompenaars and Hampden-Turner (2012) proposed a similar model in which culture can be found in three layers: the core, middle and outer layers. The outer layer is the manifestation of norms, attitudes and beliefs in systems and institutions, and in behavioral patterns. The middle layer reflects the norms (right or wrong) and values (good or bad) of a group. The norms reflect the values of the group in stable cultures, and the cultural tradition of the group can be developed and elaborated. The norms and values are in turn influenced by the core layer, which is usually learned early in life and is more difficult to change than the others. It consists of basic assumptions and values. Different groups have formed different sets of basic assumptions, since they have developed in different geographic locations.

In both of these two models, the core layer of culture lies deep within people's minds and is very hard to change. It is gained early in life and rooted mainly within the family (Hofstede et al., 2010; Trompenaars and Hampden-Turner, 2012). National culture plays a significant role here in shaping the underlying assumptions of people in the same nation. Other kinds of culture, such as organizational culture, are picked up later and are reflected mainly at the espoused values and artifacts level (Figure 2).

Organizations are not closed systems: they are influenced by external factors, such as society and the industrial sector (Alvesson, 2012). When a company goes multinational, the national cultures of employees may penetrate into the company. Each subsidiary establishes shared experiences and undergoes group learning, while new people with the national cultural background are recruited. This creates cultural challenges for the multinational organization. Schein's cultural model suggests that there are ways to set up common artifacts that can promote organizational culture at the level of espoused values, making it unique and strong throughout the MNC and causing less conflict with the national cultural background of each subsidiary. Finally, the espoused values may affect the underlying assumptions, as shown in the model (Schein, 2010).

\subsection{Quality Management}

Quality is a familiar word with numerous definitions. Some of them are considered to be too narrow (Bergman and Klefsjö, 2010), for example, "fitness for use (Juran, 1988)", and 
"conformance to requirements (Crosby, 1979)". Shewhart (1931) suggested that quality has two sides that are important for manufacturers - objective and subjective. Objective quality can be measured and must be considered by manufacturers during design and production. Subjective quality, in contrast, concerns how customers experience the products. This means that quality is defined not only by manufacturers (in terms of product specification), but also by customers, who assess the products from their subjective point of view (Shewhart, 1931; Bergman and Klefsjö, 2010). Nevertheless, researchers and practitioners do not have a single accepted definition of quality, and it remains an ambiguous term. Product specifications do contribute to measurable objective quality, but manufacturers face challenges in managing quality, due to the way employees work with the products. For example, a product specification may be clearly written, but deviations from the specification differ significantly between different employees who work with the same product. It is, therefore, important in an organization to establish a clear and common understanding of quality among all employees, in order to prevent confusion and ensure that everyone is working towards the same goal (Dale et al., 2007).

Approaches to quality management have evolved over time and been given many names. Except for understanding the content of $Q M$, it is essential for this thesis to describe $Q M$ in cross-cultural settings and problems with $\mathrm{QM}$ measurements across borders.

\subsubsection{Evolution of Quality Management Approaches}

The roots of QM can be traced back to the early 1920s when statistical theory was applied to control product quality in the industrial sector, following the work of Shewhart (Fisher and Nair, 2009; Weckenmann et al., 2015). The concept of quality control was subsequently developed by American academics such as Juran and Deming (Fisher and Nair, 2009). Although most quality control concepts were developed by Americans, the Japanese turned theoretical concepts into operational procedures, prompted by the need to shift focus onto economic success after losing WWII (Strang and Kim, 2004). They realized that it was difficult to achieve high-quality with scarce resources, and invited quality gurus to Japan to help. As a result, Juran and Deming played key roles in raising quality consciousness in Japan, and later in the Western countries (Fisher and Nair, 2009). Moreover, the development of quality management in Japan was also influenced by several Japanese quality gurus, including Ishikawa and Kano (Strang and Kim, 2004).

As a consciousness of quality evolved in Japan during the 1950s, the concept of total quality control (TQC) became popular among manufacturers, one of them Toyota (Dahlgaard et al., 2006). TQC consists of several basic principles, such as process control, line-stop for nonconformities, self-corrected mistakes, and facilitating concepts (such as small lot sizes and the use of housekeeping routines). TQC consists also of techniques and aids from analysis tools, and quality control circles (ibid). However, the concept of TQC initially spread mostly in Japan, and was introduced to the Western countries in the 
1980s, under the new name of total quality management (TQM) (Dahlgaard et al., 2006). As TQM evolved, a stronger emphasis was given to quality from the customer's perspective with support from employee involvement (Schonberger, 2007). Finally, TQM became a holistic management philosophy that concerns not only production but also company-wide processes in all types of industries and services (Dahlgaard et al., 2006).

Around the end of the 1980s, another quality management approach developed by Motorola started to gain interest. It was based on statistical methods and was given the name 'six sigma' (Fisher and Nair, 2009). Six sigma is a quality program that focuses on reducing variation through continuous and breakthrough improvements (Andersson et al., 2006). It is highly disciplined and data-oriented, with a focus on a top-down approach and the use of statistical tools. It is explicitly linked to tactical methods and strategic thinking (Klefsjö et al., 2001; Andersson et al., 2006).

In the 1990s, a new concept in operation management was spread under the name of lean production, having arisen in a research project at MIT that studied the Toyota Production System and its success (Womack et al., 1990). Toyota adopted the TQC philosophy, and used its principles to improve quality as a critical factor in surviving a crisis in the automotive industry that had arisen during the 1950s (Dahlgaard et al., 2006). Lean production is a Western interpretation of the Toyota Production System that was rooted in TQC and the work of the quality gurus. Lean production is generally defined as a systematic approach to identifying and eliminating the non value-added activities in processes, and striving for perfection with customer focus (Andersson et al., 2006).

TQM, Lean production and Six Sigma have the same origin of the philosophy, namely the work of quality gurus around WWII, but the three strategies have taken different paths and developed differently, to a certain extent (Andersson et al., 2006; Dahlgaard et al., 2006; Schonberger, 2007; Sreedharan V et al., 2018). Dahlgaard et al. (2006) suggested that Lean and Six Sigma provide clearer roadmaps than TQM, which makes them easier for companies to adopt. TQM is more ambiguous, and often associated with philosophy and the theory of how to achieve better organizational performance and customer satisfaction (Andersson et al., 2006). Nevertheless, two core values are the basis of all three: a focus on employee involvement and a focus on continuous improvement (Schonberger, 2007). In summary, the three concepts do not contradict each other and all focus on achieving the same results of business excellence and customer satisfaction: they are simply slightly different packaging of tools (Andersson et al., 2006; Dahlgaard et al., 2006; Sreedharan V et al., 2018).

\subsubsection{Defining Quality Management}

Quality management $(\mathrm{QM})$ is a concept based on ideas proposed by Shewhart, Ishikawa, Juran, Deming and Crosby (Bergman and Klefsjö, 2010). In the subsequent decades of QM development around the world, several definitions of QM have been proposed. (Flynn 
et al., 1994) defined QM as "an integrated and inter-functional approach to achieving and sustaining high quality output for competitive advantage". Klefsjö et al. (2008) emphasize that QM is a means of achieving the goal of quality excellence, and ultimately business excellence, by focusing on customers and their satisfaction.

$\mathrm{QM}$ is a management system that consists of social and technical aspects. The social aspects focus on people and organizational work setting, while the technical aspects are related to techniques and tools for managing and improving product and process quality (Flynn et al., 1995; Ho et al., 2001; Sousa and Voss, 2002; Zu, 2009). Hellsten and Klefsjö (2000) suggested that QM has three components: values, techniques and tools. The values form the basis for the culture of the organization that is adopting QM (Hellsten and Klefsjö, 2000), and thus QM values can be linked to the social aspects, which is intended to establish a proper organizational environment through management support and employee involvement. The technical aspects, in contrast, involve the use of procedures, techniques and tools to solve quality problems and improve product and service quality (e.g. Flynn et al., 1995; Zu, 2009). QM values, techniques and tools are combined to form what are known as QM principles, which are applied in organizations and result in QM practices. These are the observable facet of QM (Dean and Bowen, 1994; Sousa and Voss, 2002; Prajogo and McDermott, 2005; Zu, 2009). In other words, QM practices are related to a set of activities that organizations and their employees undertake to meet the organization's objectives, such as satisfying the quality requirements posed by customers. Figure 3 shows the components of QM principles, values, techniques and tools) with the social and technical aspects, and their relationship

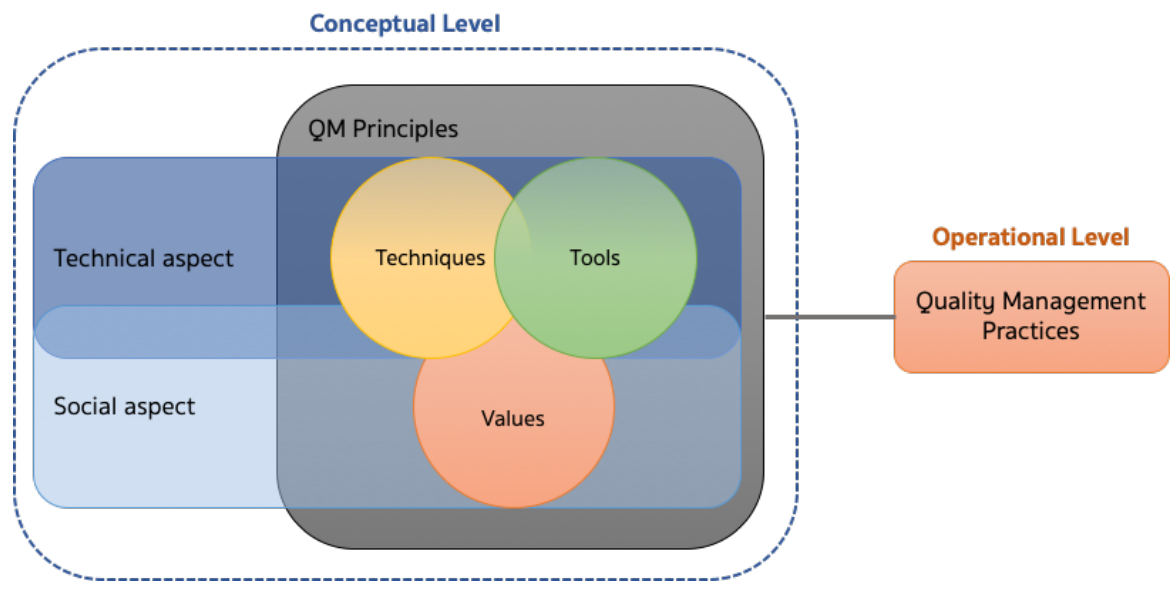

Figure 3: Relationships between the conceptual and operational levels of quality

to QM practices. These elements of QM are intertwined and must be adopted together as a system (e.g. Deming, 1994; Hellsten and Klefsjö, 2000). The QM techniques and tools must have a strong technical structure, to allow the social aspects to be made operative and in this way achieve an effective QM system (Calvo-Mora et al., 2013). 
Techniques and tools are distinguished in that tools are simple stand-alone devices with a narrow focus, while techniques are collections of tools used in an integrated approach for specific purposes such as problem solving and product development (Dale and McQuater, 1998; Hellsten and Klefsjö, 2000; Bamford and Greatbanks, 2005). Common QM principles are presented below and used in this thesis.

\section{Management Strategy and Leadership}

Management support and an appropriate leadership style are important for QM (e.g. Anderson et al., 1994; Dean and Bowen, 1994; Puffer and McCarthy, 1996). One reason

for this is that commitment from the top management is important for the success of $Q M$ adoption in the organization (Hoang et al., 2006; Dahlgaard et al., 2008). Further, the top management's role is to continuously promote $\mathrm{QM}$ throughout the organization (Bergman and Klefsjö, 2010). The management should explain clearly the advantages of QM and the reasons it is carried out. It should also present objectives for continuous improvement (Beer, 2003), and establish a working environment in which quality performance is rewarded (Flynn et al., 1994). Further, the top management's role is to establish QM strategies from a long-term perspective, and promote the attitudes, skills and behavior of leaders that bring about quality performance (Flynn et al., 1995). Subunit managers and leaders should work to encourage a positive attitude of employees towards QM, and engage in a transparent learning process (Beer, 2003). Hence, the responsibilities of QM leaders include managing information, building and maintaining relationships, influencing people, and participating in decision-making (Puffer and McCarthy, 1996; Calvo-Mora et al., 2013). The vision and strategies should be broken down and transparently communicated throughout the organization, so that all employees have a common understanding, especially with respect to quality (Anderson et al., 1994; Dean and Bowen, 1994; Calvo-Mora et al., 2013). QM techniques are available that can be adopted to support this practice, one of which is policy deployment (Oakland, 2011).

\section{Customer Focus}

Customer focus is the principle that is missing in earlier management theories (Dean and Bowen, 1994). It aims to increase the commitment of the organization to improve customer satisfaction (Samson and Terziovski, 1999).

Two different types of customer have been defined: external and internal. External customers are usually the end customers outside of the organizational boundary, for whom the organization is striving to exceed expectations, while internal customers are those in the next process step along the line of work (Bergman and Klefsjö, 2010). Both external and internal customers should be in focus if QM is to succeed (Dean and Bowen, 1994; Samson and Terziovski, 1999), but for different reasons. External customer is vital if the organization is to survive and perform satisfactorily, while internal customer is required to establish the quality of the product or service and deliver it to the external 
customer (Bergman and Klefsjö, 2010). Customer satisfaction is often based on the perception of customers of the quality of the product or service they receive (Anderson et al., 1994), which is, in turn, related to customer expectations and requirements (Hill et al., 2017). As a result, organizations need to continuously measure how their products or services satisfy customers and improve their performance to exceed, or at least meet customer expectations and requirements (Dean and Bowen, 1994; Kanji and Wallace, 2010). Moreover, measurement of customer satisfaction can promote improvement work and support decision-making (Anderson and Fornell, 2010; Birch-Jensen et al., 2018). Information about customer expectations and requirements also helps employees to focus quality improvement on the working processes that are crucial for customer satisfaction (Hackman and Wageman, 1995). Therefore, a customer focus improves not only the overall performance of the organization but also individual performance (Nair, 2006). Several QM techniques and tools are available to gather and analyze customer data, such as quality function deployment (QFD), benchmarking, the completion of check sheets, diagrams and graphs (scatter diagrams, histograms, pareto charts, etc.) (Bunney and Dale, 1997; Bamford and Greatbanks, 2005; Bergman and Klefsjö, 2010).

In order to satisfy an internal customer, a stable process must be built that increases quality from within the organization, while providing employees with greater job satisfaction. Understanding internal customer requirements helps to shape such a strategy, and to design and improve working processes. This brings another core principle of $\mathrm{QM}$ into focus: employee management and training. With a strong customer focus throughout the organization, employee management and training help to link external customer requirements to the manufacturing strategy of the organization (Sousa, 2003).

\section{Process Management}

In quality management, an organization is defined as a set of interlinked processes that aim to create values for customers (Dean and Bowen, 1994). Effective process management can have a direct impact on quality performance by reducing variation in the process (Flynn et al., 1995). Thus, process management is an important $Q M$ value, in that it promotes customer focus, system perspective and proper mindset for work with quality improvement. The processes within an organization should be mapped, standardized, measured and improved, in order to better meet the quality objectives (Cronemyr and Danielsson, 2013).

Flynn et al. (1995) suggested that process management focuses primarily on the manufacturing process to ensure that it runs without unplanned stoppages. The technical aspects of process management can be defined as a set of techniques and tools used to improve processes, in particular those that create value for customers, both internal and external. Such management is also an integrating method for the complete organization (Lee and Dale, 1998). Process maps can be drawn up by cross-functional teams (Hellström et al., 2008) to help to understand the chain of activities before 
improvements (such as reducing variation, and omitting unnecessary activities) are made. Techniques and tools that can be used to monitor, analyze and improve the processes include statistical process control, quality control tools, and flow charting (Bunney and Dale, 1997; Bamford and Greatbanks, 2005; Bergman and Klefsjö, 2010).

Process management, however, is not restricted to the main production process, and considers also support and management processes (Bergman and Klefsjö, 2010). Anderson et al. Anderson et al. (1994) adopted this wider view of process management and proposed that process management consists of both methodological approaches and human resource management. These are combined to manage and improve the processes that result in products and services. In other words, all employees are involved in continuously analyzing and improving the processes (Dean and Bowen, 1994; Spencer, 1994), adding value, increasing quality and productivity, and reducing waste and costs in the organization (Hoang et al., 2006).

\section{Continuous Improvement}

Continuous improvement governs the values that guide the behavior of people when they use techniques and tools to improve their daily work (Imai, 2012; Marin-Garcia et al., 2018). The underlying idea arose in the quality improvement framework proposed by Deming (1994) and in Kaizen philosophy (Imai, 1986; Marin-Garcia et al., 2018). It suggests that the purpose of QM - to achieve better quality with less variation along the process - results from process management practices that promote incremental improvements and innovation (Anderson et al., 1994). Bessant et al. (1994: 18) defined continuous improvement as "a company-wide process of focused and continuous incremental innovation". This continuous improvement is supported by process management and employee involvement (Dean and Bowen, 1994). Thus, it should be managed throughout the organization with all employees involved, and a clear strategy promoting a never-ending process of improvement and learning, not just occasional events (Bessant et al., 1994). Continuous improvement and incremental innovation are related concepts in $\mathrm{QM}$ and process management contexts showing that small improvement steps can lead to considerable developments over time (Anderson et al., 1994; Bessant et al., 1994; Marin-Garcia et al., 2018). A wide variety of techniques and tools are available to support continuous improvement, such as a Kaizen team, quality circles, a Kaizen event, process management tools, and quality control tools (Bergman and Klefsjö, 2010; Marin-Garcia et al., 2018).

As previously stated, continuous improvement should be managed strategically with a framework, and in a supportive environment. Moreover, it should be managed as a continuous process with a need for proper infrastructure, such as a flatter organizational structure, employee involvement and empowerment, and a scientific approach to decision-making (Bessant et al., 1994). 


\section{Scientific Approach and Actions Based on Facts}

In order to continuously improve work processes and increase quality, organizations need to systematically collect and analyze information about customer requirements and operational problems (Dean and Bowen, 1994). To be more precise, analysis of customer requirements is needed to set up strategies and goals, while analysis of operational problems and successful improvements support employee development and learning throughout the organization (Flynn et al., 1995). Therefore, the core value of this principle is to collect and analyze data, and use this information to decide and act accordingly. Several information processing tools are available to analyze such information, such as benchmarking and quality control tools (Hackman and Wageman, 1995; Bunney and Dale, 1997; Bergman and Klefsjö, 2010).

However, it is not sufficient to gather and analyze information for this QM principle. To solve problems and take action based on facts, it is recommended that a cross-functional team be formed, in order to monitor performance, and to identify and solve problems together using a broad range of expertise (Hackman and Wageman, 1995). This is also a good opportunity for improvement initiatives related to continuous improvement, and for those related to individual and organizational learning.

\section{Employee Involvement and Development}

Continuous improvement is important in quality work, and thus it is necessary to create conditions that foster both commitment and participation in decision-making and improvement work (Bergman and Klefsjö, 2010). Therefore, employee involvement and development are two other important $\mathrm{QM}$ values, focusing on letting employees commit to and be involved in the improvement work, as well as developing the skills needed for the tasks.

Different researchers have slightly different approaches to this principle. Anderson et al. (1994) describe employee fulfillment as a core concept of QM which is defined as a degree to which employees believe that an organization satisfies their needs and feel pride in and commitment to the work. This employee fulfillment concept is closely related to the previously discussed concept of internal customer satisfaction. However, the way to achieve employee fulfillment lies within the employee management principle. According to Anderson et al. (1994), three factors lead to job commitment: employees should like their work, they should enjoy work when it is challenging, and they should be willing to take responsibility for the outcome of their actions. Flynn et al. (1995) agree with this analysis, and they propose that the framework for QM should contain positive work attitudes (including loyalty to the organization), pride in work, the ability to work as cross-functional teams, and workforce management. As a result, employee commitment and involvement are important to creating positive work attitudes. When such attitudes prevail, employees can design and make decisions about their own quality tasks as also known as 'employee empowerment', and supervisors act more as coaches 
than as controllers (Anderson et al., 1994). Consequently, employee involvement and development help to improve their behavior, and help them to respond professionally to customer needs. This, in turn, increases the level of customer satisfaction (Bouranta et al., 2019).

However, workforce management to support QM requires a non-traditional approach to problem-solving - one that emphasizes the ideas of employees and brings continuous improvement in their skills (Flynn et al., 1995). The use of cross-functional teams to identify and solve problems is one way to manage and develop employees in QM (Hackman and Wageman, 1995). Accordingly, an egalitarian approach that minimizes the distance between hierarchical levels in the organization is appreciated (Flynn et al., 1994).

\section{Supplier Partnerships}

Suppliers are a part of supply chain that can influence quality and cost of product or service in the whole chain. Therefore, it is important to consider suppliers when managing quality (e.g. Bergman and Klefsjö, 2010). Anderson et al. (1994) suggest that both internal and external cooperation should be established. While the internal cooperation has been discussed above, in the section on employee involvement and development, where the use of cross-functional teams was emphasized, external cooperation in the form of supplier partnerships is discussed here. With respect to $Q M$, supplier selection should not be based solely on price, but should focus also on quality (Anderson et al., 1994; Flynn et al., 1994; Flynn et al., 1995; Hackman and Wageman, 1995). It is better to have a small number of suppliers with long-term relationships, rather than many short-term contract suppliers, because this allows a systematic information exchange to be set up. Further, suppliers have the opportunity to contribute to product design processes to achieve better quality (Flynn et al., 1995; Quazi et al., 1998). Organizations should work directly with their suppliers to ensure the quality of materials and the use of on-time purchasing systems (Anderson et al., 1994; Hackman and Wageman, 1995; Bergman and Klefsjö, 2010).

\subsubsection{Quality Management in Cross-cultural Settings}

Two main schools of thought exploring the relationship between $\mathrm{QM}$ and culture have been proposed (Bright and Cooper, 1993; Prajogo and McDermott, 2005; Green, 2012). The first view tends to a 'unitarist' point of view, and argues that $\mathrm{QM}$ is a unidimensional package that should be promoted as a set of organization-wide practices with unified mindsets and perceptions among the members of an organization. The unitarist approach, thus, suggests that $\mathrm{QM}$ is associated with a single organizational culture typically regarded as a flexible and people-oriented culture (e.g. Tata and Prasad, 1998; Yong and Wilkinson, 1999; Mohammad Mosadegh Rad, 2006; Bortolotti et al., 2015). One of the main streams of research in this school is an investigation into quality culture, focusing on identifying and fostering the culture appropriate for QM (e.g. Kanji and Yui, 
1997; Dellana and Hauser, 1999; Harvey and Stensaker, 2008; Cronemyr et al., 2017). The second view tends to a 'pluralist' point of view, and supports the idea of a multidimensional relationship between $\mathrm{QM}$ and culture in which different cultural characteristics are associated with different elements of QM (e.g. Sitkin et al., 1994; Spencer, 1994; Prajogo and McDermott, 2005; Zu et al., 2010; Gambi et al., 2015). Research in the pluralist school has been focused primarily on QM techniques (e.g. Gambi et al., 2015) and QM practices at operational level (e.g. Prajogo and McDermott, 2005; Kull and Wacker, 2010; Zu et al., 2010; Losonci et al., 2017).

Cross-cultural QM has emerged as a research field in recent decades. The relationship between QM and culture has been well established in previous research, and thus interest has shifted to what happens when $Q M$ is applied in cross-cultural settings - different cultural contexts at the same time. Sousa-Poza et al. (2001) explore relationships between organizational culture and the implementation of $\mathrm{QM}$, and suggest that the characteristics of organizational culture have different impacts on the the adoption of QM values. They show that such impacts differ between different national cultures. The study concludes that there is a complex relationship between QM values, organizational culture and national culture.

At the national level, many studies have shown that national culture affects the perceptions of QM values, and the use of QM techniques and tools (e.g. Mathews et al., 2001; Flynn and Saladin, 2006; Vecchi and Brennan, 2009). Mathews et al. (2001) studied the motivation for QM adoption, the use of QM techniques and tools, and the results of QM in the UK, Finland and Portugal. They revealed several differences between the countries. The motivation of QM adoption in the UK has been mostly external, while a focus on internal co-ordination drives QM in Finland and Portugal. The techniques and tools used in the three countries also differ, which Mathews et al. (2001) consider to be related to the national culture. The Portuguese mostly apply measurement-based and statistical tools, while the Finns favor soft communication and decision-making tools. Other studies have presented different QM principles that are influenced by national culture. Flynn and Saladin (2006) suggested that leadership, employee engagement and empowerment, process management, and the way in which decisions are based on facts are the $\mathrm{QM}$ values that are correlated with dimensions of national culture. According to Lagrosen (2003), customer focus, process management and continuous improvement are the factors that are most strongly influenced by culture.

In terms of national cultural models, most previous studies refer to Hofstede's dimensions (e.g. Mathews et al., 2001; Lagrosen, 2002; Flynn and Saladin, 2006; Jung et al., 2008; Vecchi and Brennan, 2009). The studies do not fully agree about which of Hofstede's cultural dimensions has the greatest influence on $\mathrm{QM}$, but they make it clear that power distance and uncertainty avoidance play significant roles in the differences between QM perception and practices (Mathews et al., 2001). Some recent studies refer to the GLOBE cultural dimensions (Kull and Wacker, 2010; Vecchi and Brennan, 2011). 
Kull and Wacker (2010) studied QM effectiveness among the East Asian countries of China, South Korea and Taiwan, and found that the effectiveness differs considerably, and depends on the specific cultural dimensions of uncertainty avoidance and assertiveness. Vecchi and Brennan (2011) suggests that the GLOBE dimensions of uncertainty avoidance, power distance, institutional collectivism and performance orientation influence quality priority and practices. It remains unclear which cultural dimensions influence QM value perceptions and quality management practices, and previous studies have given conflicting results. However, it is clear that the cultural dimensions of power distance, individual vs. group identity, relations and motivation, and uncertainty avoidance are related to $Q M$.

Previous studies have shown that QM practices, problems concerning quality, and the strategies used to overcome such problems differ between the subsidiaries of an MNC (Lagrosen, 2002; Lagrosen, 2003; Jung et al., 2008). In one study, for example, the main problem in the UK subsidiary of an MNC was related to the lack of commitment by employees to quality, while the main problems in the German subsidiary were more related to technical aspects, such as working procedures and the software system used (Lagrosen, 2002). This leads to the conclusion that perceptions of quality and QM values at various subsidiaries are affected by the local national culture. From another perspective, Zgodavova et al. (2017) studied the Slovakian subsidiaries of several MNCs, and found differences in the culture of quality related to the country in which the parent company was located.

According to Flynn and Saladin (2006), practices can be changed, but the fundamental values that underlie the practices can only be changed with great difficulty. It has, therefore, been suggested that global companies adapt their QM practices to the local national culture, by developing programs that can be implemented in the local culture. This would avoid compromising the integrity of global quality-management policies (Vecchi and Brennan, 2009).

For a company that operates globally, it is crucial to measure customer satisfaction, in order to be able to develop products and services such that they exceed the expectations of a diverse customer base (Fornell, 1992; Morgeson et al., 2010). Customers assess products and services based on their own culture-bound expectations (Voss et al., 2004), which implies that national culture influences their satisfaction (Riddle, 1992; Morgeson et al., 2015). Several studies have revealed that customers with different national cultural backgrounds evaluate a service differently, and act differently towards it (Mattila, 1999; Voss et al., 2004; Morgeson et al., 2015). Therefore, global customers may have different expectations, different ways of evaluating products and services, and different understandings of response scales in a survey (Vavra, 2002). It is important not to assume that customers are identical in terms of objectives and behavior, and in their response to survey questions. 


\subsubsection{Quality Management Measurements in Cross-cultural Settings}

From a QM perspective, measurements are 'information resources concerning certain organizational activity in relation to a specific topic taken up in the discussions within a particular work setting" (Elg, 2001). The process of measurement is an important element of $\mathrm{QM}$, and it is reflected mostly in the principle of using a scientific approach and taking actions based on fact. Moreover, measurement is a fundamental technique that supports other principles. For example, measurements of customer satisfaction can be used to drive continuous improvement and promote a focus on customers (Birch-Jensen et al., 2018). The most important requirements of measurement are that it reflects reality and determines facts with minimum bias.

Surveys are commonly used to collect data on a large scale such as the national and company-wide scales. However, traditional survey methods, in which self-assessment of respondents is directly achieved by the respondents answering the survey questions, may be culturally biased and, as such, subject of criticism (e.g. Malhotra et al., 1996; Cavusgil and Das, 1997). This cultural bias in traditional survey methods introduces further difficulties regarding cross-cultural $\mathrm{QM}$ from an external perspective, since customer satisfaction is commonly accessed using surveys (Hill et al., 2017). When data are collected in cross-cultural settings using traditional survey methods, the way in which respondents interpret questions and use the response scale may differ across cultures. Previous studies have shown that respondents from various national cultural backgrounds respond differently to Likert-scale items (e.g. Smith, 2004; He et al., 2014; Smith et al., 2016). Chevalier and Fielding (2011) suggests that difficulties in comparing survey responses are often ignored, and the data collected are treated equally across cultures. As a result, inaccurate results are produced and misleading conclusions made.

Therefore, the fundamental challenge of cross-cultural survey research is enacting equivalence (Smith and Reynolds, 2002). Van de Vijver (1997) identified three types of equivalence in questionnaire design. Construct or structural equivalence deals with whether the concepts or constructs used in the questionnaire are understood and have the same significance across different cultural settings; measurement equivalence refers to the use and interpretation of measurement units across cultures; and scalar equivalence examines whether the measurement scale has the same zero point in different cultures (Malhotra et al., 1996; van de Vijver et al., 1997; Boer et al., 2018). These equivalences cannot be assumed, and they must be established during the process of research design by an explicit procedure (van Herk et al., 2005).

Construct equivalence concerns problem formulation and questionnaire design (van Herk et al., 2005). As a result, the impact of culture on the questionnaire construction must be realized early in the process of research design, so that possible bias can be handled and construct equivalence achieved. Cognitive pretests - such as interviewing, context assessment, and statistical methods - can be used to enhance this type of equivalence (Boer et al., 2018). On the other hand, measurement and scalar equivalence 
concern mainly the survey instrument, sample selection, data selection, and data analysis (van Herk et al., 2005). Several statistical methods are available to ensure these equivalences. This thesis, however, focuses on one survey method - the use of what is known as 'anchoring vignettes'.

Anchoring vignettes is a questionnaire design that aims to cope with the difficulty of comparing survey results between people (King et al., 2004; Boer et al., 2018). The problem of interpersonal incomparability arises since individuals may understand the 'same' question and respond to the 'same' measurement scale differently (King et al., 2004). When anchoring vignettes is used, the respondents are asked to evaluate hypothetical situations that illustrate the constructs being measured (the hypothetical situations are known as 'vignettes') and their own situation. The self-assessment score is subsequently adjusted relative to the vignette assessment, and considered as a mechanism to reduce bias and improve the comparability of the survey result (King et al., 2004; Datta Gupta et al., 2010; Paccagnella, 2013). Anchoring vignettes has been applied in several cross-cultural research areas to enhance all three equivalences: construct, measurement and scalar. They have been used in political science (e.g. King et al., 2004; Bakker et al., 2014), healthcare research (e.g. Salomon et al., 2004; Poksinska and Cronemyr, 2017), psychology (e.g. Weiss and Roberts, 2018), and customer satisfaction research (e.g. Paccagnella et al., 2018). Hence, anchoring vignettes may be a survey methodology that helps us to understand differences in $Q M$ perceptions and enables the comparison of QM performances among subsidiaries in MNCs. Anchoring vignettes may also help to study and compare the satisfaction of customers with diverse cultural backgrounds.

\subsection{Multinational Companies from an Organizational Perspective}

In the 1970s and early 1980s, organizational researchers defined the characteristics of MNCs based on the dominance of the economic paradigm (Ghoshal and Westney, 2016). In this paradigm, companies extend their organizational boundaries across national borders to exploit the advantages of having overseas subsidiaries (e.g. Dunning, 1977; Kogut, 1986; Buckley and Casson, 2016). An MNC is considered to be a single organization with expanded organizational boundaries. However, it became clear that this perspective of MNCs is too simple, and cannot explain the internal diversity and complexity of a global organization. Later, Ghoshal (1990) suggested a model of the MNC as an internally differentiated interorganizational network that is embedded in an external network of other organizations, such as customers, suppliers, etc. In this model, MNCs are viewed as networks of different organizational units - headquarters and subsidiaries. Each organizational unit is treated as a specific entity defined by organizational boundaries, with the units connected to each other in a network (Ghoshal and Bartlett, 1990; Andersson et al., 2015; Kostova et al., 2016). 
MNCs thus comprise interconnected dispersed parts, and are thus internally diversified, while remaining integrated due to the interdependencies between organizational units. This leads to MNCs facing many different, and possibly conflicting, contextual pressures (Westney, 2016). On the one hand, MNCs need to maintain legitimacy in all their environments, which is often achieved by adopting local practices and becoming isomorphic with the local contexts of their subsidiaries. This isomorphic concept means that organizations that are in the same environment have similar practices (Meyer and Rowan, 1977). Consequently, organizational practices vary across countries due to many elements of the environment, such as laws, the economic system, and culture (Kostova and Roth, 2002). On the other hand, MNCs gain competitive advantage by utilizing their organizational capabilities worldwide (e.g. Bartlett and Ghoshal, 1988; Kogut, 1991). As a result, MNCs usually face dilemmas between global integration and the local adaptation of strategies and practices (Prahalad and Doz, 1987; Kostova and Roth, 2002; Westney, 2016). Prahalad and Doz (1987) suggested the 'integration-responsiveness' (I-R) framework used in international strategy research. The core idea of the I-R framework is that companies that operate globally balance the need to be responsive to local demand, while they as well exploit the advantages of being present in many countries (Roth and Morrison, 1990; Haugland, 2010).

In this thesis, organizational theories of coupling and boundary spanning are used to understand the settings of MNCs, in order to build a connection between MNCs and QM.

\subsubsection{Coupling in Organizations}

'Coupling' is a concept in organizational theory commonly used to describe the extent of interdependence between two entities on the loose-tight continuum (Weick, 1976). The concept of coupling arises in several coupling domains - in any organizational location and at any hierarchical level (Orton and Weick, 1990). It can, therefore, be applied to the relationships between individuals or structural units, for example, work groups, departments and subsidiaries. Tightly coupled system is characterized by strong interdependence, centralized authority, and standardization (Perrow, 1984; Weick, 2012; Burke, 2014). In contrast, loosely coupled system is characterized by temporary states of events, and is dissolvable and tacit (Weick, 1976). Loosely coupled systems are responsive, while having enough space to preserve their identities and physical or logical separation (Glassman, 1973; Weick, 1976; Burke, 2014). Regarding MNCs, the concept of coupling is often used to describe the tension between global integration and local adaptation, in which global integration is associated with tight coupling, and local adaptation with loose coupling.

Entities that are loosely coupled can preserve their identity, uniqueness and separation, and thus have more diversity. This enables them to adapt to changing environments, and leads to more mutations and novel solutions than are possible when elements are tightly coupled (Weick, 1976). As a result, loosely coupled system provides a more sensitive mechanism that detects changes in the environment better than tightly coupled system. 
One entity of an organization can easily adjust to a local contingency without influencing the whole organization. Therefore, loosely coupling system offers a cultural insurance that may be necessary when a radical change in the surroundings raises the need for local adaptation (Weick, 1976). However, if radical change is required, loose coupling might provide greater persistence, and lead to a greater difficulty to change (Orton and Weick, 1990). Tight coupling, in contrast, better facilitates such a change of the organization. Weick (1976) suggest that loosely coupled organizations are cheaper to run than tightly coupled ones, since less resources are necessary to coordinate the coupled entities in the system. This gives higher organizational efficiency.

MNCs are geographically dispersed organizations, and they embody the puzzle of how to achieve balance between loose and tight coupling. MNCs must retain sufficient unity and coherence to operate as one company - global integration, while they must adapt to varying circumstances - local adaptation (Scott and Davis, 2015). This dilemma between global integration and local adaptation can be linked to tight and loose coupling. Spender and Grevesen (1999) drew a matrix that combines the I-R framework and the tight-loose coupling dimension (Figure 4).

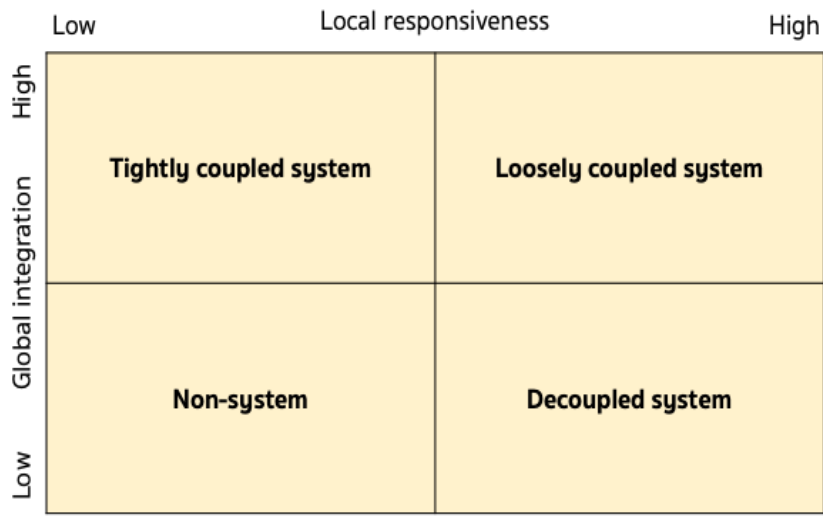

Figure 4: Matrix combining the I-R framework and the tight-loose coupling dimension

(Spender and Grevesen, 1999)

A company that focuses on high local responsiveness and low global integration is a multidomestic company with a decoupled system in which subsidiaries hardly collaborate. The tight coupling, in contrast, with strong interdependence, centralized authority, and standardization favors high global integration, but can result in low local responsiveness. Loosely coupled systems are a promising theoretical and practical alternative that might lead to the high global integration and local responsiveness that MNCs possess (Spender and Grevesen, 1999). When MNCs are loosely coupled, they can absorb changes at the local level of the subsidiaries, which promotes local responsiveness without affecting the fundamental strategy of the companies (Kwantes and Glazer, 2017). As a result, loosely coupled MNCs might be able to promote local 
responsiveness at the level of the subsidiaries, and global integration at the strategic level.

Organizations can be both loose and tight at the same time, depending on which elements are analyzed, and it may be more productive to determine within an organization what should be tightened and what should be loosened (Burke, 2014).

\subsubsection{Boundary Spanning in Multinational Companies}

Both formal and informal boundaries exist in MNCs. The formal boundaries are easier to see in the hierarchical structure, while the informal boundaries are embodied in contextual factors such as social, cultural, and political preferences (Schotter et al., 2017). Both formal and informal boundaries divide the in-groups from the out-groups (Gaertner and Dovidio, 2014), and create separations within MNCs. Strong identification, such as that formed by a strong organizational culture, can create powerful in-group bonds within the whole MNC and facilitate boundary spanning (Schotter et al., 2017). Schotter et al. (2017) proposed a rubber-band model for loosely bound systems, in which boundary spanners connect two organizational subunits while giving them enough room to respond to local contextual factors if necessary. In this case, boundary spanners act as the agents of organizational loose couplings (Orton and Weick, 1990). The coupled entities have the flexibility required to deviate from formal guidelines and pursue benefits arising from the local context, while the ability of the rubber band to stretch prevents the entities from deviating too far from the company structure. The boundary spanners play an important role as the increasing degree of dispersion of the subsidiaries and the activities of the MNCs requires a higher degree of coordination. Boundary spanners are often individual actors. According to Williams (2002), the boundary spanner is the critical link in MNCs who facilitates relational, non-hierarchical networking at the level of individuals. The role of the boundary spanner in MNCs is often attached to specific individuals, such as regional managers (Vora et al., 2007). However, in other scenarios the role of boundary spanner is played by a certain individual, who takes on this role as a result of personal experiences, even though it is not attached to his or her functions. Such occurs, for example, when the managers have multicultural experience (Schotter and Beamish, 2011).

\subsection{Theoretical Synthesis}

This thesis uses three main theoretical concepts: culture, QM and organizational theories on MNCs. Of these, QM is the main research field, while cross-cultural QM is the focused research domain. In this thesis, QM is separated into internal and external perspectives, where the internal perspective is related to people and the organizational work settings of MNC, while the external perspective is related to customers, and focuses on customer satisfaction measurement (Figure 5). The relationship between national cultures and customer satisfaction measurement is explored as part of the external perspective of QM. 
This thesis focuses on MNCs as a study object when discussing the internal perspective of QM. Therefore, organizational theories on MNCs are used to set a base for understanding the contexts, especially in relation to cultures and organizational work settings. As previously discussed and illustrated in Figure 5, the organizational parts of MNCs (headquarters and subsidiaries) are interconnected and form a network that shares the MNC's organizational culture. However, it needs to be clarified that the organizational culture of an MNC refers to its shared values and norms that, in this thesis, give a focus to $\mathrm{QM}$ and how to distribute the management of quality between the headquarters and subsidiaries. While embedded in the organizational network of the MNC, the headquarters and subsidiaries are also established in local contexts and are influenced by national cultures. Thus, MNCs are internally diversified from a cultural point of view.

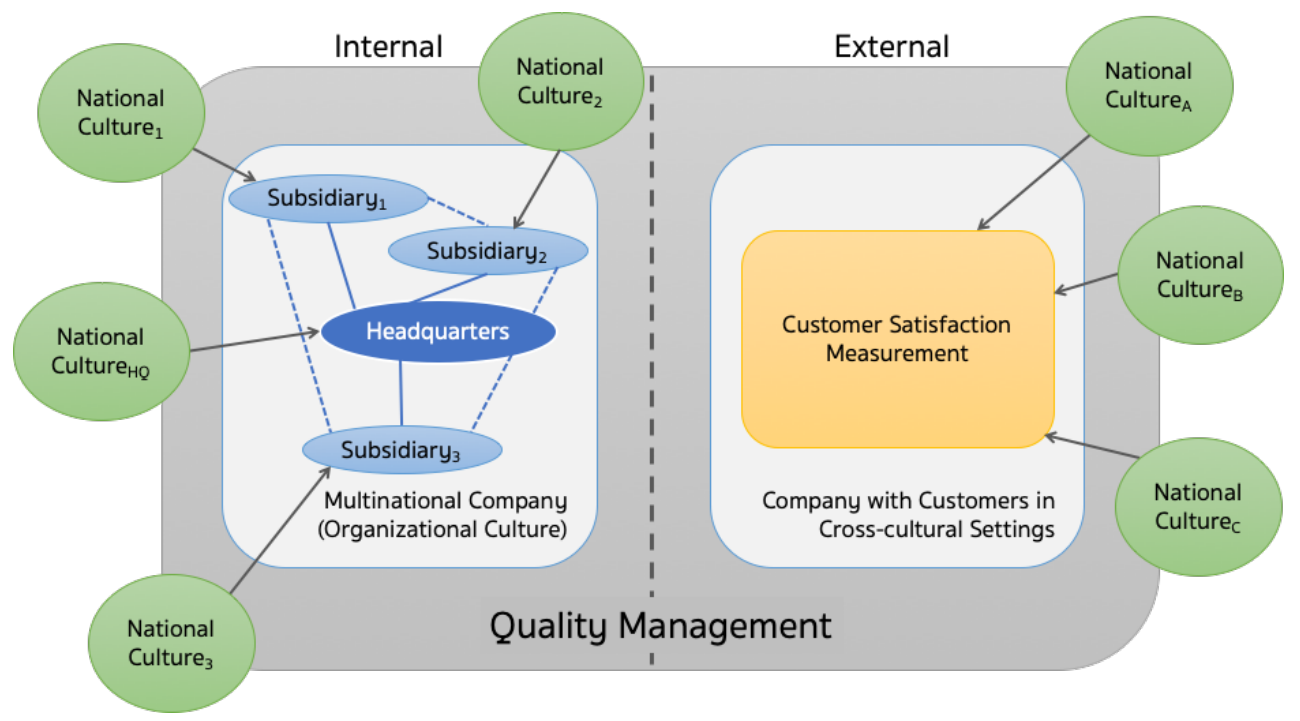

Figure 5: Theoretical synthesis of this thesis 



\section{Research Methodology}

This chapter presents the research methodology used in the studies of this thesis, in five sections. First, the overall design and research approach of the thesis are discussed. The second, third and fourth sections then present the research process and methodology of the three studies that shape this thesis. Finally, the fifth section describes a meta-analysis in which the three studies have been jointly analyzed.

\subsection{Research Design}

This thesis has been designed such that the scope of the material presented is initially broad, and subsequently becomes narrower. The research approach has combined induction and abduction (Williamson, 2002; Danermark et al., 2003). The starting idea was to explore how QM and cultures are related, focusing on the national cultural level, and to identify challenges in cross-cultural QM related to RQ1. The work presented in this part of the thesis was mostly inductive, and data were collected within the disciplinespecific theoretical framework to build concepts and answer the research question (Merriam and Tisdell, 2015). Subsequent work concerning possible means to facilitate cross-cultural QM represented by RQ2 adopted an approach with a more abductive nature. Abduction is the process in which several theories are applied to a set of data using creative and iterative methods, followed by reinterpretation, to describe the data in several ways (Danermark et al., 2003). In this thesis, abduction was practiced by reasoning and moving iteratively between the data and the theoretical framework in an attempt to explain the phenomena.

The thesis consists of three studies named A, B, and C. Study A explored the research field of cross-cultural $Q M$, leading to research ideas that concerned challenges and possible means to facilitate QM in cross-cultural settings. The result of Study A revealed a research gap in how to understand the differences in managing quality in different cultures. Therefore, Study B developed an instrument to study cross-cultural quality management and to identify differences in perceptions related to $\mathrm{QM}$ in different cultural backgrounds. Finally, Study $C$ tested the instrument, and provided more insight into managing quality in the diverse cultural settings of MNCs. An overview of the research design and methodology is presented in Table 2 . In order to explore the research field and gather preliminary findings to answer the research questions. A quantitative research strategy was subsequently used, to develop a survey instrument appropriate for the cross-cultural QM study. Finally, Study $\mathrm{C}$ used both qualitative and quantitative research approaches. 
Table 2: Research design and methodology

\begin{tabular}{|l|l|l|l|}
\hline & Study A & Study B & Study C \\
\hline Research approach & Qualitative & Quantitative & Mixed method \\
\hline Type of study & Case study & $\begin{array}{l}\text { Survey with anchoring } \\
\text { vignettes }\end{array}$ & $\begin{array}{l}\text { Interview-based and } \\
\text { case study }\end{array}$ \\
\hline
\end{tabular}

\subsection{Study A - Research Field Exploration}

Study A aimed to explore the research field of cross-cultural QM and gain some understanding of the challenges in QM that stem from different national cultures. Case studies are a common research tool in a qualitative research approach. A case study has been defined as "a research strategy which focuses on understanding the dynamics present within single settings" (Eisenhardt, 1989: 534). Another definition Yin (2013: 18) is that a case study is "an empirical inquiry that investigates a contemporary phenomenon within its real-life context, especially when the boundaries between phenomenon and context are not clearly evident". Therefore, during a case study, investigators observe what happens in a real-life setting and relate it to theoretical concepts. The use of a case study was selected for Study A, to explore the research field and to identify challenges related $Q M$ in the cross-cultural settings of MNCs.

Study A consisted of two sub-studies (A-1 and A-2). In Sub-study A-1, Lean production and Lean product development were examined in order to identify and compare national cultural aspects that influence their implementations in Swedish organizations. The study compared Lean as it is applied in Sweden to the original way it is applied in Japan, and discovered some differences. This enabled the contextual factors, which influence the translation and implementation processes of Lean, to be discussed. Interviews and a workshop were used to collect data, and helped to capture and reflect on the experiences that the interviewees and workshop participants gained during the implementation process (Qu and Dumay, 2011). Alvesson (2003: 13) describes a qualitative interview as "relatively loosely structured and open to what interviewer feels is relevant and important to talk about, given the interest of the research project". Nevertheless, interviewing requires a systematic effort to listen and a striving to understand what the interviewees are saying, as well as a respect for and curiosity about the content (Rubin and Rubin, 2012).

Prior to the data collection, literature related to national cultural differences, contextual factors, Lean production and Lean product development was studied. Table 3 presents details concerning the data collection. Data regarding Lean production were collected within a collaborative research project studying the extent to which social and technical factors are relevant to the implementation of Lean production in manufacturing 
companies in Sweden. Twenty practitioners from industry participated in the workshop, ten of whom responded to a subsequent qualitative questionnaire. Data regarding Lean product development were collected through semi-structured interviews with two practitioners in industry and two academic experts from research organizations and short qualitative questionnaires. Semi-structured interviews are the most common qualitative research method that can reveal hidden facets of human and organizational behavior, making them an effective and convenient means to collect qualitative empirical data (Kvale and Brinkmann, 2009; Qu and Dumay, 2011). The aim of the study was to identify differences between Swedish Lean product development and the Lean product development practiced by Toyota, described by Morgan (2006). The data were systematically analyzed using interview transcripts together with written notes taken during the interviews and workshop. Brainstorming sessions among the researchers were organized to analyze the data in the light of the theoretical framework and to discuss the findings. Paper I presented the results.

Table 3: Overview of data collection and analysis method in study A

\begin{tabular}{|c|c|c|c|c|}
\hline $\begin{array}{l}\text { Sub- } \\
\text { study }\end{array}$ & $\begin{array}{l}\text { Data collection } \\
\text { methods }\end{array}$ & No. & Participants & $\begin{array}{l}\text { Data analysis } \\
\text { method }\end{array}$ \\
\hline \multirow[t]{4}{*}{ A-1 } & Interview & 4 & 2 industrial and 2 academic participants & \multirow{4}{*}{$\begin{array}{l}\text { Content } \\
\text { analysis }\end{array}$} \\
\hline & Workshop & 1 & 20 industrial and 5 academic participants & \\
\hline & $\begin{array}{l}\text { Qualitative } \\
\text { questionnaire }\end{array}$ & 2 & 12 industrial and 5 academic participants & \\
\hline & \multicolumn{3}{|c|}{ Related documents such as quality policy and training materials } & \\
\hline \multirow[t]{3}{*}{ A-2 } & Interview & 35 & 27 industrial participants & \multirow{3}{*}{$\begin{array}{l}\text { Coded } \\
\text { transcribed } \\
\text { interviews, } \\
\text { content } \\
\text { analysis }\end{array}$} \\
\hline & Workshop & 5 & 5-10 industrial participants/session & \\
\hline & \multicolumn{3}{|c|}{ Related documents such as product specifications and production designs } & \\
\hline
\end{tabular}

Sub-study A-2 was a longitudinal case study of a new product introduction across national borders. The aim of the sub-study was to explore challenges during collaboration to introduce a new product in several countries, and to examine how QM can facilitate the process and mitigate cultural challenges. The validity of case studies that have only a single case is often questioned, and their ability to capture the complexity of the real world called into doubt (e.g. Eisenhardt, 1989; Yin, 2013). Case studies of a single case, however, allow researchers to capture in more detail the phenomena being studied in the specific context (Dyer Jr and Wilkins, 1991). Therefore, single case studies are useful in a longitudinal research approach (Voss, 2010), during 
which qualitative data are collected at different points in time (Barratt et al., 2011). This enables the causes and effects of the studied phenomena to be tracked, which enhances internal validity (Leonard-Barton, 1990; Barratt et al., 2011). The longitudinal approach used for Sub-study A-2 gave an opportunity to study in real-time a product introduction project from the beginning to the end, in order to identify challenges and observe working processes at different stages. It also allowed data to be collected after the project had been completed, focusing on reflections and the lessons learnt by those involved.

Data for Sub-study A-2 were collected during three phases of a product-introduction project: the planning and preparation phase in Sweden, the introduction phase in China, and the post-introduction phase, also in China. Several sets of semi-structured interviews and workshops were conducted during the planning, product introduction, and postproject phases in the period 2008-2014. In total, 35 interviews and five workshops were conducted in the research project (Table 3), of which I did two interviews by myself. Moreover, related documents were examined, since it was possible that they reflected other dimensions of the case, such as product specification and production design. The data were analyzed with respect to content (Corbin and Strauss, 2014) by reviewing interview transcripts and written notes taken during the interviews and workshops. In this way, challenges were identified. The data were then categorized and mapped (Miles et al., 1994), and related to the theoretical framework using pattern matching techniques suitable for a longitudinal case study (Yin, 2014). Discussion sessions were subsequently set up to discuss and compare the data and relate them to the theoretical framework. In order to mitigate own bias, all researchers actively took part in the discussion. The results from Sub-study A-2 were presented in Paper II.

The results from the two sub-studies showed that national cultures influence quality management in cross-cultural settings, and create challenges in collaboration across borders. Sub-study A-2, however, demonstrated that it is possible to use $\mathrm{QM}$, with proper modification, as a means to facilitate cross-cultural collaboration. This led to the more specific research area of MNCs. These have subsidiaries in many countries with various cultural backgrounds, and thus they face challenges in managing quality. For example, as global organizations, MNCs must maintain a common quality management strategy and platform, such that the headquarters and the subsidiaries can work and collaborate effectively. However, employees in different subsidiaries might understand $Q M$ values differently, leading to challenges in managing quality for MNCs.

After challenges had been identified, it was difficult to identify any discrepancy in the perceptions of employees without support from suitable instruments. It was clear that a research gap in cross-cultural QM existed, and that an instrument was needed to identify and analyze different perceptions of $\mathrm{QM}$ among employees with various cultural backgrounds. Study B addressed this research gap. 


\subsection{Study B - Instrument Development}

The aim of Study B was to develop an instrument that organizations can use to understand similarities and differences in people's perception of QM and customer satisfaction, and make the results more comparable across cultures. An interesting method used to develop this instrument was anchoring vignettes. This method was suggested by King (2004) to avoid the problems associated with interpersonal comparisons from which traditional surveys suffer. The problem of differential item functioning (DIF) is well-known, and arises from issues of measurement and scalar equivalence. DIF occurs when respondents understand the same question differently, or use the measurement scale differently (King et al., 2004), which creates problems when comparing self-assessment results across respondents (Sen, 2002).

The responses to self-assessment questions posed in traditional surveys differ across respondents in both the actual level and the DIF. As a result, asking respondents to evaluate their own situation based solely on their perceptions of the survey questions may give ambiguous results. This method works from an individual perspective, but comparing the results across respondents is difficult (Sen, 2002). The use of anchoring vignettes minimizes DIF, and can be used to determine the true level of the selfassessment (King et al., 2004; Chevalier and Fielding, 2011). Respondents are asked to evaluate the vignettes, which are hypothetical scenarios that represent the constructs being assessed, and their own situation using the same measurement scale. The evaluations of the vignettes are then used to adjust the self-assessment scores, and in this way reduce personal and cultural bias in the survey responses. This increases the comparability and validity of the results (King et al., 2004; Datta Gupta et al., 2010; Paccagnella, 2013).

Two key measurement criteria in the anchoring vignettes method must be considered during questionnaire development: the response consistency and the vignette equivalence (King et al., 2004). Response consistency assumes that each respondent understands and uses the response categories of the constructs in the same way when evaluating the vignettes and the self-assessment questions. The response consistency is related to construct equivalence, and it determines the validity of the vignette approach (Datta Gupta et al., 2010). Vignette equivalence requires that all respondents understand each vignette in the same way, and evaluate it on the same one-dimensional scale. If this is the case, differences in their evaluations are random and not correlated the characteristics of interest. Therefore, the questionnaire used with the anchoring vignettes must be carefully designed and tested several times to ensure that these two measurement criteria are satisfied. Small aspects of questionnaire design may have substantial effects, for example, small adjustments in the formulation of the vignette or the questions, the order in which the questions are presented, etc. Hopkins et al. (Hopkins and King, 2010), for example, conducted a test and showed that presenting a set of vignettes before the self-assessment questions helps to define the response scale 
in a common way, and thus leads to better communication of the meaning of the question.

Study B consisted of two sub-studies: B-1 focusing on employees' perceptions of QM principles and QM practices, while B-2 focusing on customer satisfaction. The aim of Substudy B-1 was to demonstrate how anchoring vignettes can be applied to study QM across cultures. The sub-study developed and tested vignettes to be used to study crosscultural QM. In order to develop the questionnaire, QM literature and previous research into surveys used in quality management practices were examined, as was also the quality management standard ISO 9001. Eight groups of constructs were identified, based on several QM principles. The vignettes were tested and modified several times in a striving to ensure response consistency and vignette equivalence. The vignettes were tested by distributing for verification the questionnaire, which consisted of eight QM principles with two vignettes in each. The goal was that the respondent should rank the vignettes in the same order - the 'rather good' vignettes should be given a higher score than the 'rather bad' vignettes. The vignettes were initially tested by direct contact with ten QM experts from both academia and industry, who gave feedback about the survey design and the vignettes. The vignettes were revised, and then distributed for the first pilot test, which used a web-based survey platform. In the first pilot test, only Swedish students were invited to participate, which enabled the cultural variable to be controlled. The vignettes were improved after the first pilot test, and then distributed to international students for the second pilot test. The results of the pilot tests were presented in Paper III.

Having demonstrated that anchoring vignettes can be used in cross-cultural QM and after reviewing the results of the pilot tests, the idea emerged to use them to measure customer satisfaction across countries. A further factor was a growing research interest into why Sweden usually has one of the lowest scores in the European Performance Satisfaction Index (EPSI). This gave rise to Sub-study B-2, the aim of which was to evaluate anchoring vignettes as a survey method that would give better comparability of customer satisfaction measurements across countries. The questionnaire was based on the models of the American Customer Satisfaction Index (ACSI) and the EPSI, and the sub-study used anchoring vignettes to measure and compare customer satisfaction with mobile phone services across four countries - Costa Rica, Poland, Sweden and Thailand.

The questionnaire was designed and tested as a part of Master's project, of which I was a supervisor. The vignettes were tested step-wise three times with students in Sweden, with a fourth pilot test that compared university students in Sweden and Spain. The original English questionnaire was then translated into Polish, Spanish, Swedish and Thai - the native languages of the countries to be studied and the researchers involved. The translation process was carried out as one-way translation (McGorry, 2000), but for each language, at least one independent bilingual individual was asked to double-check the translated texts and revise them in collaboration with the translator, if necessary. The 
same procedure for data collection was used in all four countries to enhance the reliability and internal validity. The target groups were relatively homogenous to control variation relating to other variables such as age, education, and professional background. University students were selected as the target group in this study. It was, however, difficult to achieve the required rate of responses in Sweden, so in this case the target group was expanded to include young adults aged 20-30 years. The survey results were then transformed using a data transformation procedure based on two vignettes (King and Wand, 2007; Poksinska and Cronemyr, 2017). The vignette ratings were analyzed and compared using ANOVA. In addition, the self-assessment scores were analyzed and compared with the relative values after data transformation, also here using ANOVA. The results from Sub-study B-2 were presented in Paper IV, which discusses cultural influences on customer satisfaction measurement.

It was, however, still necessary to apply the method of QM surveys using anchoring vignettes developed in Sub-study B-1 in industry, and to suggest strategies that MNCs can use to manage quality in diverse cultural environments.

\subsection{Study C - Application and Consolidation}

Study C consisted of two sub-studies: C-1 and C-2. The primary aim of this study was to apply the QM survey based on anchoring vignettes developed in Study B in a real-life industrial setting. It was important to find a suitable MNC for the study, and thus Substudy C-1 was conducted, with interviews in several MNCs. The sub-study had several aims: 1 ) to find a suitable $M N C$ for the $Q M$ anchoring vignettes survey study; 2) to gain more insight into cross-cultural $\mathrm{QM}$ challenges in MNCs; 3) to examine how MNCs manage quality in their cross-cultural settings; and 4) to suggest strategies for crosscultural QM in MNCs.

The companies studied in Sub-study C-1, were selected on the following criteria: 1) MNCS with manufacturing subsidiaries in several countries; 2) MNCs with a high focus on the quality of products and/or services; and 3) MNCs with a global QM strategy. The case selection strategy was a mix of convenience, snowball, and confirming and disconfirming cases (Miles et al., 1994). The empirical data were collected using semi-structured interviews with 11 quality managers in seven MNCs.

Conducting interview-based studies requires not only several skills related to interviewing technique, but also careful planning and preparation, and expertise in the relevant areas (Qu and Dumay, 2011). Semi-structured interviews were used in this Substudy C1. The most important property of semi-structure interview is that they allow interviewers to ask follow-up questions and provide responses in their own terms, based on their understanding of the way in which the interviewees view the social world ( $\mathrm{Qu}$ and Dumay, 2011). This type of interview was found appropriate for this sub-study since it helps increase the validity of the data collected. The interview questions were designed based on several QM principles, and examined QM values, practices, techniques and 
tools. In the interviews, the experiences of interviewees when working with cross-cultural QM in MNCs were also discussed. Related documents such as annual reports, quality documents, and meeting presentations were examined.

The data were analyzed using a qualitative content-analysis approach (Corbin and Strauss, 2014). The interview transcripts and summaries of related documents were coded, with mainly descriptive and pattern codes (Miles et al., 1994), and subsequently analyzed using the NVIVO analysis software. Differences and similarities in the perceptions of quality and QM values, QM practices and the use of QM techniques and tools were identified and compared between different companies. This allowed to identify challenges and advantages of cross-cultural $Q M$, and finally to suggest strategies to handle the challenges. Paper V presents the results of Sub-study C-1.

One MNC was identified as a suitable case company for the QM anchoring vignettes survey. This company claimed to have a promising strategy for handling the internal challenges of cross-cultural QM. This led to Sub-study C-2, in which this company was used as a case study, and which had two aims. The first was to apply the instrument of the QM anchoring vignettes survey in an industrial setting. The second was to further explain the quantitative result from the survey and to verify the handling strategy that was developed during the qualitative study using a quantitative research approach. Therefore, sub-study C-2 adopted mixed methods data collection that builds on the idea of between-methods triangulation, involving the use of both a quantitative and a qualitative research approach (Denzin, 1978; Johnson et al., 2007; Denzin, 2017).

The QM questionnaire developed in Sub-study B-1 was used during the quantitative part of Sub-study C2. The data were collected in two subsidiaries of the MNC, situated in Sweden and France. The Swedish questionnaire was translated into French using oneway translation (McGorry, 2000), with an independent bilingual individual asked to double-check the translated texts and improve them if necessary. The web-based survey was sent to selected respondents in the same kind of assembly facilities in the two countries. The respondent groups consisted of engineers, technicians and production line supervisors. The survey results were transformed using a data transformation procedure for two vignettes (King and Wand, 2007). The vignette ratings, the selfassessments, and the relative values were analyzed and compared using the MannWhitney test, since the sample sizes were small (35 and 28 respondents) and the data were not normally distributed (Newbold et al., 2013).

The qualitative data were collected using semi-structured interviews and the study of related documents (Table 4). The interview questions were mostly the same as those used in the work presented in Paper $V$, and enabled a discussion of experiences of working with QM in cross-cultural settings, based on several QM principles. However, the focus was more toward how the interviewees facilitated quality practices in their global company, and how they promoted QM values, established common QM practices, and used QM techniques and tools. The interviewees were one global quality manager and 
three managers responsible for quality in production facilities of the MNC. All of them had considerable experience in

Table 4: Data collection and analysis methods in Sub-study C-2

\begin{tabular}{|l|l|l|}
\hline $\begin{array}{l}\text { Research } \\
\text { approach }\end{array}$ & Data collection method & Data analysis method \\
\hline Qualitative & $\begin{array}{l}\text { Semi-structured interviews, document } \\
\text { study such as QM policy and internal } \\
\text { presentations }\end{array}$ & $\begin{array}{l}\text { Coded transcribed interviews, cross- } \\
\text { company analysis, content analysis }\end{array}$ \\
\hline Quantitative & Anchoring vignettes survey & $\begin{array}{l}\text { Data transformation regarding } \\
\text { anchoring vignettes, ANOVA }\end{array}$ \\
\hline
\end{tabular}

managing quality in cross-cultural settings, and experience of working abroad. A qualitative content-analysis approach (Corbin and Strauss, 2014) was used for data analysis. The interview transcripts and summaries of related documents were coded with mainly descriptive and pattern codes (Miles et al., 1994), and analyzed using NVIVO. Paper VI presented the results of Sub-study C-2.

\subsection{Meta-analysis}

This thesis comprises three studies that resulted in six appended papers. Each of the papers has a specific research focus, and each contributes to the overall aim of the thesis as shown in Table 5. The papers together serve as a basis for answering the research questions posed by the thesis.

The research process of this doctoral study was sequential, as Study A led to B and then C. However, while compiling the appended papers and writing the thesis, I was able to reconsider each paper from new perspectives. The initial step in writing the thesis was to summarize the six papers. This led to the design of the thesis structure, in particular the structure of the theoretical framework, such that it would combine and link the six papers. All papers were subsequently analyzed in unison, based on the theoretical framework. The analysis process was iterative, and switched between the thesis framework and the papers, in order to discuss and connect the data presented in the papers with the theoretical framework of the thesis. This gave the answers to the research questions and allowed the results and discussion to be written.

The answer to the first research question of the thesis is found primarily in Paper II and $\mathrm{V}$, which focus on challenges related to QM in the cross-cultural setting of MNCs. Results presented in Paper I also contributed, by demonstrating how national culture can influence QM strategies in an organization. Furthermore, the results of questionnaire testing presented in Paper III show that respondents from different nations can perceive 
Table 5: Studies, research methods, and aims of the appended papers

\begin{tabular}{|c|c|c|c|c|}
\hline Study & $\begin{array}{l}\text { Sub- } \\
\text { study }\end{array}$ & $\begin{array}{l}\text { Research } \\
\text { methods }\end{array}$ & Aim & Paper \\
\hline \multirow[t]{2}{*}{ A } & A-1 & $\begin{array}{l}\text { Qualitative } \\
\text { case study }\end{array}$ & $\begin{array}{l}\text { To identify and compare national cultural aspects that } \\
\text { influence } \mathrm{QM} \text { in Swedish organizations }\end{array}$ & $\begin{array}{l}\text { Paper } \\
\text { I }\end{array}$ \\
\hline & A-2 & $\begin{array}{l}\text { Longitudinal } \\
\text { case study }\end{array}$ & $\begin{array}{l}\text { To explore challenges in collaboration during a new product } \\
\text { introduction across countries, and to see how QM can } \\
\text { facilitate the process and mitigate cross-cultural challenges }\end{array}$ & $\begin{array}{l}\text { Paper } \\
\text { II }\end{array}$ \\
\hline \multirow[t]{2}{*}{ B } & B-1 & $\begin{array}{l}\text { Anchoring } \\
\text { vignette } \\
\text { survey }\end{array}$ & $\begin{array}{l}\text { To suggest that anchoring vignettes can be applied when } \\
\text { studying cross-cultural QM and to demonstrate that this is } \\
\text { the case by developing and testing a questionnaire }\end{array}$ & $\begin{array}{l}\text { Paper } \\
\text { III }\end{array}$ \\
\hline & B-2 & $\begin{array}{l}\text { Anchoring } \\
\text { vignette } \\
\text { survey }\end{array}$ & $\begin{array}{l}\text { To evaluate anchoring vignettes as a method for improving } \\
\text { the comparability of customer satisfaction measurements } \\
\text { across countries }\end{array}$ & $\begin{array}{l}\text { Paper } \\
\text { IV }\end{array}$ \\
\hline \multirow[t]{2}{*}{ C } & $C-1$ & $\begin{array}{l}\text { Interview } \\
\text { study }\end{array}$ & $\begin{array}{l}\text { To gain more insight into the cross-cultural QM challenges } \\
\text { faced by MNCs, and to suggest strategies for QM in MNCs }\end{array}$ & $\begin{array}{l}\text { Paper } \\
\text { V }\end{array}$ \\
\hline & $C-2$ & $\begin{array}{l}\text { Case study } \\
\text { (mixed } \\
\text { method) }\end{array}$ & $\begin{array}{l}\text { To identify and understand differences in QM perceptions, } \\
\text { practices and performances among employees in } \\
\text { subsidiaries of an MNC }\end{array}$ & $\begin{array}{l}\text { Paper } \\
\text { VI }\end{array}$ \\
\hline
\end{tabular}

QM principles differently. These findings from Paper III were implied in terms of employees at subsidiaries who have different national cultural backgrounds, which might give rise to cross-cultural challenges in MNCs.

As part of the work to answer the second research question, the method of anchoring vignettes was adopted and used to develop a questionnaire to study cross-cultural QM from two perspectives. This gave rise to two sub-questions: a) how can cultural diversity in $\mathrm{QM}$ be understood from an internal perspective of MNCs? and b) how can cultural diversity in $\mathrm{QM}$ be understood from an external perspective of customers? The answer to sub-question 2a is mainly found in Paper III, which focuses on QM principles and the perceptions of employees with different national cultural backgrounds. Paper VI also helps to answer this sub-question, by demonstrating how an anchoring vignette survey of QM principles can be used in an MNC, and how it can lead to better understanding of the QM perceptions and comparisons of the QM performances at different subsidiaries. Paper IV deals with customers from different national cultural backgrounds and how to improve the comparability of cross-cultural customer satisfaction measurements. This gives the answer to sub-question 2b. Although Paper III and IV developed and tested the 
anchoring vignettes survey method and used it in different research focuses, the results presented allow an instrument to be developed that helps to understand cultural diversity and thus provides better understanding of national cultural influences on QM.

The third research question is answered mainly by Papers $V$ and VI. The findings of Paper $\mathrm{VI}$ allow the model suggested in Paper $\mathrm{V}$ to be extended and refined. Paper II also supports the answer, by laying a foundation that shows how QM principles can be used to mitigate cross-cultural challenges in a collaboration project between two subsidiaries. Nevertheless, in an attempt to answer this research question, additional theories were included into the theoretical framework, connecting the analysis with the organizational settings of MNCs. The data presented in Papers II, V and VI were analyzed from an organizational perspective that was not used while working with the papers. Finally, the findings from case companies presented in Papers II, V and VI were jointly analyzed as part of the work to answer the third research question. 



\title{
4 Summary of Appended Papers
}

This chapter summarizes the six appended paper, one in each section. Each summary describes aims, a background, findings and contributions to the thesis. This chapter forms a basis for the discussion in Chapter 5.

\subsection{Paper I}

Cultural aspects when implementing Lean production and Lean product development - Experiences from a Swedish Perspective

\author{
Promporn Wangwacharakul ${ }^{\mathrm{a}}$, Martina Berglund ${ }^{\mathrm{a}}$, Ulrika Harlin ${ }^{\mathrm{b}}$ and Per Gullander ${ }^{\mathrm{b}}$ \\ ${ }^{a}$ Department of Management and Engineering, Linköping University, Linköping, Sweden \\ ${ }^{b}$ Department of Production System Development, Swerea IVF, Mölndal, Sweden
}

As a concept being developed in a Japanese cultural context, applying Lean in different cultures such as Sweden can lead to challenges during the implementation process. This paper considers Lean as a quality management approach, and aims to identify and compare national cultural dimensions that influence Lean production and Lean product development implementation in Swedish companies.

The result from the Lean production study shows that different principles have different dependency levels in relation to the human, cultural and organizational contextual factors that represent social aspects of QM. The main differences between Lean product development as practiced by Toyota and that practiced in Sweden were principles regarding people, which also constituted the social aspects. This led to the conclusion that principles that are highly related to social aspects require considerable attention during the implementation of Lean in different national cultures. Apparently, Swedish culture of low power distance, low masculinity and high individualism (Hofstede et al., 2010) supports Lean implementation in different ways. For example, low power distance and high individualism promote the Lean principles regarding respect for the individual and trust building within the team. However, high individualism may, on the contrary, imply that some Lean principles are not built into Swedish culture compared to Japanese culture being more group-oriented.

The findings imply that Lean implementation should be carried out in an incremental manner, and it should start with the development of organizational values, culture and leadership style such that these are compatible with Lean. The principles must be translated and carefully implemented into the organizations. Some more concrete principles (such as specific techniques and tools) can be adopted directly, and are for this reason often the first principles that are applied in the transformation process. In 
contrast, it takes longer to adopt and integrate into the organizational culture principles that are more related to social aspects such as people, values, and organization.

The main contribution of this paper is to demonstrate how national culture and Lean are related. It shows differences between Swedish Lean and that practiced by Toyota related to differences in national culture, which implies that various dimensions of national culture influence QM. The paper further suggests that organizations that adopt Lean face challenges in transforming their principles of management to fit the local contexts.

\subsection{Paper II}

\section{Quality management to facilitate new product introduction across borders}

Promporn Wangwacharakul ${ }^{a}$, Martina Berglund ${ }^{a}$ and Ulrika Harlin ${ }^{b}$

${ }^{a}$ Department of Management and Engineering, Linköping University, Linköping, Sweden

${ }^{b}$ Department of Production System Development, Swerea IVF, Mölndal, Sweden

New product introduction is a crucial phase in the product life cycle that is costly and needs to be accomplished in a timely manner. It often involves a number of organizational functions and implies a high degree of complexity, leading to uncertainty. This paper presents a longitudinal case study of a new product introduction project that involved one Swedish and one Chinese subsidiary under the umbrella of the same MNC. It illustrates managerial challenges that might stem from cultural differences of the two subsidiaries. Moreover, the paper explores how various principles of $\mathrm{QM}$ can be used to mitigate such managerial challenges and facilitate collaboration among the subsidiaries of an MNC.

The findings reveal that the MNC faced several challenges when introducing a new product across national borders. The problems encountered in the new product introduction project included differences in priority levels given to the project in the two countries, different understandings of what quality is, a lack of insight into working styles, and difficulties in collaboration due to language and cultural barriers. These problems were related mainly to people and how the project was organized, and can thus be seen as managerial challenges.

The results also suggest that several QM principles can be used to handle the managerial challenges. In this case, strong top management support from all involved parties was extremely important and necessary to drive the product introduction forward. Customer focus helped to establish common goals for customer satisfaction through understanding customer requirements and striving for high-quality products. Employee involvement and development helped to narrow the gap between the employees from the two subsidiaries in both social and technical aspects of $\mathrm{QM}$, and were able to bridge the cultural distance between the team members from the two countries. Engaging employees in improvement work was an opportunity to empower them, develop 
competence, build networks, and promote a team-based working culture. Production data were regularly collected during the project, and formed a solid ground for decisions based on facts. The data also helped in systematic problem solving. In this case, QM techniques and tools, such as visualization and the completion of checklists, were extensively used during the introduction process. This established standard working procedures and ensured mutual understanding among the team members from the two subsidiaries. Furthermore, some principles of QM, such as continuous improvement, and employee engagement and empowerment, helped to establish common goals that bridged cultural differences and set the base for a strong organizational culture in the MNC. Although QM might not directly minimize the gaps in national cultural dimensions, it made collaboration easier by supporting the working processes with QM techniques and tools. The paper shows that QM can help to mitigate national cultural discrepancies, and can form the basis for a strong organizational culture that focuses on quality management in MNCs.

This paper contributes to the thesis by identifying challenges in managing quality that arise between two subsidiaries with different national cultural backgrounds, and suggests that several principles of QM can be used to bridge cultural differences and facilitate collaboration across borders.

\subsection{Paper III}

\section{Using anchoring vignettes to study quality management across cultures}

Promporn Wangwacharakul and Bozena Bonnie Poksinska

Department of Management and Engineering, Linköping University, Linköping, Sweden

To manage quality effectively, members in the organization should have a common understanding of quality and QM principles. However, the understanding may differ considerably between individuals because of factors such as culture, life experience and education. Therefore, it is important to understand how culture may influence people' perception of QM principles in multinational organizations. Besides, cultural factors may have a significant influence on how people interpret and respond to survey questions, which means that a survey method to reduce cultural bias is needed. This paper focuses on developing an instrument based on anchoring vignettes as a survey method, and provides a concrete example of how such a survey, based on QM principles, can be designed, tested and used to cope with cultural bias in a cross-cultural quality management survey.

Promising results were obtained from pilot studies, and suggest that anchoring vignettes can be used to study $\mathrm{QM}$ in cross-cultural settings. The findings confirm that different understandings of QM (as reflected in vignette ratings) exist due to different national cultural backgrounds, as Swedish and Indian respondents gave significantly different 
vignette ratings in the pilot study, even though they had participated in the same quality management education. The paper shows that anchoring vignettes can help to provide more accurate survey results with a minimum of cultural bias, and can contribute to understanding QM perceptions in cross-cultural settings.

By that, the paper contributes to the thesis by showing that anchoring vignettes as a promising survey method to study cross-cultural QM. Moreover, the paper demonstrates how the proposed instrument can be used in MNCs to explore the perceptions of QM principles held by employees, and to compare QM performances across cultures with minimum bias.

\subsection{Paper IV}

Cross-cultural comparability of customer satisfaction measurement - The case of mobile phone service providers

Promporn Wangwacharakul, Silvia Márquez Medina, and Bozena Bonnie Poksinska

Department of Management and Engineering, Linköping University, Linköping, Sweden

Measuring customer satisfaction is important for any organization from a $\mathrm{QM}$ perspective. It is, however, difficult to measure and compare customer satisfaction ratings among people from different cultural backgrounds. People from different cultures may have different expectations and perceptions of the same product or service, which lead to different levels of customer satisfaction. Furthermore, it is difficult to compare cross-cultural surveys due to equivalence issues. This paper, therefore, aims to evaluate the survey method that uses anchoring vignettes to improve the comparability of customer satisfaction measurements across countries.

Respondents from different countries assessed the same situation described in the vignettes differently, which confirmed that the problem of construct equivalence in cross-cultural surveys exists. These differences might stem from different cultural backgrounds, different expectations, or the different use of response scales. When selfassessments were adjusted using the vignette ratings, many differences between countries in various constructs became insignificant. Thus, the variation that stems from cultural bias in construct and measurement equivalences was mitigated by the anchoring vignettes method, and the obtained results reflected more accurately true differences in performance levels. Therefore, anchoring vignettes can be used to improve the comparability of customer satisfaction measurements across borders.

The main contribution of this paper is the development and test of anchoring vignettes questionnaire that can be used as a measurement instrument to improve the crosscultural comparability of customer satisfaction ratings between countries. The paper also demonstrates how a cross-cultural customer satisfaction survey using anchoring vignettes can be carried out. 


\subsection{Paper V}

Quality management in cross-cultural settings: challenges and possible strategies for quality managers

Promporn Wangwacharakul

Department of Management and Engineering, Linköping University, Linköping, Sweden

MNCs have high cultural diversity. Their subsidiaries are a part of the multinational company network and have a shared organizational culture with the parent company, but they are also part of their local contexts and are shaped by national culture. This paper explores challenges of QM in the cross-cultural setting of MNCs, and suggests strategies that can be used to manage quality in MNCs.

The paper adopted Schein's (2010) model for levels of culture and translated it into a cross-cultural QM model of challenges and handling strategies. The findings suggest that different subsidiaries of an MNC can perceive quality and QM principles differently. The differences can be derived from national cultural differences at the underlying assumption level of culture (Schein, 2010). This might lead to a mismatch in levels of quality awareness, which creates challenges for quality managers in the cross-cultural setting of MNCs. Also, different subsidiaries used different practices of $\mathrm{QM}-$ at the artifact level of culture (Schein, 2010).

The QM principles that are most strongly influenced by the national culture of subsidiaries are leadership, employee engagement and empowerment, and continuous improvement. These QM principles are strongly intertwined with each other and directly related to people, and thus reflect the social aspects of QM. However, the differences varied from company to company, depending on the strength of the shared organizational culture with respect to quality, and the strength of focus on QM. In MNCS with a strong quality culture ${ }^{1}$, the differences in the way that subsidiaries perceived $Q M$ values were small, and appeared mostly at the artifact level of QM practices. In contrast, companies with a weak quality culture faced more serious challenges, in terms of a mismatch in the perceptions of $\mathrm{QM}$ principles leading to different $\mathrm{QM}$ practices at subsidiaries. As a result, these practices were not based on a mutual understanding of QM values, or on equal levels of expertise in using QM techniques and tools. This issue could result in different levels of product quality between subsidiaries and problems in collaboration across subsidiaries, both of which created challenges for quality managers in MNCs.

This paper also suggests strategies to handle QM challenges in cross-cultural settings. First, QM principles and common quality goals must be made clear to all employees at

\footnotetext{
${ }^{1}$ In this thesis, "quality culture" refers to the organizational culture of an MNC that is based on QM values.
} 
all levels in all subsidiaries of the MNC, to set a base for a shared perception of QM. Second, sufficient training in the technical aspects of QM techniques and tools should be provided for relevant employees. These technical aspects of QM support the QM system of the MNC and establishes means and measures for the social aspects - QM values. A strong, shared organizational culture needs to be promoted throughout the MNC, focusing on quality and customers. One technique to mitigate differences that stem from the national cultures of the subsidiaries is to rotate managers between the headquarters and the subsidiaries. These managers act as agents that promote a culture of quality and transfer common QM values and practices between subsidiaries, creating a bridge between them.

This paper strengthens the results presented in Paper I by elaborating differences in QM perceptions and practices among subsidiaries that can lead to challenges related to QM within MNCs. Moreover, it suggests strategies that quality managers in MNCs can use to cope with the challenges at both conceptual and practical levels, which extends the results presented in Paper II.

\subsection{Paper VI}

Common yet diverse - A case study of managing quality in a multinational company

Promporn Wangwacharakul and Bozena Bonnie Poksinska

Department of Management and Engineering, Linköping University, Linköping, Sweden

Different cultural backgrounds of employees in MNCs can lead to different QM perceptions and practices that might affect $Q M$ performances at subsidiaries. This paper used the questionnaire developed in Paper III to study QM in two subsidiaries of an MNC. The purpose was to apply anchoring vignettes as a survey method in a cross-cultural QM study, and to identify and understand differences in QM perceptions, practices and performances among employees in subsidiaries of an MNC. The paper also aimed to describe how an MNC manages quality in subsidiaries with different national cultural backgrounds.

The analysis of the good vignette ratings showed that the employees in the two subsidiaries had a common understanding of how the good QM practices in each principle should be, and the employees had achieved in some way shared perceptions of $\mathrm{QM}$ values. However, opinions about the bad situations of QM practices differed as shown by trends between the two countries in survey responses, and significant differences in bad vignettes ratings of some QM principles. Consequently, national cultures maintained an influence over the employees in these two subsidiaries, especially in how they evaluated bad practices. The self-assessments before the data transformation showed significant differences in performances between employees of the two subsidiaries in 
most of the QM principles. After the adjustment using vignettes, the performance levels still differed in the principle of leadership, customer focus, process management and continuous improvement. This was also supported by the qualitative results (interview and related document study) providing insights on different QM practices in some QM principles.

The studied MNC is one of the cases presented in Paper V. This MNC focuses strongly on quality, and has substantial experience in working globally. The managers have realized that employees in subsidiaries have different national cultural backgrounds, and they respect this diversity. They promote global QM strategies throughout the whole company and translated the strategies into more detailed goals for each production area. Moreover, they provide a sound training in quality techniques and tools and have used the technical aspects of QM as a backbone for the quality system. Rotating managers in the middle and top levels between the headquarters and the subsidiaries helps these managers to learn about the local cultural contexts in different subsidiaries, and to transfer the company culture between headquarters and subsidiaries. This creates a strong and unique quality culture for this MNC worldwide. By doing these, shared perceptions of QM principles and values have been achievable among subsidiaries of this MNC.

Even though managers in this MNC claimed that they did not experience noticeable discrepancy in QM performances among subsidiaries, the survey results showed otherwise. There were significant differences in QM performances in the principle of leadership, customer focus, process management and continuous improvement. The survey results were in-line with the differences in practices identified in the qualitative results in most of those $\mathrm{QM}$ principles, and thus may explain the different levels of performance. Therefore, anchoring vignettes questionnaire has a potential to be used in MNCs to evaluate perceptions of QM principles and performance levels associated with each QM principles among subsidiaries to identify further opportunity to improve quality management work in the company.

This paper contributes to the thesis by showing how the instrument can be useful for MNCs in evaluation of QM perceptions and performances. It also suggests strategies that can lead to desirable results in the global quality management in MNCs. 



\section{Discussion}

In this chapter, the results and research methodology of the thesis are discussed. First, the research questions are discussed and answered with support from the theoretical framework. Second, reflection and discussion of the research methodology and the quality of the research are presented.

\subsection{Discussion of Results}

This thesis focuses on challenges in managing quality related to national cultural diversity in MNCs, understanding cultural diversity in quality management, and strategies to manage quality in MNCs are suggested accordingly. The appended papers and their contributions to the research questions are presented in Table 6.

\subsubsection{Challenges in Managing Quality Related to National Cultural Diversity in Multinational Companies}

Previous research has shown that culture and $\mathrm{QM}$ are related (e.g. Dean and Bowen, 1994; Mohammad Mosadegh Rad, 2006; Barouch and Kleinhans, 2015; Gambi et al., 2015). However, few studies have examined QM in MNCs. Most previous research has focused on differences in QM perceptions and practices among subsidiaries (Lagrosen, 2002; Lagrosen, 2003; Jung et al., 2008), but does not pinpoint challenges related to those differences. This thesis has taken it a step further by not only identifying differences in QM perceptions and practices, but also discussing challenges related to managing quality in the face of national cultural diversity in MNCs.

QM principles are a combination of QM values, techniques and tools, of which the values have a stronger connection to the social aspects of QM that is related to people and organizational work settings, while the $\mathrm{QM}$ techniques and tools have a stronger connection to the technical aspects related to improving product and service quality (e.g. Flynn et al., 1995; Hellsten and Klefsjö, 2000; Zu, 2009). Paper I shows that the Lean principles related to social aspects - people and organizational work settings - are most affected by national culture. Moreover, Paper $\mathrm{V}$ shows that leadership, employee engagement and empowerment, and continuous improvement are the QM principles that are more affected by the national cultural contexts of the subsidiaries in MNCs. These three QM principles are related to each other, since continuous improvement relies on employee engagement and empowerment, which is enhanced by good leadership from the management. As these QM principles concern people, they tend to be influenced by national culture. This confirms the results obtained by Flynn and Saladin (2006) and Lagrosen (2003) in cross-cultural QM at the national level.

These influences from culture lead to challenges in implementing quality management approaches in organizations with inhomogeneous cultural backgrounds. In the case of 


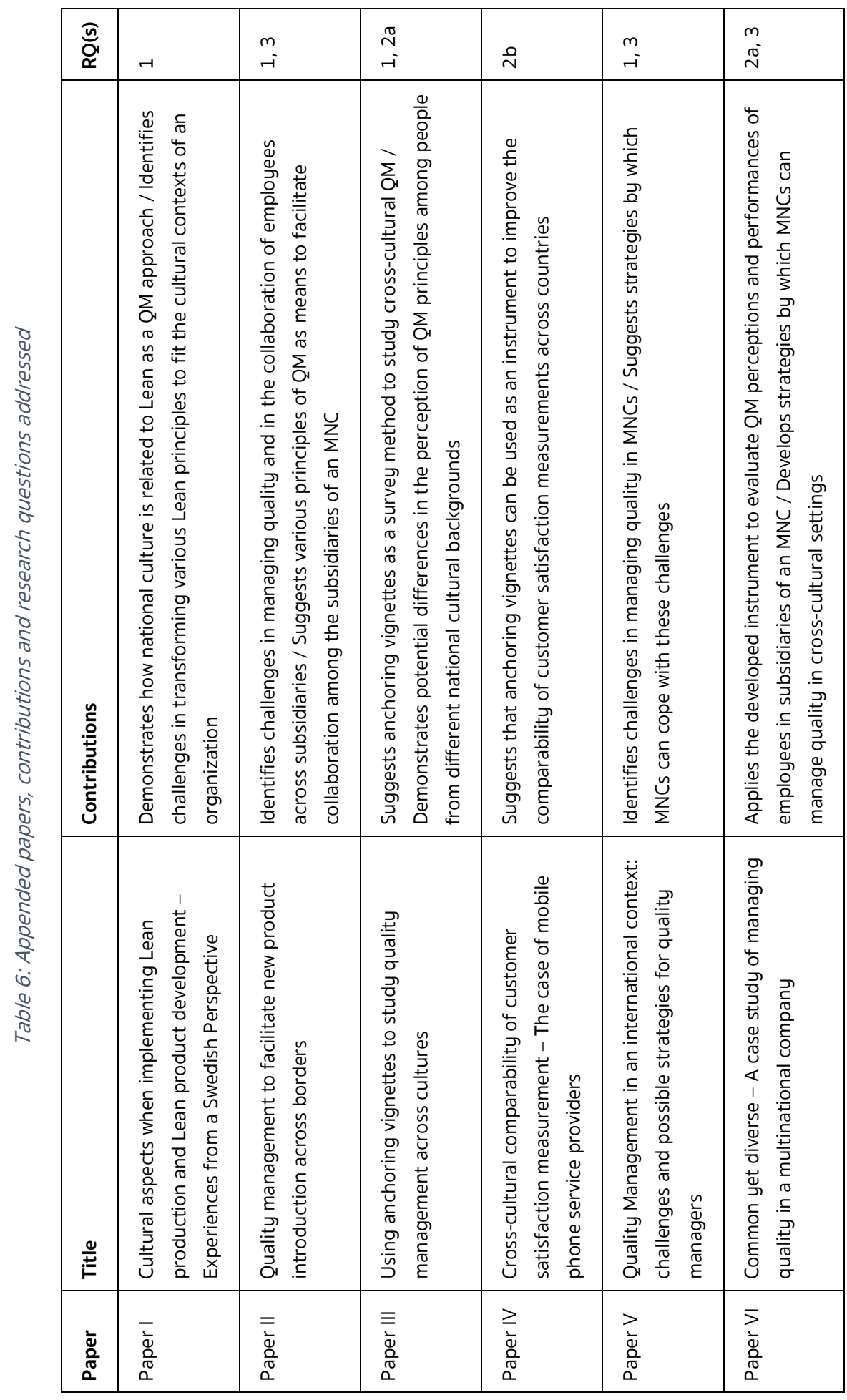


MNCs, the headquarters usually decide which management approaches should be adopted, but the subsidiaries put them into practice. Problems arise if the top managers at the headquarters do not appreciate the national cultural diversity of subsidiaries, or are not aware of cultural influences on the management approaches they propose. Paper I shows that both the management approach and the culture of the adopting organization should be adjusted to obtain a good fit between them. However, MNCs often experience problems if the management approach is not compatible with the national cultural backgrounds of the subsidiaries, since it is hard to change the imprint of national culture on employees (Hofstede et al., 2010; Trompenaars and Hampden-Turner, 2012). For example, the high individualism in Sweden may imply that some QM principles are not built into Swedish culture, while they are built into Japanese culture being more group-oriented. This gives rise to challenges in contributing to teamwork compared to individual development, which might require alternative mindsets and different practices in different local cultural contexts (Paper I). Another challenge concerning employees with different national cultural backgrounds is to engage and motivate them, and to bring them to understand and accept diversity and see the benefits of working together (Paper V). The process of empowering and engaging employees (as one principle of $Q M$ ) is more difficult in some cultures with a high power distance. Even in cases with the same level of commitment, engagement may differ due to different norms, understandings of quality and perceptions of QM principles (Papers V). It is, for example, more difficult to implement continuous improvement through Kaizen events in China than in Sweden. With a large power distance, Chinese employees are not used to taking initiatives or suggesting ideas for improvement without orders or guidance from supervisors (Paper II). In some cases, subsidiaries arrange competitions to encourage employees to suggest ideas for improvement, and offer special rewards for successful ones (Paper V).

Four of the appended papers (Papers II, III, V, and VI) confirm the findings of previous research in cross-cultural QM, which showed that people with different cultural backgrounds understand quality and perceive QM principles differently (Lagrosen, 2002; Lagrosen, 2003; Prajogo and Sohal, 2006; Gambi et al., 2015; Weckenmann et al., 2015). The comparison of vignette ratings between Swedish and Indian respondents revealed in Paper III suggests that different understandings of QM principles (presented as situations that describe QM practices) exist and might be related to different national cultural backgrounds. Several managerial challenges discussed in Paper II may be influenced by the national culture of subsidiaries. For example, the two subsidiaries collaborating in the project to introduce a new product used the same words, but perceived product quality and addressed quality in practice differently. Paper $\mathrm{V}$ showed also that employees in some local cultural backgrounds find it difficult to understand the concept and basic principles of $\mathrm{QM}$. These different perceptions of QM principles led to different practices. For example, some subsidiaries used quality controls and inspections that had been discontinued in other subsidiaries. Moreover, they may lead to different levels of quality awareness and different practices being adopted by subsidiaries. This issue may 
make it difficult to, for example, maintain consistent quality levels of products/services from the subsidiaries, and may make collaboration between different subsidiaries difficult. Thus, MNCs find it hard to establish shared perceptions of QM principles in a global organization, due to the different national cultural backgrounds of subsidiaries.

The work presented in the thesis focused on identifying challenges, but cultural diversity in MNCs is not solely a source of challenges. The study identified some benefits. For example, the diverse cultural backgrounds of employees open up for different ways of thinking and contributes to solving quality problems.

\subsubsection{Understanding Cultural Diversity in Quality Management}

Several challenges relating to managing quality in cross-cultural settings stem from different national cultural backgrounds (Section 5.1.1). However, an important question is how cultural diversity in relation to QM can be studied and understood. The work presented in this thesis encompasses the development of an instrument that can be used to study QM in cross-cultural settings. Further, the adoption of the instrument is described from two perspectives - an internal perspective of MNCs related to employees with diverse local cultural backgrounds, and an external perspective related to the cultural diversity of customers.

\section{Internal Perspective of Multinational Companies}

This thesis shows that anchoring vignettes can be applied to study cultural diversity in QM from an internal perspective of MNCs, and provide more accurate survey results with a minimum of cultural bias (Papers III and VI). Paper III shows that people from different cultures evaluate the $\mathrm{QM}$ practices described in the vignettes differently. Some practices that were perceived as good and having the potential to improve performance in some cultures were considered by other cultures as bad practices that lead to lower performance. The results show that it is necessary to use anchoring vignettes when studying QM across cultures, as the method can cope with cultural bias and obtain more accurate survey results. However, there are challenges in designing and using anchoring vignettes survey. Many variables, as for example age or gender of the persons described in vignettes, may influence respondents' assessments. Vignettes design process requires high precision, so that several rounds of improvements and pilot tests are needed to make the method work.

In case of an MNC, Paper VI shows that there were no significant differences in the evaluation of good vignettes between respondents from the two subsidiaries, which implies that they share perceptions of QM principles. Since good vignettes describe the almost ideal practices of various QM principles, the evaluations of these good vignettes reflect the way in which respondents perceive the QM principles and values. Although the employees of the two subsidiaries shared perceptions of QM principles, they evaluated the bad vignettes differently. They rated the level of performance in bad vignettes on the basis of their expectations and experience of QM practices, the views of 
which differed considerably between the two countries. Further, the adjusted selfassessment results of the anchoring vignettes survey agreed with the results from interviews, which indicated that the two subsidiaries had different practices in some QM principles that could lead to different levels of QM performance. Therefore, anchoring vignettes have a potential for use by MNCs to study perceptions of QM principles, and to compare the QM performance of subsidiaries. In this way, their use contributes to a better understanding of cultural diversity in $\mathrm{QM}$ and give more information for MNCs to improve the levels of $\mathrm{QM}$ performance related to specific QM principles in different subsidiaries.

\section{External Perspective - Customers}

Customers evaluate products and services based on their culture-bound expectations (Donthu and Yoo, 1998; Voss et al., 2004), and national cultures significantly affect their satisfaction ratings (Riddle, 1992; Mattila, 1999; Voss et al., 2004; Morgeson et al., 2015). Paper IV confirms that people from different national cultural backgrounds expect, experience and evaluate a mobile phone service differently. Since quality is defined primarily by customers (e.g. Juran, 1988; Bergman and Klefsjö, 2010), it can be concluded that companies that have customers from different countries need to understand the diversity of their customers - their expectations and how they evaluate and express their experiences of products or services.

Customer satisfaction is usually measured by survey (Hill et al., 2017). Traditional surveys, however, have been criticized due to the risk of cultural bias (e.g. Malhotra et al., 1996; Cavusgil and Das, 1997). Paper IV confirmed that the problem of bias in the cross-cultural survey method exists. Since customer satisfaction and its ratings are culturally dependent, companies that operate globally need to understand cultural diversity that stems from the difference in cultural backgrounds of customers, and they should be able to measure customer satisfaction with a minimum of bias. Customer satisfaction measurements can be used to encourage continuous improvement in QM, and support decision-making (Anderson and Fornell, 2010; Birch-Jensen et al., 2018). Therefore, it is important for companies to gather accurate information, compare customer satisfaction ratings across different markets with different cultural backgrounds and take actions based on facts.

The work presented in this thesis showed that anchoring vignettes can be used to improve the comparability of customer satisfaction measurements across customer groups with different cultural backgrounds. This gives a better understanding of cultural diversity related to $\mathrm{QM}$ from the external perspective of the customers. Paper IV suggests that variations stemming from cultural bias are mitigated by anchoring vignettes, and that survey results obtained in this way reflect more accurately the performance levels of the mobile operators in the four countries. Such measurements give better comparability and reveal more comparable customer satisfaction with the product or service, and thus make it easier for companies to focus on distinct markets, solve 
problems, and allocate resources efficiently. Moreover, this customer satisfaction rating instrument can initiate improvements for each regional market, or provide a basis for setting product development strategies. However, similar challenges in vignettes design were faced and several rounds of improvements and pilot tests were needed to make the questionnaire works. Moreover, it might be challenging to convince customers to participate in the survey since this type of questionnaire is not common and it takes longer time to respond.

\subsubsection{Strategies to Manage Quality in Multinational Companies}

The challenges discussed in Section 5.1.1 and a better understanding of cultural diversity in MNCs gained by the instrument suggested in Section 5.1.2 lead to strategies that can be used to manage quality in MNCs. However, the connections between QM, national culture and the organizational culture of MNCs should first be clarified. Several aspects of $\mathrm{QM}$ are then explained in the context of MNCs, to form a basis for suggested strategies. Furthermore, the strategies are discussed in relation to the coupling concepts of organizational theory, as applied to MNC settings.

\section{Quality Management in Relation to National and Organizational Culture}

As described before, national and organizational cultures are located on different levels (e.g. Hofstede et al., 2010; Schein, 2010; Trompenaars and Hampden-Turner, 2012). The connection between national, organizational culture and QM is illustrated in Figure 6 as an attempt to build a conceptual model based on Schein's cultural levels. In the case of an MNC, the organizational culture appears at the levels of espoused values and artifacts,

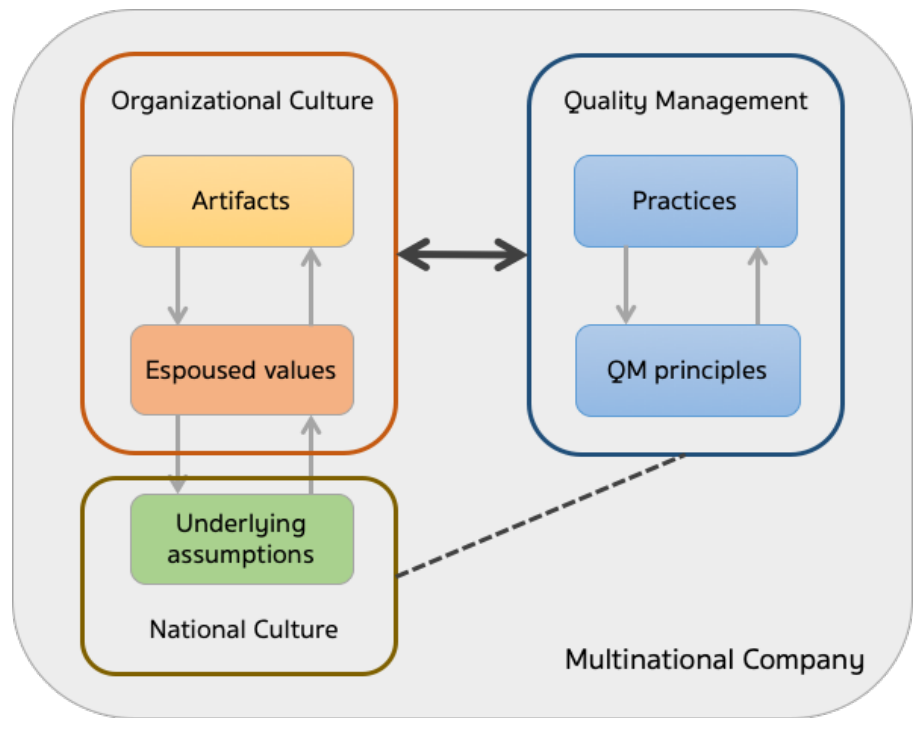

Figure 6: Connection between national, organizational culture and QM (adapted from Schein's model) 
while the underlying assumptions that are imprinted deep in the minds of people are usually gained earlier in life. These are more related to the local national cultures of the headquarters and subsidiaries. This means that QM can influence the organizational culture of MNCs at the espoused values and artifacts levels. Nevertheless, QM and national culture are related (e.g. Chevrier, 2009; Vecchi and Brennan, 2009; Vecchi and Brennan, 2011), which is indicated by the dotted line in Figure 6. QM does not have a direct influence over the national culture of the headquarters or subsidiaries, nor is the inverse the case as indirect influences may be present.

\section{Understanding Aspects of Quality Management}

However, as previously discussed, national cultural diversity poses several challenges for MNCs, one of which is to transform quality management approaches and implement them in all subsidiaries, while another is to establish common perceptions of QM principles across subsidiaries. QM offers supporting structures that can be used to cope with managerial challenges, bridge cultural differences, and facilitate collaboration across borders within the same MNC (Paper II). For example, if the management promotes continuous improvement globally, employees can be encouraged and learn to take more initiative and contribute to improvements in a team-based working environment. This is uncommon in some cultures, and its use might be facilitated by fine tuning the mindsets and working styles of employees, which may narrow the gap between employees with different national cultural backgrounds. Also, some QM techniques and tools can be used to establish standard working procedures, and ensure mutual understanding among employees from different subsidiaries with different national cultural backgrounds.

Paper I shows that companies usually apply techniques and tools, which are associated with technical aspects, immediately at the beginning of the implementation process. Social aspects are subsequently taken into consideration, since it takes time and effort to align QM values and organizational cultures to each other. Papers $\mathrm{V}$ and $\mathrm{VI}$ confirm this, and describe how MNCs with extensive international experience have focused on the training of employees in QM techniques and tools, in order to establish mutual understanding and expertise in the technical aspects of QM in all subsidiaries. Values cannot be changed simply by describing the desired values but need to be accompanied by supporting structure and management practices. Therefore, expertise in the technical aspects of QM are important for employees so that they can start dealing with quality issues such that they can make decisions themselves. This helps create a strong basis for managing quality in the global company. The common understanding and practices of the technical aspects of QM can act as a supporting structure that enhances the social aspects of $\mathrm{QM}$ and promotes a common perception of QM principles. This, together with Schein who suggests that artifacts can gradually affect the espoused values (Schein, 2010), leads to the suggested strategy by which MNCs can globally manage quality. MNCs should focus first on the technical aspects of QM by providing sufficient training in QM techniques and tools for the employees. These techniques and tools are easier to 
apply since they can be seen in practice, and are primarily located at the artifact level of culture. The technical aspects of QM act as a supporting structure or 'backbone' of the QM system of the MNC, and establishes means and measures for the social aspects. Regarding the social aspects, QM values and goals need to be shared by all employees at all levels, in order to establish a basis for the work with QM. These QM values and goals that are shared with the employees in the global company are beneficial in promoting a strong quality culture, and may reduce differences that stem from the national cultures at subsidiaries, to some extent.

Paper VI describes how an MNC using this strategy has been successful in establishing shared perceptions of QM principles and values. The differences between subsidiaries appear mostly at the operational level of QM practices, considered as local adaptations of QM practices. This result supports the suggestion by Vecchi and Brennan (2009) that MNCs should adapt QM practices to the local national cultures of subsidiaries. Vecchi and Brennan (2009) also suggest that this local adaptation of practices should not compromise the quality standard of the MNCs and therefore MNCs should develop quality management programs that can be effectively implemented in the various local cultures of subsidiaries. However, the results presented in this thesis do not fully support Vecchi and Brennan's claim that such programs can be developed and effectively implemented in various local cultures. National cultures affect the perceptions and practices of $\mathrm{QM}$, and it is doubtful to have a one-program-fits-all solution. Instead, a shared perception of QM values and common quality goals should be established across the subsidiaries, to enhance a strongly unified basis on which quality can be managed, and which allows room for local adaptation at the operational level.

Nevertheless, the local adaptation of QM practices can be beneficial to the global company, if it is based on a shared perception of QM values and expertise in QM techniques and tools. Paper $V$ shows that local adaptation of $Q M$ practices that is not based on a mutual understanding of quality and QM values can create a more serious long-term issue for MNCs in their management of quality. Consider, for example, an MNC that gives an incentive for employees to promote improvement work. If a subsidiary gives the incentive injudiciously, the employees might not appreciate that continuous improvement is an important QM value, and something they should do as a part of their daily work. They are committed to improvement only because they receive a reward. The improvement work may proceed satisfactorily at the subsidiary, but the discrepancy at the level of espoused values becomes larger than at other subsidiaries that do not have the incentive system. Therefore, without a strong basis of a shared perception of QM values, local adaptation of practices may not give the desired result in the long run.

The discussion above sheds some light on the debate between the unitarist and pluralist schools of thought in QM. In the case of MNCs, the shared perceptions and goals of QM are promoted at the conceptual level, which supports the unitarist point of view that QM is based on a unified mindset and perceptions among the members of an MNC. However, 
QM practices differ between subsidiaries at the operational level, as a consequence of the diversity of local cultures, which supports the pluralist point of view. The results presented in this thesis suggest that different practices at subsidiaries (based on shared QM perceptions and goals) can lead to the satisfactory management of quality in MNCs. Consequently, it is perhaps unimportant to completely separate QM between the two schools, but accept that $\mathrm{QM}$ is multifaceted and can be described by different schools of thought at different levels - unitarist at the conceptual and pluralist at the operational level.

\section{Global Integration or Local Adaptation?}

This thesis suggests that MNCs can set quality management strategies based on the coupling concept in organizational theories (e.g. Glassman, 1973; Weick, 1976). MNCs that have not yet established a shared perception of QM values have a weak organizational culture to focus on quality, and may need to act to make them more tightly coupled, with higher global integration (Figure 4). Standardized practices and controls need to be introduced, such that the quality levels across subsidiaries become more consistent. Also, situations, in which differences in QM perception create bigger issues at the operational level affecting the quality performance of the whole company, should be prevented. In contrast, MNCs that have successfully established a shared perception of $\mathrm{QM}$ values and expertise in the use of $\mathrm{QM}$ techniques and tools may benefit from local adaptation of QM practices. These MNCs may take action to make them more loosely coupled, allowing some parts of an organization to retain their central focus while others adapt to their local contexts (Glassman, 1973; Weick, 1976). Each subsidiary and the headquarters are coupled entities that are responsive, while having enough space between them to preserve their own identities. The different national cultural backgrounds of the subsidiaries make it necessary to allow contextual factors at the subsidiaries to play their roles in local adaptation, and this is often reflected in $\mathrm{QM}$ practices. Subsidiaries that have common goals and perceptions of the global QM strategy may, even so, have slightly different means to achieve those goals, resulting in local adaptation of practices. This result is compatible with the conclusion from previous research that MNCs should have close linkages between the subsidiaries and the headquarters with a coordinated strategy in $\mathrm{QM}$, while achieving an organizational structure that is sufficiently flexible to keep up with changes in the market and adapt to the local context (Ghoshal and Westney, 2016; Westney, 2016).

The bond between subsidiaries and the headquarters can be strengthened by a system in which top and middle managers rotate (Papers $\mathrm{V}$ and $\mathrm{VI}$ ), and act as boundary spanners that connect the subunits. The managers are then agents in a loosely coupled system (Orton and Weick, 1990; Schotter et al., 2017). Schein (2010) has shown that organizational culture grows from the learning experiences of group members, and new group members or leaders who bring in new beliefs, values and assumptions. As a result, the quality culture of MNCs that is cultivated by the headquarters can grow gradually at 
the subsidiaries with helps from the rotating managers. Since a strong organizational culture can create powerful bonds within the MNC, it promotes boundary spanning while preventing the boundary extending beyond the main company structure (Schotter et al., 2017). It is important for effective management of quality to establish a strong, shared organizational culture focusing on quality throughout the global company. Moreover, the QM 'backbone' previously described can support this culture of quality.

Nevertheless, it is important for MNCs to accept that subsidiaries are acting in diverse cultural contexts (Papers V and VI). MNCs should not see cultural diversity only as a problem. On the contrary, MNCs can learn to live with diversity and take advantage of it.

\subsection{Discussion of Research Methodology}

Reflection on the research approach used during the work presented in this thesis is important to enhance the quality of the research. The background and context of the studies are presented, and the reliability and validity of the studies are discussed.

\subsubsection{Reflection on the Research Conducted}

The research was designed such that general broad studies to identify challenges in managing quality in cross-cultural settings were initially conducted. A pre-study identified some challenges in cross-cultural QM and established some tentative ideas of means to facilitate $Q M$ in cross-cultural settings (Study $A$ ).

Study A showed that an instrument was necessary to analyze and present challenges in cross-cultural QM, and to provide a better understanding of the relationships between $\mathrm{QM}$, national cultures and the organizational cultures of MNCs. Once the instrument had been developed, it was necessary to establish contact with industrial sectors to test it in real industrial settings and collect more data (both broader and deeper) about the challenges, and how the MNCs currently manage cross-cultural QM. A period of unsuccessful attempts to contact companies and obtain their cooperation for a survey study followed. Based on opportunities seen during the development and testing of anchoring vignettes for studying $\mathrm{QM}$ in $\mathrm{MNC}$, another idea for the application of the instrument emerged. As a result, we developed and tested a new survey that used anchoring vignettes to improve the comparability of customer satisfaction measurements across cultures, while continuing the attempts to find companies for studying QM in MNCs.

The greatest difficulty during my PhD research was to find suitable and committed companies for in-depth case studies. Sending emails to potential case companies did not lead to expected outcomes since the anchoring vignettes survey is not common or easy to understand. As a result, I decided to make a broader interview study with quality engineers and managers, in order to establish contacts and have a chance to explain the purposes of the employee survey. Besides, gaining preliminary understanding about the 
case companies would contribute to better quality of the in-depth case studies. This resulted in Study C-1. The interviews provided me with new perspectives on QM in MNCS and allowed me to discuss opportunities for an in-depth case study with the developed instrument. As a result, one MNC agreed to participate in Study C-2. This study confirmed the results concerning challenges in managing quality across cultures, the relationship between $\mathrm{QM}$, national cultures and the organizational cultures of MNCs, and possible means to facilitate cross-cultural QM discussed in other papers.

\subsubsection{Reliability}

Reliability is a measure of correctness, and a reliable study is one that gives results that remain the same when the study is repeated under the same circumstances (Yin, 2013). This definition, however, cannot often be applied in real situations, as the context of the research is hard to duplicate. Another definition of reliability is one that uses the concepts of consistency and dependability (Lincoln and Guba, 1985).

The reliability of the qualitative research presented here (Papers I, II, V and part of Paper $\mathrm{VI}$ ) does not rely on whether the results can be reproduced, but on their internal validity which is explained in the next section. Furthermore, the concept of an 'audit-trail', a method in which an auditor tracks the accounts of a business, was adopted (Merriam and Tisdell, 2015). To be more precise, data collection and analysis were described in the way that allows independent researchers to authenticate the findings by following the trail.

Previous research using the survey method based on anchoring vignettes was carefully studied before conducting the studies described in Papers III, IV and a part of Paper VI. The questionnaire was developed according to the guidelines, and tested several times before being used to collect data. The respondent groups were carefully selected to ensure that the samples were comparable. Then, the data were statistically analyzed using SPSS, and discussed within the research team.

\subsubsection{Validity}

Internal validity measures how the findings represent 'reality'. In other words, it describes how the interpretation of the dataset eventually leads to one explanation (Yin, 2013: 18), and excludes others. The work presented here has used 'triangulation' (or 'crystallization' as its post-modern aspect is known) to determine its internal validity (Richardson and St. Pierre, 2017). The validity was improved by conducting well-structured interviews, close observation of the studied units, and study of documents (Merriam and Tisdell, 2015). The use of several methods to collect data gave several advantages, which mitigated limitations at the different stages of the research. For example, during the research design stage, qualitative data from interviews, workshops and document study could help to establish the conceptual model and develop a basis for the later survey design. Moreover, data collected using different methods play different roles in the analysis, which leads to triangulation and confirmation that the findings are valid (Sieber, 1973; 
Denzin, 1978; Denzin, 2017). By this strategy I could compare data collected in a case study using an anchoring vignettes survey with data collected by interviews and document study. This allowed the results to be crystalized, and viewed from different perspectives. Peer review was also available, since papers were presented at academic conferences, and comments were obtained from supervisors and senior researchers during the research process.

External validity is a measure of the generality of the findings (Yin, 2013: 18). However, it is more useful to identify the extent to which the findings may be applied than it is to try to expand the scope of the study to cover as many aspects as possible. Although case studies have advantages when investigating complex social phenomena with multiple variables, as was the case for much of the work presented here, it is difficult to obtain generally applicable results from case studies (Merriam and Tisdell, 2015). However, the primary purpose of this study was not to generalize but to explore, and to gain insight into $\mathrm{QM}$ in complex cross-cultural settings. The scope of the findings of this study has been defined and its limitation identified. As a result, the degree of generalization of the study has been established in connection with the research design and the data collection procedures.

Achieving high response rates in web-based surveys is a common problem (Nulty, 2008). In my research, email invitations to participate in the survey did not lead to expected numbers of responses. As a result, links to surveys were spread via several channels, such as social media, third party contacts, and it was difficult to have control over the total numbers of the surveys sent. In case of the case company in Paper VI, the links to the surveys were distributed by the contacts at the company and I did not have much influence over the process. However, the purpose of anchoring vignette studies was not to generalize to population or test some hypotheses, but to make group by group comparisons. Therefore, the exact and high response rates would be beneficial, but not as critical as in surveys aiming to generalize the findings from samples to population. 


\section{Conclusions, Contributions and Future Research}

This final chapter consists of four sections. The first section answers the research questions and presents the conclusions of the thesis. The second section discusses the research contributions in the relevant research fields. The third section describes managerial implications that can be drawn from the results of this thesis. The fourth and final section suggests lines of future research.

Cross-cultural QM is an important research topic as companies operate across national borders and global markets grow. This thesis provides insight into how quality in crosscultural settings can be managed: it identifies challenges related to QM and suggests means to facilitate $Q M$ in MNCs. The following research questions were formulated:

RQ1: What are the challenges in managing quality related to national cultural diversity in MNCs?

RQ2: How can cultural diversity in QM be studied:

a) from an internal perspective of the MNCs?

b) from an external perspective of the customers?

RQ3: What are possible strategies to manage quality in MNCs?

\subsection{Conclusions}

Several challenges in managing quality related to national cultural diversity in MNCs were identified. First, implementing quality management approaches, such as Lean, is challenging in global organizations with diverse national cultural backgrounds, and the principles associated with social aspects are particularly difficult. The management approach needs to be adapted to fit the cultural contexts of the companies. However, MNCs face a dilemma due to the difference between the local cultural contexts of the headquarters and those of the subsidiaries, and the implemented QM approach itself. It is challenging to implement a management approach such that it avoids conflict with any of the local national cultures but a common QM approach is desired to be implemented across headquarters and subsidiaries. The headquarters of MNCs often take decisions about adopting management approaches, and thus they need to be aware of the national cultures of subsidiaries and the relation to the $Q M$ approach being implemented. Second, it is difficult to motivate and engage employees with different national cultural backgrounds such that they understand and accept diversity, and see the benefits of working together across cultures. Employees who hold different values may engage with the work to ensure quality differently, even if they have the same level of commitment. Third, it is difficult to establish shared perceptions of QM values among employees. This thesis has demonstrated differences in the perception of QM values that stem from the 
different national cultural backgrounds of employees in subsidiaries. This can create a mismatch in the levels of quality awareness, which may lead to problems in collaboration across subsidiaries or an uneven quality of products or services.

A method of anchoring vignettes was adopted to study cultural diversity in QM. First, a questionnaire with anchoring vignettes was developed and applied as an instrument to study QM from the internal perspective of MNCs. In this case, the questionnaire allows to study employees' perceptions of QM principles and to compare the levels of QM performance between different subsidiaries, contributing in this way to a better understanding of cultural diversity in QM. Second, another questionnaire with anchoring vignettes was used to measure satisfaction of customers with different cultural backgrounds. In this case, the questionnaire provides better comparability of satisfaction ratings between customer groups across culture. Using anchoring vignettes can support a more targeted work of improvement for each regional market and serve as a basis for defining better product development strategies.

Finally, the thesis suggests strategies to manage quality in MNCs, based on the concept of coupling in organizational theories. MNCs with a weak quality organizational culture that have not yet established shared perceptions of $\mathrm{QM}$ values and goals need to work with tight coupling and global integration. Such MNCs tend to achieve this integration by 'command and control' that means standardizing working procedures and setting clear quality specifications in order to prevent bigger discrepancies in quality performance. However, in the long run, MNCs should move toward loosely coupled system and local adaptation based on shared perceptions of QM values and goals. In order to achieve this, the initial step for MNCs is to promote the technical aspects of QM, the techniques and tools, to form a 'backbone' of the QM system. In this way, MNCs can establish a strong quality culture and adapt QM practices to some extent, while maintaining a focus on achieving the same goals. As a result, the subsidiaries can preserve their identity and uniqueness, and increase their ability to cope with a changing environment, and thereby increase the growth of the global company.

One technique to strengthen the bond between the headquarters and the subsidiaries of MNCs is to rotate managers, who then act as agents and span across boundaries to link, exchange and grow a strong shared organizational culture that focuses on QM in the whole MNC. This loosely coupled QM system allows MNCs to gain benefits simultaneously from a high global integration and a high local responsiveness.

\subsection{Research Contributions}

This thesis contributes to filling the gaps in the research field of cross-cultural QM by exploring QM in MNCs in which national and organizational cultures are intertwined. First, it identifies challenges in managing quality in MNCs, and in this way extends previous research in cross-cultural $\mathrm{QM}$, which has to a large extent simply highlighted differences without discussing the challenges related to them. Second, it proposes an instrument 
based on anchoring vignettes that can be used to study cross-cultural QM with two applications: 1) to analyze perceptions of $Q M$ values and compare performance related to QM principles across employees at different subsidiaries of an MNC, and 2) to improve the comparability of customer satisfaction measurements across cultures. As described earlier, anchoring vignettes is a survey methodology that was developed in the research field of political science in order to reduce cultural and personal bias in survey results, especially in cross-cultural studies. In the work presented in this thesis, the instrument has been developed, tested and applied to QM, a different context from the one in which the method was originally used. Third, based on the suggestion of Vecchi and Brennan (2009) in the local adaptation of QM practices, this thesis proposes strategies that can be used to manage quality in the diverse cultural setting of an MNC, in connection to the organizational theory of coupling. This is an attempt to view cross-cultural QM research from an organizational theory perspective, bridging the gap between the two research fields.

The work presented in this thesis separates $\mathrm{QM}$ into conceptual and operational levels, and shows that QM is multifaceted at these two levels. At the conceptual level, shared perceptions and goals of $\mathrm{QM}$ should be promoted, which is compatible with a unitarist point of view. In contrast, at the operational level, QM practices are influenced by the diversity of local cultures, and thus differ between subsidiaries. This is more closely compatible with the pluralist point of view. By that the thesis contributes to the discussion between the unitarist and pluralist schools of thought in the research field of QM.

Last but not least, this thesis also contributes to the development of research methodology by the application of the anchoring vignettes into new areas: QM in MNCs, and the measurement of customer satisfaction across borders.

\subsection{Managerial Implications}

This thesis discusses challenges in managing quality in the cross-cultural settings of MNCs. It is important for companies that operate globally to be aware of these challenges and have a plan to cope with them. Companies should also be aware that traditional surveys have a cultural bias and do not provide accurate information in cross-cultural settings, and should thus consider other methods.

The work presented here has developed an instrument based on a survey method with anchoring vignettes, and demonstrated their use in two cases. First, the anchoring vignettes questionnaire regarding customer satisfaction can measure the satisfaction of customers and improve comparability across customer groups with different cultural backgrounds. Second, the anchoring vignettes questionnaire that focuses on $\mathrm{QM}$ principles can analyze the QM perceptions of employees with different cultural backgrounds, and compare performance between different groups of employees. This questionnaire can be used to give MNCs a better understanding of their own situation 
with respect to QM perceptions, practices and performance, and use this understanding as a basis for global quality strategies. For example, if employees in different subsidiaries perceive some QM values differently, the company might need to standardize QM practices, while working to promote shared perceptions of those QM values. MNCs with shared perceptions of $Q M$ values among employees can gain long-term benefit from local adaptations of QM practices.

Therefore, MNCs should set up a global QM strategy with common goals and promote them throughout the company. Common training sessions that focus on basic $Q M$ values and the use of in-depth techniques and tools should be provided for employees at all levels in subsidiaries. These technical aspects, techniques and tools, helps to create a strong base for the company's QM system and to support the social aspect of QM values. The subsidiaries can subsequently design and adapt the QM practices to be more suitable to their local cultural background. Nevertheless, this local adaptation should be focused on achieving the same goals, and it should be based on a strong shared organizational culture of the MNC that focuses on quality and considerable expertise in QM techniques and tools. This thesis suggests that this strong shared organizational culture throughout the MNC can be facilitated by rotating top and middle managers between the headquarters and the subsidiaries.

\subsection{Future Research}

The work presented in this thesis contributes primarily to the research field of crosscultural QM in MNCs, and opens some opportunities for future research in the field. First, the challenges identified in this thesis should be further explored in more cases for better understanding of the phenomenon behind them. This might lead to a more thorough strategies or techniques to cope with the challenges that MNCs face. Second, as the instrument based on anchoring vignettes to study QM has been applied to only one company, it would be interesting to adopt it in other cases. The instrument may be improved if applied in several MNCs. Further, it would be useful to apply the instrument used to study cross-cultural customer satisfaction in other contexts. One example is its use to study customers of the same MNC in different countries. Third, other methods to reduce cultural and personal bias in questionnaires can be studied. Future research may develop and test instruments based on other methods than anchoring vignettes to study $\mathrm{QM}$ in MNCs. Fourth, the strategies used to manage quality in MNCs suggested in this thesis are primarily based on one interview study and one case study. More studies are needed to test and confirm these strategies. 


\section{References}

Adler, N. J. and Gundersen, A. (2007), International dimensions of organizational behavior. Mason, $\mathrm{OH}$ : Thomson South-Western.

Alvesson, M. (2003), "Beyond neopositivists, romantics, and localists: A reflexive approach to interviews in organizational research", Academy of Management Review, Vol. 28, No. 1, pp. 1333.

Alvesson, M. (2012), Understanding organizational culture. Trowbridge, Wiltshire: Sage.

Anderson, E. W. and Fornell, C. (2010), "Foundations of the American Customer Satisfaction Index", Total Quality Management, Vol. 11, No. 7, pp. 869-882.

Anderson, J. C., Rungtusanatham, M. and Schroeder, R. G. (1994), "A Theory of Quality Management Underlying the Deming Management Method", The Academy of Management Review, Vol. 19, No. 3, pp. 472-509.

Andersson, R., Mi Dahlgaard-Park, S., Eriksson, H. and Torstensson, H. (2006), "Similarities and differences between TQM, six sigma and lean", The TQM Magazine, Vol. 18, No. 3, pp. 282-296.

Andersson, U., Forsgren, M. and Holm, U. (2015), "Balancing subsidiary influence in the federative MNC: A business network view". In: Forsgren, M., Holm, U. and Johanson, J. (Eds.), Knowledge, Networks and Power. Basingstoke, Hampshire: Palgrave Macmillan, pp.393-420.

Baird, K., Jia Hu, K. and Reeve, R. (2011), "The relationships between organizational culture, total quality management practices and operational performance", International Journal of Operations \& Production Management, Vol. 31, No. 7, pp. 789-814.

Bakker, R., Edwards, E., Jolly, S., Polk, J., Rovny, J. and Steenbergen, M. (2014), "Anchoring the experts: Using vignettes to compare party ideology across countries", Research and Politics, Vol. 1, No. 3, pp. 1-8.

Bamford, D. R. and Greatbanks, R. W. (2005), "The use of quality management tools and techniques: a study of application in everyday situations", International Journal of Quality \& Reliability Management, Vol. 22, No. 4, pp. 376-392.

Barney, J. B. (1986), "Organizational Culture: Can It Be a Source of Sustained Competitive Advantage?", Academy of Management Review, Vol. 11, No. 3, pp. 656-665.

Barouch, G. and Kleinhans, S. (2015), "Learning from criticisms of quality management", International Journal of Quality and Service Sciences, Vol. 7, No. 2/3, pp. 201-216. 
Barratt, M., Choi, T. Y. and Li, M. (2011), "Qualitative case studies in operations management: Trends, research outcomes, and future research implications", Journal of Operations Management, Vol. 29, No. 4, pp. 329-342.

Bartlett, C. A. and Ghoshal, S. (1988), "Organizing for worldwide effectiveness: The transnational solution”, California Management Review, Vol. 31, No. 1, pp. 54-74.

Beekun, R. I. and Glick, W. H. (2001), "Organization structure from a loose coupling perspective: A multidimensional approach", Decision Sciences, Vol. 32, No. 2, pp. 227-250.

Beer, M. (2003), "Why Total Quality Management Programs Do Not Persist: The Role of Management Quality and Implications for Leading a TQM Transformation*”, Vol. 34, No. 4, pp. 623-642.

Bergman, B. and Klefsjö, B. (2010), Quality from customer needs to customer satisfaction. Lund: Studentlitteratur AB.

Bessant, J., Caffyn, S., Gilbert, J., Harding, R. and Webb, S. (1994), "Rediscovering continuous improvement", Technovation, Vol. 14, No. 1, pp. 17-29.

Birch-Jensen, A., Gremyr, I., Hallencreutz, J. and Rönnbäck, Å. (2018), "Use of customer satisfaction measurements to drive improvements", Total Quality Management \& Business Excellence, printed online, pp. 1-14.

Boer, D., Hanke, K. and He, J. (2018), "On Detecting Systematic Measurement Error in CrossCultural Research: A Review and Critical Reflection on Equivalence and Invariance Tests", Journal of Cross-Cultural Psychology, Vol. 49, No. 5, pp. 713-734.

Bortolotti, T., Boscari, S. and Danese, P. (2015), "Successful lean implementation: Organizational culture and soft lean practices", International Journal of Production Economics, Vol. 160, No. 1, pp. 182-201.

Bouranta, N., Psomas, E., Suárez-Barraza, M. F. and Jaca, C. (2019), "The key factors of total quality management in the service sector: a cross-cultural study", Benchmarking: An International Journal, Vol. 26, No. 3, pp. 893-921.

Brady, M. K., Robertson, C. J. and Cronin, J. J. (2001), "Managing behavioral intentions in diverse cultural environments: an investigation of service quality, service value, and satisfaction for American and Ecuadorian fast-food customers", Journal of International Management, Vol. 7, No. 2, pp. 129-149.

Bright, K. and Cooper, C. L. (1993), "Organizational Culture and the Management of Quality", Journal of Managerial Psychology, Vol. 8, No. 6, pp. 21-27.

Brislin, R. (2000), Understanding culture's influence on behavior. San Diego, CA: Harcourt Brace Jovanovich. 
Buckley, P. J. and Casson, M. (2016), The future of the multinational enterprise. London: Macmillan.

Bunney, H. S. and Dale, B. G. (1997), "The implementation of quality management tools and techniques: a study", The TQM Magazine, Vol. 9, No. 3, pp. 183-189.

Burke, W. W. (2014), "Changing Loosely Coupled Systems", The Journal of Applied Behavioral Science, Vol. 50, No. 4, pp. 423-444.

Calvo-Mora, A., Picón, A., Ruiz, C. and Cauzo, L. (2013), "The relationships between soft-hard TQM factors and key business results", International Journal of Operations \& Production Management, Vol. 34, No. 1, pp. 115-143.

Cavusgil, S. T. and Das, A. (1997), "Methodological issues in empirical cross-cultural research: A survey of the management literature and a framework", MIR: Management International Review, Vol. 37, No. 1, pp. 71-96.

Chevalier, A. and Fielding, A. (2011), "An introduction to anchoring vignettes", Journal of the Royal Statistical Society, Vol. 174, No. 3, pp. 569-574.

Chevrier, S. (2009), "Is National Culture Still Relevant to Management in a Global Context?", International Journal of Cross Cultural Management, Vol. 9, No. 2, pp. 169-183.

Chhokar, J. S., Brodbeck, F. C. and House, R. J. (2013), Culture and leadership across the world: The GLOBE book of in-depth studies of 25 societies. Hoboken: Taylor and Francis.

Corbin, J. and Strauss, A. (2014), Basics of Qualitative Research: Techniques and Procedures for Developing Grounded Theory. Thousand Oaks, CA: Sage.

Cronemyr, P., Bäckström, I. and Rönnbäck, A. (2017), "Quality culture deployment - using behaviours to explain, diagnose and improve a quality culture", International Journal of Quality and Service Sciences, Vol. 9, No. 3/4, pp. 498-518.

Cronemyr, P. and Danielsson, M. (2013), "Process Management 1-2-3 - a maturity model and diagnostics tool", Total Quality Management \& Business Excellence, Vol. 24, No. 7-8, pp. 933944.

Crosby, P. B. (1979), Quality is free: The art of making quality certain. New York: McGraw-hill.

Dahlgaard, J. J., Khanji, G. K. and Kristensen, K. (2008), Fundamentals of total quality management. London: Routledge.

Dahlgaard, J. J., Mi Dahlgaard-Park, S. and Mi Dahlgaard-Park, S. (2006), "Lean production, six sigma quality, TQM and company culture", The TQM Magazine, Vol. 18, No. 3, pp. 263-281.

Dale, B. G. and McQuater, R. E. (1998), Managing business improvement and quality: implementing key tools and techniques. Oxford: Blackwell Business. 
Dale, B. G., van der Wiele, T. and van Iwaarden, J. (2007), Managing quality. Oxford: Blackwell Publishing.

Danermark, B., Ekström, M., Jakobsen, L. and Karlsson, J. C. (2003), Att förklara samhället. Lund: Studentlitteratur. (In Swedish)

Datta Gupta, N., Kristensen, N. and Pozzoli, D. (2010), "External validation of the use of vignettes in cross-country health studies", Economic Modelling, Vol. 27, No. 4, pp. 854-865.

Dean, J. W. and Bowen, D. E. (1994), "Management Theory and Total Quality: Improving Research and Practice through Theory Development", The Academy of Management Review, Vol. 19, No. 3, pp. 392-418.

Dellana, S. A. and Hauser, R. D. (1999), "Toward Defining the Quality Culture", Engineering Management Journal, Vol. 11, No. 2, pp. 11-15.

Deming, W. E. (1994), The new economics: For industry, goverment, education. Cambridge, MA: MIT, Center for Advanced Educational Services.

Denzin, N. K. (1978), The research act: A theoretical introduction to sociological methods. New York: Praeger.

Denzin, N. K. (2017), The research act: A theoretical introduction to sociological methods. London: Aldine Transaction.

Donthu, N. and Yoo, B. (1998), "Cultural Influences on Service Quality Expectations", Journal of Service Research, Vol. 1, No. 2, pp. 178-186.

Drogendijk, R., Holm, U., Andersson, U. and Holm, U. (2010), The Role of National Culture in the Headquarters-Subsidiary Relationship in the Multinational Corporation: the Effect of Power Distance. Cheltenham, UK: Edward Elgar Publishing.

Dunning, J. H. (1977), "Trade, location of economic activity and the MNE: A search for an eclectic approach". In: Ohlin, B., Hesselborn, P.-O. and Wiljkman, P. M. (Eds.), The international allocation of economic activity. Springer, pp.395-418.

Dyer Jr, W. G. and Wilkins, A. L. (1991), "Better stories, not better constructs, to generate better theory: A rejoinder to Eisenhardt", Academy of Management Review, Vol. 16, No. 3, pp. 613-619.

Earley, P. C. (2006), "Leading cultural research in the future: a matter of paradigms and taste", Journal of International Business Studies, Vol. 37, No. 6, pp. 922-931.

Eisenhardt, K. M. (1989), "Building Theories from Case Study Research", Academy of Management Review, Vol. 14, No. 4, pp. 532-550.

Elg, M. (2001), "Performance measures and managerial work: a modified behavior setting approach to the study of usage of performance measures in managerial meetings". Linköpings universitet. 
Fisher, N. I. and Nair, V. N. (2009), "Quality management and quality practice: Perspectives on their history and their future", Applied Stochastic Models in Business and Industry, Vol. 25, No. 1, pp. 1-28.

Flynn, B. B. and Saladin, B. (2006), "Relevance of Baldrige constructs in an international context: A study of national culture", Journal of Operations Management, Vol. 24, No. 5, pp. 583-603.

Flynn, B. B., Schroeder, R. G. and Sakakibara, S. (1994), "A framework for quality management research and an associated measurement instrument", Journal of Operations Management, Vol. 11 , No. 4, pp. 339-366.

Flynn, B. B., Schroeder, R. G. and Sakakibara, S. (1995), "The Impact of Quality Management Practices on Performance and Competitive Advantage", Decision Sciences, Vol. 26, No. 5, pp. 659691.

Fornell, C. (1992), "A national customer satisfaction barometer: The Swedish experience", Journal of Marketing, Vol. 56, No. 1, pp. 6-21.

Gambi, L. D. N., Boer, H., Gerolamo, M. C., Jørgensen, F. and Carpinetti, L. C. R. (2015), "The relationship between organizational culture and quality techniques, and its impact on operational performance", International Journal of Operations \& Production Management, Vol. 35, No. 10, pp. 1460-1484.

Ghoshal, S. and Bartlett, C. A. (1990), "The multinational corportation as an internorganizational network”, Academy of Management, Vol. 15, No. 4, pp. 603-625.

Ghoshal, S. and Westney, D. E. (2016), "Introduction and overview". In: Ghoshal, S. and Westney, D. E. (Eds.), Organization theory and the multinational organization. New York: St. Martin's press.

Glassman, R. B. (1973), "Persistence and loose coupling in living systems", Behavioral science, Vol. 18, No. 2, pp. 83-98.

Green, T. J. (2012), "TQM and organisational culture: How do they link?", Total Quality Management \& Business Excellence, Vol. 23, No. 2, pp. 141-157.

Hackman, J. R. and Wageman, R. (1995), "Total Quality Management: Empirical, Conceptual, and Practical Issues", Administrative Science Quarterly, Vol. 40, No. 2, pp. 309-342.

Harvey, L. and Stensaker, B. (2008), "Quality Culture: understandings, boundaries and linkages", European Journal of Education, Vol. 43, No. 4, pp. 427-442.

Haugland, S. A. (2010), "The integration-responsiveness framework and subsidiary management: A commentary", Journal of Business Research, Vol. 63, No. 1, pp. 94-96. 
He, J., Van De Vijver, F., Jr., Espinosa, A. D. and Mui, P. H. (2014), "Toward a unification of acquiescent, extreme, and midpoint response styles", International Journal of Cross Cultural Management, Vol. 14, No. 3, pp. 306-322.

Hellsten, U. and Klefsjö, B. (2000), "TQM as a management system consisting of values, techniques and tools", The TQM Magazine, Vol. 12, No. 4, pp. 238-244.

Hellström, A., Mi Dahlgaard-Park, S. and Eriksson, H. (2008), "Are you viewing, mapping or managing your processes?", The TQM Journal, Vol. 20, No. 2, pp. 166-174.

Hill, N., Brierley, J. and MacDougal, R. (2017), How to measure customer satisfaction. London: Routledge.

Ho, D. C. K., Duffy, V. G. and Shih, H. M. (2001), "Total quality management: An empirical test for mediation effect", International Journal of Production Research, Vol. 39, No. 3, pp. 529-548.

Hoang, D. T., Igel, B. and Laosirihongthong, T. (2006), "The impact of total quality management on innovation", International Journal of Quality \& Reliability Management, Vol. 23, No. 9, pp. 1092-1117.

Hofstede, G. (1996), "Riding the waves of commerce: A test of trompenaars' "model" of national culture differences", International Journal of Intercultural Relations, Vol. 20, No. 2, pp. 189-198.

Hofstede, G., Hofstede, G. J. and Minkov, M. (2010), Cultures and organizations: software of the mind: intercultural cooperation and its importance for survival. New York: McGrow-Hill.

Hopkins, D. J. and King, G. (2010), "Improving Anchoring Vignettes: Designing Surveys to Correct Interpersonal Incomparability", Public Opinion Quarterly, Vol. 74, No. 2, pp. 201-222.

Imai, M. (1986), Kaizen: The key to Japan's Competitive Success. New York: McGrow-Hill.

Imai, M. (2012), Gemba Kaizen: A commonsense approach to a continuous improvement strategy. New York: McGraw-Hill.

Johnson, M. D., Herrmann, A. and Gustafsson, A. (2002), "Comparing customer satisfaction across industries and countries", Journal of Economic Psychology, Vol. 23, No. 6, pp. 749-769.

Johnson, R. B., Onwuegbuzie, A. J. and Turner, L. A. (2007), "Toward a Definition of Mixed Methods Research", Journal of Mixed Methods Research, Vol. 1, No. 2, pp. 112-133.

Jung, J., Su, X., Baeza, M. and Hong, S. (2008), "The effect of organizational culture stemming from national culture towards quality management deployment", The TQM Journal, Vol. 20, No. 6, pp. 622-635.

Juran, J. M. (1988), Quality Control Handbook. New York: McGraw Hill.

Kanji, G. K. and Wallace, W. (2010), "Business excellence through customer satisfaction", Total Quality Management, Vol. 11, No. 7, pp. 979-998. 
Kanji, G. K. and Yui, H. (1997), "Total quality culture", Total Quality Management, Vol. 8, No. 6, pp. 417-428.

Kaynak, H. (2003), "The relationship between total quality management practices and their effects on firm performance", Journal of Operations Management, Vol. 21, No. 4, pp. 405-435.

King, G., Murray, C. J., Salomon, J. A. and Tandon, A. (2004), "Enhancing the validity and crosscultural comparability of measurement in survey research", American political science review, Vol. 98, No. 1, pp. 191-207.

King, G. and Wand, J. (2007), "Comparing Incomparable Survey Responses: Evaluating and Selecting Anchoring Vignettes", Political Analysis, Vol. 15, No. 1, pp. 46-66.

Klefsjö, B., Mi Dahlgaard-Park, S., Bergquist, B. and Garvare, R. (2008), "Quality management and business excellence, customers and stakeholders”, The TQM Journal, Vol. 20, No. 2, pp. 120-129. Klefsjö, B., Wiklund, H. and Edgeman, R. L. (2001), "Six sigma seen as a methodology for total quality management”, Measuring Business Excellence, Vol. 5, No. 1, pp. 31-35.

Kogut, B. (1986), "Foreign direct investment as a sequential process". In: Kindleberger, C. P. and Audretsch, D. B. (Eds.), The multinational corporation in the 1980s. Cambridge, MA: MIT Press.

Kogut, B. (1991), "Country capabilities and the permeability of borders", Strategic Management Journal, Vol. 12, No. S1, pp. 33-47.

Kostova, T., Marano, V. and Tallman, S. (2016), "Headquarters-subsidiary relationships in MNCs: Fifty years of evolving research", Journal of World Business, Vol. 51, No. 1, pp. 176-184.

Kostova, T. and Roth, K. (2002), "Adoption of an organizational practice by subsidiaries of multinational corporations: institutional and relational effects", Academy of Management, Vol. 45, No. 1, pp. 215-233.

Kull, T. J. and Wacker, J. G. (2010), "Quality management effectiveness in Asia: The influence of culture", Journal of Operations Management, Vol. 28, No. 3, pp. 223-239.

Kvale, S. and Brinkmann, S. (2009), Interviews: Learning the craft of qualitative research interviewing. London: Sage.

Kwantes, C. T. and Glazer, S. (2017), "Organizations and Culture". In: Kwantes, C. T. and Glazer, S. (Eds.), Culture, Organizations and Work. Cham: Springer International Publishing, pp.45-66.

Lagrosen, S. (2002), "Quality management in Europe: a cultural perspective", The TQM Magazine, Vol. 14, No. 5, pp. 275-283.

Lagrosen, S. (2003), "Exploring the impact of culture on quality management", International Journal of Quality \& Reliability Management, Vol. 20, No. 4, pp. 473-487. 
Lee, R. G. and Dale, B. G. (1998), "Business process management: a review and evaluation", Business Process Management Journal, Vol. 4, No. 3, pp. 214-225.

Lemon, M. and Sahota, P. S. (2004), "Organizational culture as a knowledge repository for increased innovative capacity", Technovation, Vol. 24, No. 6, pp. 483-498.

Leonard-Barton, D. (1990), "A dual methodology for case studies: Synergistic use of a longitudinal single site with replicated multiple sites", Organization Science, Vol. 1, No. 3, pp. 248-266.

Lin, L.-H. (2014), "Subsidiary performance: The contingency of multinational corporation's international strategy", European Management Journal, Vol. 32, No. 6, pp. 928-937.

Lincoln, Y. S. and Guba, E. G. (1985), Naturalistic inquiry. London: Sage.

Losonci, D., Kása, R., Demeter, K., Heidrich, B. and Jenei, I. (2017), "The impact of shop floor culture and subculture on lean production practices", International Journal of Operations \& Production Management, Vol. 37, No. 2, pp. 205-225.

Mak, W. M. (1999), "Cultivating a quality mind-set", Total Quality Management, Vol. 10, No. 4\&5, pp. 622-626.

Malhotra, N. K., Agarwal, J. and Peterson, M. (1996), "Methodological issues in cross-cultural marketing research", International Marketing Review, Vol. 13, No. 5, pp. 7-43.

Malhotra, N. K., Ford, J. B., Ulgado, F. M., Agarwal, J., Shainesh, G. and Wu, L. (2005), "Dimensions of service quality in developed and developing economies: multi-country cross-cultural comparisons", International Marketing Review, Vol. 22, No. 3, pp. 256-278.

Marin-Garcia, J. A., Juarez-Tarraga, A. and Santandreu-Mascarell, C. (2018), "Kaizen philosophy", The TQM Journal, Vol. 30, No. 4, pp. 296-320.

Mathews, B. P., Ueno, A., Kekäle, T., Repka, M., Lopes Pereira, Z. and Silva, G. (2001), "European quality management practices", International Journal of Quality \& Reliability Management, Vol. 18, No. 7, pp. 692-707.

Mattila, A. S. (1999), "The role of culture and purchase motivation in service encounter evaluations", Journal of Services Marketing, Vol. 13, No. 4/5, pp. 376-389.

McGorry, S. Y. (2000), "Measurement in a cross-cultural environment: survey translation issues", Qualitative Market Research: An International Journal, Vol. 3, No. 2, pp. 74-81.

McSweeney, B. (2002), "Hofstede's Model of National Cultural Differences and their Consequences: A Triumph of Faith - a Failure of Analysis", Human Relations, Vol. 55, No. 1, pp. 89-118.

Merriam, S. B. and Tisdell, E. J. (2015), Qualitative research: A guide to design and implementation. San Francisco, CA: John Wiley \& Sons. 
Meyer, J. W. and Rowan, B. (1977), "Institutionalized organizations: Formal structure as myth and ceremony", American Journal of Sociology, Vol. 83, No. 2, pp. 340-363.

Miles, M. B., Huberman, A. M., Huberman, M. A. and Huberman, M. (1994), Qualitative data analysis: An expanded sourcebook. London: Sage.

Mohammad Mosadegh Rad, A. (2006), "The impact of organizational culture on the successful implementation of total quality management", The TQM Magazine, Vol. 18, No. 6, pp. 606-625.

Morgan, J. M. and Liker, J. K. (2006), The Toyota product development system. New York: Productivity Press.

Morgeson, F. V., Mithas, S., Keiningham, T. L. and Aksoy, L. (2010), "An investigation of the crossnational determinants of customer satisfaction", Journal of the Academy of Marketing Science, Vol. 39, No. 2, pp. 198-215.

Morgeson, F. V., Sharma, P. N. and Hult, G. T. M. (2015), "Cross-National Differences in Consumer Satisfaction: Mobile Services in Emerging and Developed Markets", Journal of International Marketing, Vol. 23, No. 2, pp. 1-24.

Nair, A. (2006), "Meta-analysis of the relationship between quality management practices and firm performance-implications for quality management theory development", Journal of Operations Management, Vol. 24, No. 6, pp. 948-975.

Naor, M., Goldstein, S. M., Linderman, K. W. and Schroeder, R. G. (2008), "The Role of Culture as Driver of Quality Management and Performance: Infrastructure Versus Core Quality Practices*”, Decision Sciences, Vol. 39, No. 4, pp. 671-702.

Newbold, P., Carlson, W. L. and Thorne, B. (2013), Statistics for business and economics. Boston, MA: Pearson.

Nulty, D. D. (2008), "The adequacy of response rates to online and paper surveys: what can be done?", Assessment \& Evaluation in Higher Education, Vol. 33, No. 3, pp. 301-314.

Oakland, J. (2011), "Leadership and policy deployment: the backbone of TQM", Total Quality Management \& Business Excellence, Vol. 22, No. 5, pp. 517-534.

Orton, D. J. and Weick, K. E. (1990), "Loosely Coupled System: A Reconceptualization”, Academy of Management, Vol. 15, No. 2, pp. 2003-2223.

Paccagnella, O. (2013), "Modelling individual heterogeneity in ordered choice models: anchoring vignettes and the Chopit Model", Journal of Methodological and Applied Statistics, Vol. 15, No. 1, pp. 69-89. 
Paccagnella, O., Guidolin, M. and Basei, C. (2018), "Priming effects and customer satisfaction towards online banking services", In: Department of Statistical Sciences, U. o. P. (ed)^(eds) Working Paper Series. ed. Padua, Italy.

Pache, A.-C. and Santos, F. (2013), "Inside the hybrid organization: Selective coupling as a response to competing institutional logics", Academy of management journal, Vol. 56, No. 4, pp. 972-1001.

Perrow, C. (1984), Normal Accidents: Living with High Risk Technologies. New York: Basic Books. Peters, T. J. and Waterman, R. H. (1982), In search of excellence: Lessons from America's bestrun companies. New York: Harper and Row.

Poksinska, B. B. and Cronemyr, P. (2017), "Measuring quality in elderly care: possibilities and limitations of the vignette method", Total Quality Management \& Business Excellence, Vol. 28, No. 9-10, pp. 1194-1207.

Porras, J. I. and Robertson, P. J. (1992), "Organizational development: Theory, practice, and research". In: Dunnette, M. D. and Hough, L. M. (Eds.), Handbook of industrial and organizational psychology. 2, Palo Alto, CA: Consulting Psychologists Press.

Powell, T. C. (1995), "Total quality management as competitive advantage: A review and empirical study", Strategic Management Journal, Vol. 16, No. 1, pp. 15-37.

Prahalad, C. K. and Doz, Y. L. (1987), The multinational mission: Balancing local demands and global vision. New York: Simon and Schuster.

Prajogo, D. I. and McDermott, C. M. (2005), "The relationship between total quality management practices and organizational culture", International Journal of Operations \& Production Management, Vol. 25, No. 11, pp. 1101-1122.

Prajogo, D. I. and Sohal, A. S. (2006), "The relationship between organization strategy, total quality management (TQM), and organization performance--the mediating role of TQM", European Journal of Operational Research, Vol. 168, No. 1, pp. 35-50.

Puffer, S. M. and McCarthy, D. J. (1996), "A framework for leadership in a TQM context", Journal of Quality Management, Vol. 1, No. 1, pp. 109-130.

Qu, S. Q. and Dumay, J. (2011), "The qualitative research interview", Qualitative Research in Accounting \& Management, Vol. 8, No. 3, pp. 238-264.

Quazi, H. A., Jemangin, J., Kit, L. W. and Kian, C. L. (1998), "Critical factors in quality management and guidelines for self-assessment: The case of Singapore", Total Quality Management, Vol. 9, No. 1, pp. 35-55.

Richardson, L. and St. Pierre, E. A. (2017), "Writing: A method of inquiry". In: Denzin, N. K. and Lincoln, Y. S. (Eds.), The SAGE Handbook of qualitative research. London: SAGE, pp.923-948. 
Riddle, D. (1992), "Leveraging cultural factors in international service delivery", Advances in services marketing and management, Vol. 1, No. 1, pp. 297-322.

Roth, K. and Morrison, A. J. (1990), "An empirical analysis of the integration-responsiveness framework in global industries", Journal of International Business Studies, Vol. 21, No. 4, pp. 541564.

Rubin, H. J. and Rubin, I. S. (2012), Qualitative interviewing: The art of hearing data. London: Sage.

Salomon, J. A., Tandon, A. and Murray, C. J. (2004), "Comparability of self rated health: cross sectional multi-country survey using anchoring vignettes", BMJ, Vol. 328, No. 7434, pp. 258.

Samson, D. and Terziovski, M. (1999), "The relationship between total quality management practices and operational performance", Journal of Operations Management, Vol. 17, No. 4, pp. 393-409.

Schein, E. H. (2010), Organizational culture and leadership. San Francisco, CA: Jossey-Bass A Wiley Imprint.

Scheuch, E. K. (1993), "The cross-cultural use of sample surveys: problems of comparability", Historical Social Research, Vol. 18, No. 2, pp. 104-138.

Schonberger, R. J. (2007), “Japanese production management: An evolution-With mixed success", Journal of Operations Management, Vol. 25, No. 2, pp. 403-419.

Schotter, A. and Beamish, P. W. (2011), "Performance effects of MNC headquarters-subsidiary conflict and the role of boundary spanners: The case of headquarter initiative rejection", Journal of International Management, Vol. 17, No. 3, pp. 243-259.

Schotter, A. P. J., Mudambi, R., Doz, Y. L. and Gaur, A. (2017), "Boundary Spanning in Global Organizations", Journal of Management Studies, Vol. 54, No. 4, pp. 403-421.

Scott, W. R. and Davis, G. F. (2015), Organizations and organizing: Rational, natural and open systems perspectives. London: Routledge.

Sen, A. (2002), "Health: perception versus observation: self reported morbidity has severe limitations and can be extremely misleading", BMJ, Vol. 324, No. 1, pp. 860-861.

Shewhart, W. A. (1931), Economic control of quality of manufactured product. Milwaukee, WI: ASQ Quality Press.

Sieber, S. D. (1973), "The Integration of Fieldwork and Survey Methods", American Journal of Sociology, Vol. 78, No. 6, pp. 1335-1359. 
Sitkin, S. B., Sutchliffe, K. M. and Schroeder, R. G. (1994), "Distinguishing control from learning in total quality management: a contingency perspective", Academy of Management Review, Vol. 19, No. 3, pp. 537-564.

Smith, A. M. and Reynolds, N. L. (2002), "Measuring cross-cultural service quality", International Marketing Review, Vol. 19, No. 5, pp. 450-481.

Smith, P. B. (2004), "Acquiescent Response Bias as an Aspect of Cultural Communication Style", Journal of Cross-Cultural Psychology, Vol. 35, No. 1, pp. 50-61.

Smith, P. B. (2006), "When elephants fight, the grass gets trampled: the GLOBE and Hofstede projects", Journal of International Business Studies, Vol. 37, No. 6, pp. 915-921.

Smith, P. B., Vignoles, V. L., Becker, M., Owe, E., Easterbrook, M. J., Brown, R., . . Harb, C. (2016), "Individual and culture-level components of survey response styles: A multi-level analysis using cultural models of selfhood", International Journal of Psychology, Vol. 51, No. 6, pp. 453-463.

Sousa, R. (2003), "Linking quality management to manufacturing strategy: an empirical investigation of customer focus practices", Journal of Operations Management, Vol. 21, No. 1, pp. 1-18.

Sousa, R. and Voss, C. A. (2002), "Quality management re-visited: a reflective review and agenda for future research", Journal of Operations Management, Vol. 20, No. pp. 91-109.

Sousa-Poza, A., Nystrom, H. and Wiebe, H. (2001), "A cross-cultural study of the differing effects of corporate culture on TQM in three countries", International Journal of Quality \& Reliability Management, Vol. 18, No. 7, pp. 744-761.

Spencer, B. A. (1994), "Models of organization and total quality management: A comparison and critical evaluation", Academy of Management, Vol. 19, No. 3, pp. 446-471.

Spencer-Oatey, H. (2004), Culturally speaking: Managing rapport through talk across cultures. New York: A\&C Black.

Spender, J. C. and Grevesen, W. (1999), "The multinational enterprise as a loosely coupled system: the global integration - local responsiveness dilemma", Managerial Finance, Vol. 25, No. 2, pp. 63-84.

Sreedharan V, R., Sunder M, V. and R, R. (2018), "Critical success factors of TQM, Six Sigma, Lean and Lean Six Sigma", Benchmarking: An International Journal, Vol. 25, No. 9, pp. 3479-3504.

Strang, D. and Kim, Y.-M. (2004), "The Diffusion and Domestication of Managerial Innovations: The spread of scientific management, quality circles, and TQM between the United States and Japan". In: Ackroyd, S., Batt, R., Thompson, P. and Tolbert, P. S. (Eds.), The Oxford handbook of work and organization. Oxford: Oxford university press. 
Swidler, A. (1986), "Culture in action: Symbols and strategies", American Sociological Review, Vol. 51, No. 1, pp. 273-286.

Tata, J. and Prasad, S. (1998), "Cultural and structural constraints on total quality management implementation”, Total Quality Management, Vol. 9, No. 8, pp. 703-710.

Thiagarajan, T. and Zairi, M. (1997), "A review of total quality management in practice: understanding the fundamentals through examples of best practice applications - Part I", The TQM Magazine, Vol. 9, No. 4, pp. 270-286.

Trompenaars, F. and Hampden-Turner, C. (2012), Riding the waves of culture: understanding diversity in global business. New York: McGrow-Hill.

Tsui, A. S., Nifadkar, S. S. and Amy Yi, O. (2007), "Cross-National, Cross-Cultural Organizational Behavior Research: Advances, Gaps, and Recommendations", Journal of Management, Vol. 33, No. 3, pp. 426-478.

Valmohammadi, C. and Roshanzamir, S. (2015), "The guidelines of improvement: Relations among organizational culture, TQM and performance", International Journal of Production Economics, Vol. 164, No. 1, pp. 167-178.

van de Vijver, F. J., Leung, K. and Leung, K. (1997), Methods and data analysis for cross-cultural research. Baverly Hills, CA: Sage.

van Herk, H., Lee, N., Poortinga, Y. H. and Verhallen, T. M. M. (2005), "Equivalence of survey data: relevance for international marketing", European Journal of Marketing, Vol. 39, No. 3/4, pp. 351364.

van Maanen, J. and Laurent, A. (2016), "The flow of culture: Some notes on globalization and the multinational corporation". In: Ghoshal, S. and Westney, D. E. (Eds.), Organization theory and the multinational corporation. New York: St. Martin's press.

Vavra, T. G. (2002), Customer satisfaction measurement simplified: A step-by-step guide for ISO 9001: 2000 certification. Milwaukee, WI: ASQ Quality Press.

Vecchi, A. and Brennan, L. (2009), "Quality management: a cross-cultural perspective", Cross Cultural Management: An International Journal, Vol. 16, No. 2, pp. 149-164.

Vecchi, A. and Brennan, L. (2011), "Quality management: a cross-cultural perspective based on the GLOBE framework", International Journal of Operations \& Production Management, Vol. 31, No. 5, pp. 527-553.

Vora, D., Kostova, T. and Roth, K. (2007), "Roles of subsidiary managers in multinational corporations: The effect of dual organizational identification", Management International Review, Vol. 47, No. 4, pp. 595-620. 
Voss, C. (2010), "Case research in operations management". In: Karlsson, C. (Eds.), Researching operations management. Abingdon, Oxon: Routledge, pp.176-209.

Voss, C. A., Roth, A. V., Rosenzweig, E. D., Blackmon, K. and Chase, R. B. (2004), "A Tale of Two Countries' Conservatism, Service Quality, and Feedback on Customer Satisfaction", Journal of Service Research, Vol. 6, No. 3, pp. 212-230.

Weckenmann, A., Akkasoglu, G. and Werner, T. (2015), "Quality management-history and trends", The TQM Journal, Vol. 27, No. 3, pp. 281-293.

Weick, K. E. (1976), "Educational organizations as Loosely Coupled Systems", Administrative Science Quarterly, Vol. 21, No. 1, pp. 1-19.

Weick, K. E. (2012), Making sense of the organization, Volume 2: The impermanent organization. West Sussex: John Wiley \& Sons.

Weiss, S. and Roberts, R. D. (2018), "Using Anchoring Vignettes to Adjust Self-Reported Personality: A Comparison Between Countries", Frontiers in psychology, Vol. 9, No. 1, pp. 325.

Westney, D. E. (2016), "Institutionalization theory and the multinational corporation". In: Ghoshal, S. and Westney, D. E. (Eds.), Organization theory and the multinational corporation. New York: St. Martin's press.

Williams, P. (2002), "The Competent Boundary Spanner", Public Administration, Vol. 80, No. 1, pp. 103-124.

Williamson, K. (2002), Research methods for students, academics and professionals: Information management and systems. Wagga Wagga: Quick Print.

Winsted, K. F. (1997), "The service experience in two cultures: A behavioral perspective", Journal of Retailing, Vol. 73, No. 3, pp. 337-360.

Womack, J. P., Jones, D. T. and Roos, D. (1990), Machine that changed the world. New York: Simon and Schuster.

Yin, R. K. (2013), "Validity and generalization in future case study evaluations", Evaluation, Vol. 19, No. 3, pp. 321-332.

Yin, R. K. (2014), Case study research: design and method. London: Sage Publications.

Yong, J. and Wilkinson, A. (1999), "The state of total quality management: a review", International Journal of Human Resource Management, Vol. 10, No. 1, pp. 137-161.

Zgodavova, K., Hudec, O. and Palfy, P. (2017), "Culture of quality: insight into foreign organisations in Slovakia", Total Quality Management \& Business Excellence, Vol. 28, No. 9-10, pp. 1054-1075. 
$\mathrm{Zu}, \mathrm{X}$. (2009), "Infrastructure and core quality management practices: how do they affect quality?", International Journal of Quality \& Reliability Management, Vol. 26, No. 2, pp. 129-149. Zu, X., Robbins, T. L. and Fredendall, L. D. (2010), "Mapping the critical links between organizational culture and TQM/Six Sigma practices", International Journal of Production Economics, Vol. 123, No. 1, pp. 86-106. 



\section{Papers}

The papers associated with this thesis have been removed for copyright reasons. For more details about these see:

http://urn.kb.se/resolve?urn=urn:nbn:se:liu:diva-164230 


\section{FACULTY OF SCIENCE AND ENGINEERING}

Linköping Studies in Science and Technology, Dissertation No. 2049, 2020 Department of Management and Engineering

Linköping University SE-581 83 Linköping, Sweden

www.liu.se

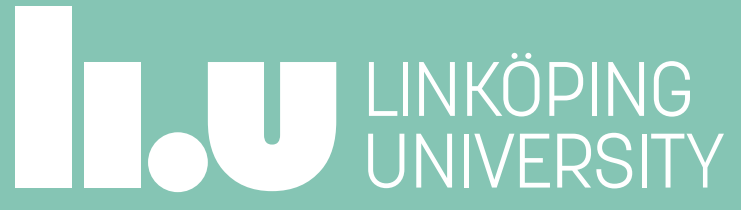

